UC-23

\title{
Cold Regions Isotope Applications
}

by

Lyle D. Perrigo

with a contribution from T. E. Divine

April 1976

Prepared for the Energy Research and Development Administration under Contract E(45-1):1830 


\title{
NOTICE
}

This report was prepared as an account of work sponsored by the United States Government. Neither the United States nor the Energy Research and Development Administration, nor any of their employees, nor any of their contractors, subcontractors, or their employees, makes any warranty, express or implied, or assumes any legal liability or responsibility for the accuracy, completeness or usefulness of any imformation, apparatus, product or process disclosed, or represents that its use would not infringe privately owned rights.

PACIFIC NORTHWEST LABORATORY

operated by

BATTELLE

for the

ENERGY RESEARCH AND DEVELOPMENT ADMINISTRATION

Under Contract $E(45-1)-1830$

\author{
Printed in the United States of America \\ Available from \\ National Technical Information Service \\ U.S. Department of Commerce \\ 5285 Port Royal Road \\ Springfield, Virginia 22151 \\ Price: Printed Copy 57.75 ; Micrutiche $\$ 2.25$
}


COLD REGIONS ISOTOPE APPLICATIONS

by

Lyle D. Perrigo

with a contribution from $T$. E. Divine

Apri1 1976

BATTELLE

PACIFIC NORTHWEST LABORATORIES

RICHLAND, WASHINGTON 99352 
CONTENTS

LIST OF FIGURES •

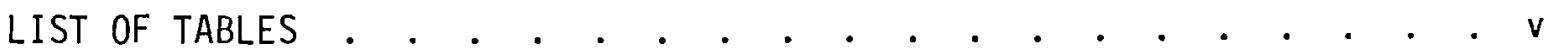
INTRODUCTION • • • • • •

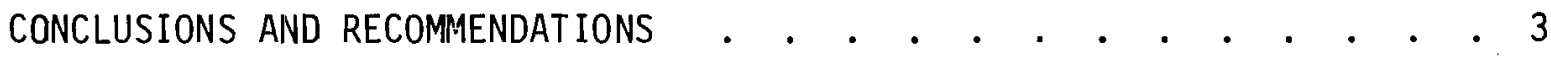
STUDY METHODOLOGY AND ORGANIZATION

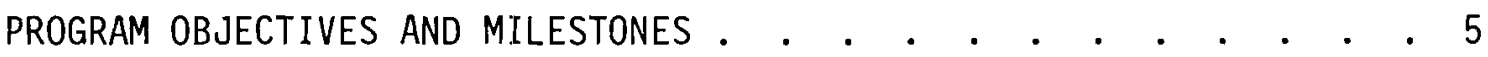

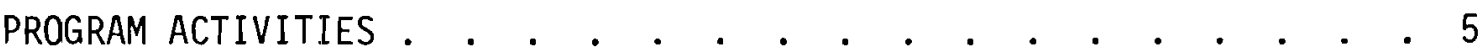

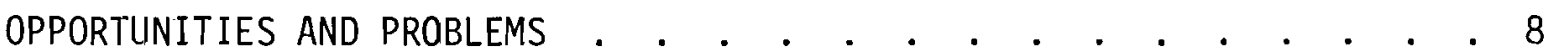

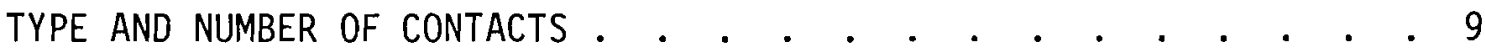

SURVEY RESULTS • • • • • • • • • • • • • • • • • • • 10 OPPORTUNITY DEVELOPMENT AND DEMONSTRATION

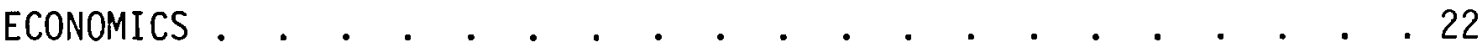

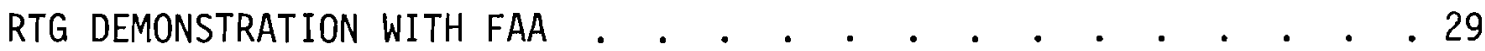
ISOTOPIC HEATERS AND STERILIZATION SYSTEMS • • • • • • • • • 36 LATENT OPPORTUNITIES • • • • • • • • • • • • • • • • • • • 51

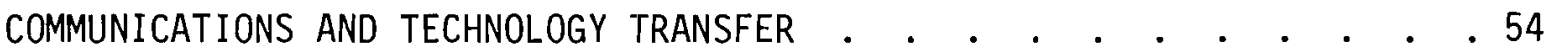

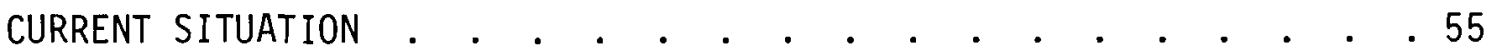

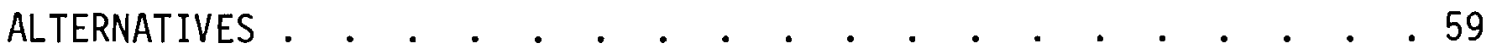

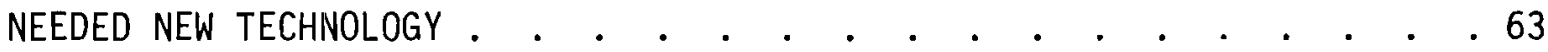

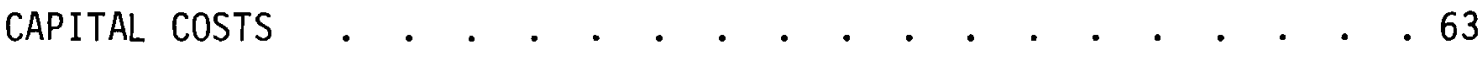

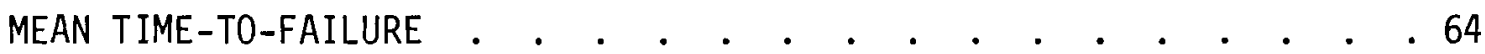
LOGISTICS • • • • • • • • • • • • • • • • • • • 65

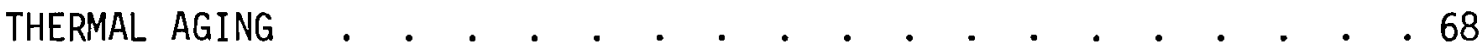

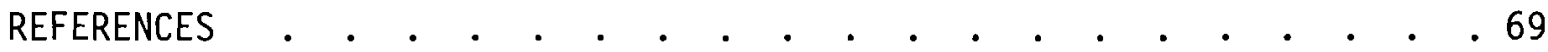
APPENDIX A - ISOTOPIC HEATERS AND THERMOELECTRIC POWER SYSTEMS • • . A-1 APPENDIX B - COLD REGIONS PROGRAM CONTACTS IN FY-1975 . • • • . . B-1

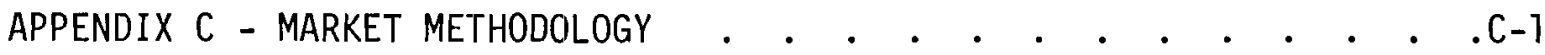
APPENDIX D - BACKGROUND INFORMATION • • • • • • • • • • • • • • . . D-1 APPENDIX E - COLD REGIONS RADIOISOTOPE GENERATOR PROGRAM PRELIMINARY ECONOMIC ANALYSIS . . . • • • • • • • . E-1 


\section{LIST OF FIGUIRES}

FY-1975 Program Milestones . . . . . . . . . . . 6 FY-1975 Work Plan. . . . . . . . . . . . . . 6 Contact Matrix for Market Areas . . . . . . . . . . 11 Contact Matrix for Alaskan Market Areas . . . . . . . 11

\section{Engineering-Economic Systems Classification of} Factors Affecting Addition of Technology . . . . . . . 27 Lake Clark Pass Area in Alaska . . . . . . . . . . 31 TEG Refueling by Helicopter . . . . . . . . . . . 32 Refueling and Maintenance Work on a TEG . . . . . . . 32 A TEG Site in the Lake Clark Pass Area . . . . . . . . 33 Hanford Waste Encapsulation and Storage Facility Capsules . 39 Sewage Lagoon at Fort Yukon, Alaska . . . . . . . . . 41 Aerial Photograph of Anaktuvuk Pass from the Northwest . . 42 Conceptual Flow Diagram for an Alaskan Native Village Thermal Radiation Treatment Process . . . . . . . . . 48 How a Radioisotope-Powered Thermoelectric Generator Works - A-4 Alaskan Trading Areas . . . . . . . . . . . . . C-1 Major Alaskan Coal Fields . . . . . . . . . . . . D-1 Possible Multimodal Transportation and Utility Corridor Systems in Alaska . . . . . . . . . D-2 Major Language Groups in Alaska . . . . . . . . . . D-3 Engineering-Economic Systems Classification of Factors Affecting Adoption of Technology . . . . . . . E-3 Production Run Quantities as Determined by Learning Curve Rates and Price Objectives . . . . . . . . . E-19 Combinations of Events Which Might Increase or Decrease Economic Feasibility of RTGS . . . . . . . E-23 Cumulative Effects of Best and Worst Conditions for RTG Economic Acceptance, Total Equivalent Annual Cost/Watt $e^{-Y e a r . ~ E-24 ~}$ 


\section{$\underline{\text { LIST OF TABLES }}$}

1 Arctic Power System Costs . . . . . . . . . . . . 24

2 Usage of Two ERDA Movies on Beneficial Use of Isotopes . . . 59

A-1 Characteristics of Radioisotopic Heat Sources . . . . . A-2

E-1 Estimated Capital costs for RTG User, \$1,000s . . . . . . E-5

E-2 Estimated Operating Costs for RTG User, $\$ 1,000 \mathrm{~s}$. . . . . E-6

E-3 Estimated Capital Costs for User of Alternative Sma11 Power Sources, \$1,000s . . . . . . . . . . E-7

E-4 Estimated Operating Costs for User of A7ternative

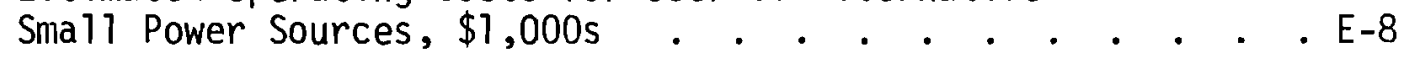

E-5 Estimated Total Equivalent Annual Costs for RTG User, $\$ 1,000$. . . . . . . . . . . . . . E-10

E-6 Estinated Total Equivalent Annual Costs for Alternative Smal1 Power Sources, $500 w_{e}, \$ 7,000$. . . . E-11

E-7 Derivation of Formulae for Cost Sensitivity Analysis . . . E-14

E-8 Percentage Change in Factors Relative to Base Case Conditions, $\%$. . . . . . . . . . . . . E-23 
INTRODUCTION 


\section{COLD REGIONS ISOTOPE APPLICATIONS}

by

Lyle D. Perrigo

\section{INTRODUCTION}

In July 1974 the Energy Research and Development Administration (ERDA) funded a program on Cold Regions Isotope Applications at the Pacific Northwest Laboratories (PNL, Battelle Memorial Institute). This program is part of a broader ERDA effort to determine if the decay heat from radioisotopes can be used economically and safely for particular energy needs. Although a limited amount of isotopes is now available at various ERDA installations for proof-of-principle demonstrations, the potential availability of isotopes from commercial nuclear fuel reprocessing operations in the 1980s gives added impetus to this program.

The Cold Regions Isotope Applications Program is not the first attempt to identify beneficial uses for radioisotope power or heater systems. To pursue President Eisenhower's interest in promoting peaceful uses of atomic energy in the 1950s, the Atomic Energy Commission conducted a program to develop isotope systems, specifically power systems, and to demonstrate their technical feasibility. This development work led to the fabrication of radioisotope thermoelectric generators used for a number of purposes in the oceans and in space as well as in Cold Regions, such as the Arctic and Antarctic. Although these demonstrations and applications indicated an almost universal technical feasibility, the terrestrial devices were not economically competitive with conventional power sources for most applications. In the deep ocean and space, where unattended operation and high reliability were requirements, radioisotope systems either displaced or were equal to other systems economically as well as technically. 
The Cold Regions Program is the first phase of what is expected to be a four-phase program designed to identify special conditions in the Arctic and similar geographic areas (Cold Regions) where radioisotope systems with high reliability and unattended operation would be economically viable.

The purpose of this initial phase is to identify critical needs in Cold Regions and determine if isotopes would satisfy these needs. Two general types of application were systematically examined in Phase I: the use of isotopes for the production of electric power and heat. Also considered to a lesser extent was their use for radiation processing. Each of these applications has a technological base that was established by earlier work by ERDA's predecessor, the Atomic Energy Commission (AEC). Phase II would determine if the uses for isotopes in Cold Regions (identified in Phase I) meet specific criteria and safety requirements. Phase III would involve laboratory demonstration of the proposed isotope systems and Phase IV would be devoted to field demonstrations in Alaska. It is anticipated that various Federal agencies and commercial firms would exploit viable opportunities following Phase IV research and demonstration.

This report details Phase I of the Cold Regions Isotope Applications Program. Conclusions and Recommendations are provided in the following section while the next section describes the methodologies and organization used in studying potential Cold Regions problems and opportunities. The result and their implications follow, then the appendices are provided containing detailed data supporting the information included in the section on results and discussion, as well as a short summary describing the operation of radioisotope heaters and thermoelectric generators for the reader who is not familiar with these devices. Other appendices contain information on the contacts made in FY-1975 and a preliminary analysis of the factors affecting the cost of radioisotope thermoelectric generators. 
CONCLUSIONS AND RECOMMENDATIONS 


\section{CONCLUSIONS AND RECOMMENDATIONS}

Pacific Northwest Laboratories (PNL) started the Cold Regions Isotope Applications Program in FY-1975 to identify special conditions in the Arctic and similar geographic areas (Cold Regions) where radioisotope power, heater, or sterilization systems would be desirable and economically viable. Significant progress was made in the first year of this program and all objectives for this initial 12-month period were achieved. The major conclusions and recommendations resulting for this effort are described below.

- Both Federal and State agencies, responsible for providing potable water and sanitary sewage treatment facilities for Alaskan Native Villages, are interested in exploring the possibilities of using isotope heater and sterilization systems for these purposes. Opportunities for the demonstration of isotopic heating of septic tanks in native villages (50 to 100 residents located in non-permafrost cold regions) is particularly strong and should be followed up in FY-1976. Since these devices are known to be technically feasible, the rationale for such an undertaking is to acquire viable economic data and create greater public awareness of their usefulness, safety and reliability. Potential use for potable water heating and sewage sterilization should be examined in greater detail and promoted as appropriate.

- Another strong possibility for the beneficial use of isotope systems is using radioisotope thermoelectric generators (RTGs) to power aircraft navigational aids in remote locations in Cold Regions. The Federal Aviation (FAA) is interested in such a demonstration and follow-up in FY-1976 with this agency is recommended. Because RTGs are known to be technically feasible the objectives for such a demonstration would be the same as those for the heated septic demonstration.

- Latent opportunities to demonstrate isotope devices with marine aids to navigation and remote meteorological instruments were also identified in FY-1975. These possibilities should be pursued in the future to determine if isotope systems can solve problens in those areas. 
- An active and expanded communications program of information on radioisotope applications is recommended to create a greater public, commercial and governmental awareness of the beneficial uses of radioisotopes. Improved transfer of isotope technology can be expected if this process were to receive increased emphasis and the assignment of one or more people with entrepreneurial capabilities to the program.

- The need for new technology was identified as being an important consideration in extending the usage of isotope systems in Cold Regions and elsewhere. Research to reduce capital costs, increase the reliability of supporting equipment, improve logistics and avoid thermal aging problems are believed to be the areas where such endeavors would produce the most fruitful results. 
STUDY METHODOLOGY AND ORGANIZATION 
STUDY METHODOLOGY AND ORGANIZATION

The methodology and organization for the Cold Regions Isotope Applications Program resulted from the program objectives and milestones discussed with ERDA staff members in 1ate FY-1974. This program methodology and organization, as well as accompanying assumptions and decisions involved in developing these items will be discussed in the following three subdivisions. The first subsection details the guidelines established by ERDA, the second deals with the program organization and supporting factors; the market research approach used in a part of this program is detailed in Appendix C.

PROGRAM OBJECTIVES AND MILESTONES

The Cold Regions Isotope Applications Program was formally accepted by ERDA in July 1974, and the objectives and milestones included in this agreement became the guiding factors for conducting this program. The program objectives as agreed upon were: "...to assure that isotope systems technology is properly applied to critical (Cold Regions) problems in an orderly, systematic manner and to provide technology development and demonstration where needed..."

Six milestones were established to regulate progress so that program objectives could be achieved within the time, funds and scope provided for the study. These six milestones, four of which fell in FY-1975, are shown in Figure 1. The impact of these objectives and milestones on FY-1975 activities and work assumptions are covered in the following subsection.

\section{PROGRAM ACTIVITIES}

A FY-1975 work plan (or activity network) for the Cold Regions Isotope Applications Program is shown in Figure 2. It was used to inform the sponsor of how PNL expected to approach work on the Cold Regions Program as well as serving as a reference for later discussions on program progress. It was also used internally at PNL to control and direct work. 


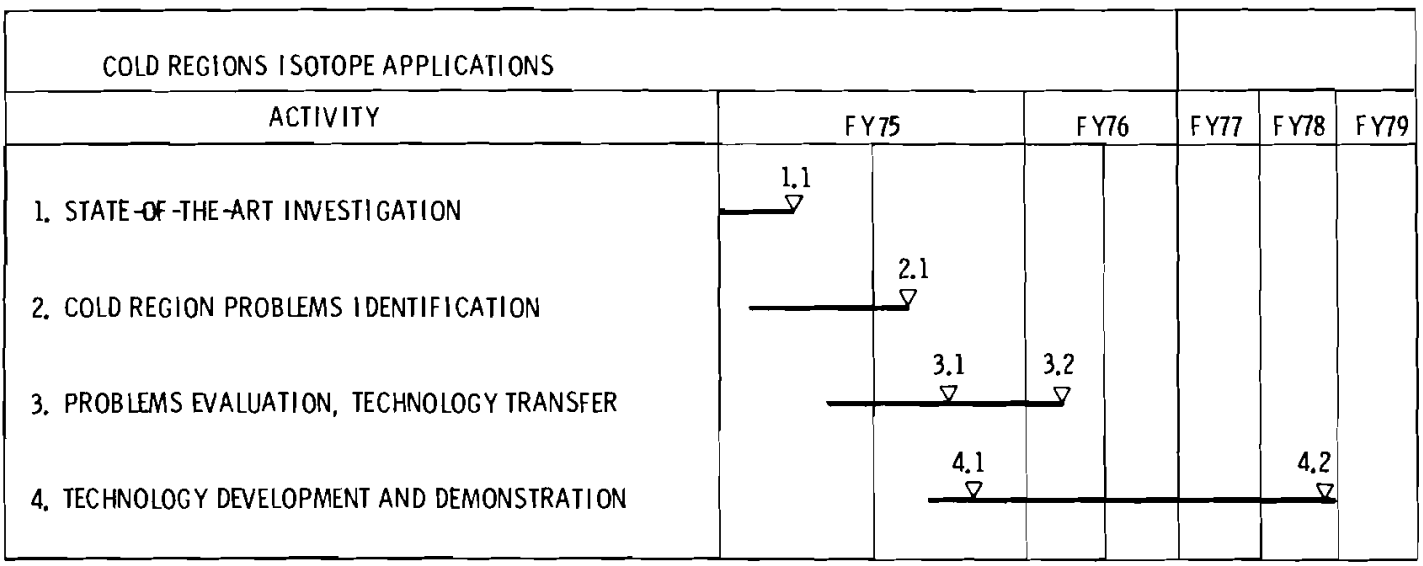

\section{MILESTONES}

Ll COMPLETE AND UPDATE LITERATURE SEARCH, DOCUMENT FINDINGS AS APPROPRIATE.

2.1 SYSTEMATICALLY IDENTIF Y COLD REGIONS OPERATIONS PROBIEMS, INCLUDING DIRECT FIELD CONTACT.

3.1 EVALUATE ECONOMIC AND TECHNICAL FEASIBILITY IN SOLVING SELECT PROB LEMS IACTIVITY Z USING ISOTOPE APPLICATIONS TECHNOLOGY, INCLUDE CONSIDERATION OF PUBLIC ACCEPTABIIIITY.

3.2 IDENTIFY PROB LEMS IMILESTONE 3.1 WHERE EXISTING TECHNOLOGY MAY BE APPLIED, COMMUNICATE FINDINGS TO ERDA AND INDUSTRY AND GOVERNMENT ORGANIZATIONS INVOLVED. HELP PROMOTE NON ERDA SUPPORT OF ACTUAL PROB LEM SOLUTIONS.

4.1 IDENTIFY PROBLEMS (MILESTONE 3.1) WHERE ISOTOPE SYSTEMS TECHNOLOG Y DEVELOPMENT IS NEEDED. MA KE RECOMMENDATIONS FOR PROGRAM ACTIVITY IN FY-76-77 AND BEYOND

4.2 BASED ON MILESTONE 1.1 AND IN CLOSE CO-OPERATION WITH ERDA AND OTHER ORGANIZATIONS, DEVELOP AND DEMONSTRATE SELECT TECHNOLOGY.

\section{FIGURE 1. FY-1975 Program Milestones}

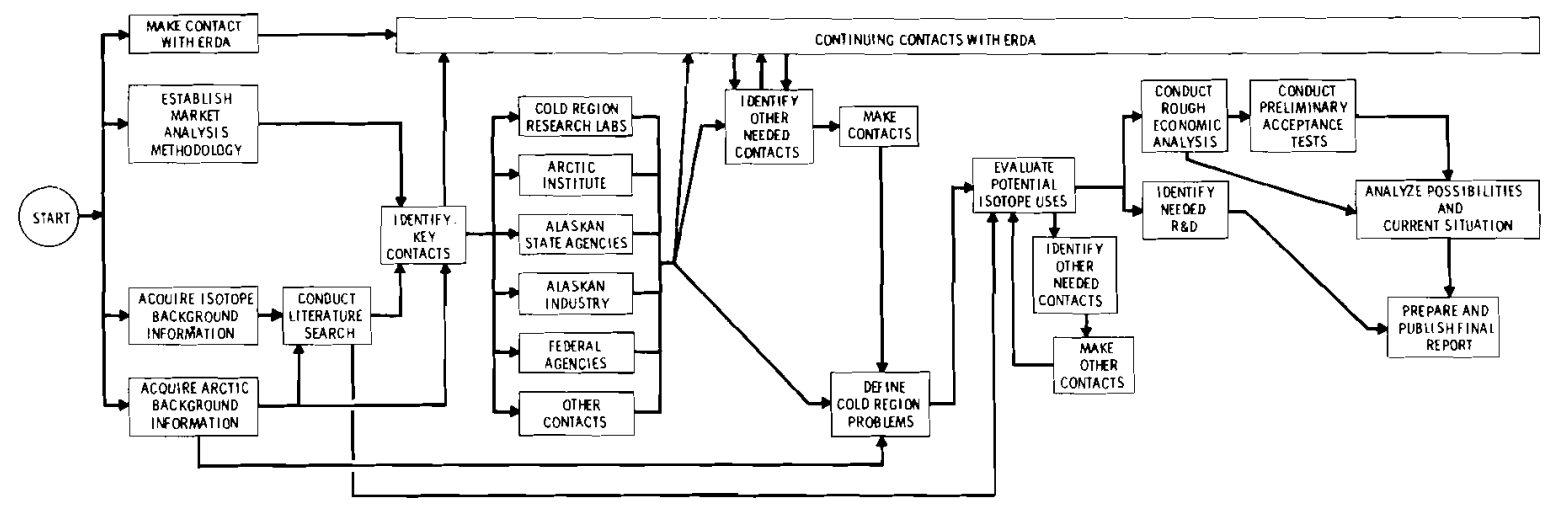

FIGIIRE 2. FY-1975 Work Plan 
The activities in Figure 2 are believed to be sufficiently clear in their intent in all cases except possibly for the one toward the end of FY-1975 effort called "Conduct Preliminary Acceptance Tests". This describes contacting a few key individuals involved in the program to check the major findings at that stage in progress. Three other activities shown in Figure 2 also merit further discussion since they are the results of certain assumptions and decisions made about acquiring information for the Cold Regions Program. The task, "Establish Market Analysis Methodology", indicates that a logical method for approaching this program is to consider that several program elements are amendable to market analyses techniques. The rationale and implications involved in this assumption and the resulting decision to pursue this approach are discussed in greater detail in Appendix $C$.

Two tasks ("Alaskan State Agencies" and "Alaskan Industries") show that a major assumption and decision were made on the likely sources of information that are pertinent to the program. The inclement weather and long duration of the winter season in Alaska are well known and would likely provide relevant examples useful in achieving program objectives. Other factors relating to the selection of Alaska came from the items in the development of a market research methodology which is discussed in Appendix C. 
OPPORTUNITIES AND PROBLEMS 


\section{OPPORTUNITIES AND PROBLEMS}

One of the primary tasks in the first year of work on the Cold Regions Isotope Applications Program was to identify opportunities for isotopic devices to be economically competitive with conventional systems. As a result of the state-of-the-art study reported in Appendix $D$ this search for opportunities was narrowed to those associated with static radioisotope thermoelectric generators, isotope heaters and thermoradiation sterilization of sewage sludge. Although there are a number of other possible applications in Cold Regions for different types of devices or approaches to the use of radioisotopes, including dynamic cycle radioisotope thermoelectric generator', their technology did not appear to be far enough advanced to warrant further consideration at this time. Other applications such as krypton lights currently had rather limited possibilities for any extensive usage so they too were not examined in any detail.

The principal method of identifying opportunities was to make direct contact with various organizations and individuals. Although the specific thrust of these contacts was the identification of opportunities for the application of RTGs, radioisotope heaters and thermoradiation treatment of sewage sludge, indirect as well as direct factors relating to such applications were explored. Time was also spent on identifying possible problems involved in the potential application of such devices in Cold Regions. These problems, which were equally as important as the advantages, dealt with technical and nontechnical topics such as those concerned with public aspirations, social effects and implications, as well as those related to availability, reliability and cost.

The detailed information contained in this section is presented in three subsections that follow. These subsections are concerned with the type and number of contacts, the opportunities/problems identified in a survey of four market segments selected for this study, and general considerations affecting the direction of future efforts in examining the 
opportunities for isotope applications in Cold Regions under the conditions prevalent at the time these surveys were made.

\section{TYPE AND NUMBER OF CONTACTS}

The type and number of contacts made during FY-1975 on the Cold Regions Isotope Application study were the result of two considerations: 1) the market segmentation procedure adapted for the study (see Appendix $C$ on Market Methodology), and 2) the number of leads that could be developed by referrals, use of the open and trade literature, letters and telephone calls. Because of the economic activity and development in Alaska, the market was divided into four segments: commercial organizations, State agencies, Federal agencies and the military services. Since information was acquired outside of the model area, a consistent procedure was also needed to classify and relate the results of this task. The same four divisions were used and, where there may be some uncertainties, both within Alaska and elsewhere, about where various groups or individuals might reside in this system, working definitions were adopted:

- Professional and technical societies were defined as being in the segment concerned with commercial organizations.

- Educational institutions were placed in the category covering state agencies.

- Towns and municipalities were also defined as being state agencies.

- Since there was a change in state administrations in Alaska during the course of this study the contacts, although within the same department and groups, were classified as being separate and independent. This approach is believed to be warranted because in all cases there was a change in responsible personnel and viewpoints.

- Since viewpoints as well as perspective varied markedly by location of Federal agencies on the regional or the national level, these contacts also were classified as being separate and independent. This approach was more than warranted because emphasis in the operating groups was found in almost all cases to be different. This same 
procedure was also employed in one case on contacts with two separate offices of the same agency within Alaska because viewpoints, responsibilities and aspirations were different.

Figure 3 is a matrix showing the type and distribution of the 52 direct contacts made during FY-1975. These contacts do not include iterative activities undertaken as follow-up unless they fall in the special category of Alaskan State Agencies as noted above. Two main divisions are used to relate contacts made in the four market segments: 1) those in Alaska and 2) those elsewhere (including contacts in the "Lower 48", (a) Canada and with AERE personne1). The specific organizations, agencies, groups, etc., contacted during FY-1975 are given in Appendix B. Unless particularly relevant the names of particular individuals contacted are not given in this report. It should be remembered that the 52 contacts identified in Figure 3 were all direct face-to-face meetings except for one military and two Federal agency contacts in the "Lower 48". In these three cases telephone conversations were followed up with written correspondence. A11 information acquired by ERDA personnel was classified as indirect information and, as such, is not included in Figure 3. The geographic source of the information acquired from contacts in Alaska is shown in Figure 4. Note that the names Anchorage, Fairbanks and Juneau are used to identify the trading areas shown in Figure $\mathrm{C}-1$ and that contacts may have occurred outside of the city used to identify each area; Appendix B provides specific information on these locations.

\section{SURVEY RESULTS}

The personal contacts that were made with the 52 organizations discussed in the previous subsection (identified in Appendix B) produced an understanding of concerns, levels of awareness, preferred modes for

(a) The "Lower 48" is terminology used in Alaska to identify the 48 contiguous states on the North American Continent. It is an effective description and it is used in other parts of this report as phraseology to indicate geographic location of ideas, materials, etc. 


\begin{tabular}{|l|c|c|c|c|}
\cline { 2 - 5 } \multicolumn{1}{c|}{} & \multicolumn{5}{c|}{ NUMBER OF } & DIRECT CONTACTS \\
\cline { 2 - 5 } & $\begin{array}{c}\text { COMMERCIAL } \\
\text { ORGANIZATIONS }\end{array}$ & $\begin{array}{c}\text { STATE } \\
\text { AGENCIES }\end{array}$ & $\begin{array}{c}\text { FEDERAL } \\
\text { AGENCIES }\end{array}$ & $\begin{array}{c}\text { MILITARY SERVICES } \\
\text { AND GROUPS }\end{array}$ \\
\hline \multirow{2}{*}{ ALASKA } & 13 & 12 & 6 & 3 \\
\hline ELSEWHERE & 5 & 1 & 6 & 6 \\
\hline
\end{tabular}

FIGURE 3. Contact Matrix for Market Areas

\begin{tabular}{|l|c|c|c|c|}
\cline { 2 - 5 } \multicolumn{1}{c|}{} & \multicolumn{4}{|c|}{ NUMBER OF } \\
\cline { 2 - 5 } & $\begin{array}{c}\text { COMMERCIAL } \\
\text { ORGANIZATIONS }\end{array}$ & $\begin{array}{c}\text { STATE } \\
\text { AGENCIES }\end{array}$ & $\begin{array}{c}\text { FEDERAL } \\
\text { AGENCIES }\end{array}$ & $\begin{array}{c}\text { MILITARY SERVICES } \\
\text { AND GROUPS }\end{array}$ \\
\hline ANCHORAGE & 6 & 3 & 4 & 2 \\
\hline FAIRBANKS & 4 & 2 & 2 & 1 \\
\hline & & & 1 & 0 \\
\hline
\end{tabular}

FIGURE 4. Contact Matrix for Alaskan Market Areas 
promoting better understanding and needs for better communications in these areas. Some of this information bears directly on opportunities for demonstration and/or beneficial use of state-of-the-art isotope devices, while other information is more indirect, but nevertheless important.

Further comments on survey results are presented under headings concerned witil the four major market segments that have been used throughout the report.

Commercial Organizations

The results of the survey indicated that all commercial organizations contacted during this study were interested in the beneficial application of radioisotope devices. This interest ranged from those who would be strictly involved in financing the devices to those who might be operators. These differing viewpoints reflected differing aspirations, management philosophies and levels of awareness. Some of these differences are amendable to better communications while others constitute separate elements of the commercial world. Relevant survey results from the commercial sector follow:

- Although interest in the potential application of isotope devices was moderately high in a few commercial organizations, no organization was willing to commit itself at this time to anything more than observing the experience of others who are using such systems.

- Commercial groups are concerned about the high capital costs of isotope systems. Although hypothetical cases. can be developed showing that capital and operating costs for conventional systems might exceed those for isotope systems in $5+$ years this concern was still evident. Major factors in the prevalence of this attitude are in existing financing, accounting and depreciation procedures used in industry. Also, high inflation rates stimulate attempts to reduce down payments on capital expenditures to minimums. Even though a similar reduction on an isotope system is probable this would still account for much higher dollar commitments with current capital costs. 
- Many commercial groups were not even aware that RTGs and isotope heater systems were available for commercial use. This condition was prevalent with Alaskan financial institutions, trade groups, small businesses, local consultants and native organizations.

- A11 commercial groups were interested in observing isotope system demonstrations in Alaska. The point was made on several occasions that any such demonstrations should be designed in such a manner that people could see the systems in operation, be advised of progress and have free access to any information generated relative to the cost and technical benefits of various applications.

- There is a general uneasiness of contacts in the commercial sector about the "red tape" and the high cost of procuring a license to use isotope devices. A significant factor in this concern may be a lack of understanding of what is involved in licensing.

- Another important factor that could have an important effect on the ul timate success and acceptance of the results of any demonstrations in Alaska is what might be called the "outsider syndrome". Many in Alaska, including certain prominent as well as small business men, are reticent, and perhaps even hostile, to suggestions from the "Lower 48" on how to conduct their business. Their ire can be and often is focused on those who enter the State, make a study, return home, evaluate data and publish results telling them how to do things more effectively than they are currently doing them. Most of these problems can be avoided by working through Alaskan-owned or Alaskanbased organizations.

- The Alaskan Native Corporations (classified for this study as commercial enterprises though they have certain municipal powers) have political power, are expected to have increasing financial strength and their leadership is ambitious, capable and generally progressive. These groups are interested in developing their natural resources in such a fashion that the benefits to the natives are maximized. The 
native groups (singly or collectively) will be involved in the local decision-making process that will affect the development of any demonstration programs in the native villages. However, the natives do not like to be the subject of experiments; this should not be a major consideration in any near-term isotope demonstration work because only processes proven technically will be used in Alaska.

- Some groups, especially the financial institutions, are interested in developing a market for secondhand isotope devices so that there will be a means for reclaiming part or all of the funds that might be advanced to the unsuccessful entrepreneur in the future.

- A few people in the commercial sector were concerned about the safety of isotope devices. Since isotope power and heater systems were new concepts, these people generally equate nuclear work with weapons and/or radiation/contamination problems. This problem should be amendable to education.

\section{State Agencies}

Several Alaskan State Agencies showed a marked interest in isotopic power, heater and thermoradiation sludge treatment systems. As would be expected in any grouping of educational institutions, municipalities, regulatory bodies, and the executive branch of State government, particular interests and attitudes varied. Important findings from the survey of State agencies follow:

- Since State agencies, Native Corporations and Federal agencies are attempting to improve the "quality of life" for Alaskan natives, there is a strong interest in promoting and developing adequate potable water and sewage systems for native villages. Heat is an important factor in keeping these systems operational when ground and ambient temperatures are below $32^{\circ} \mathrm{F}$. At the present time fuel oil is supplied to keep sewage and potable water systems operational even in remote locations. All cognizant agencies expressed a strong interest in 
isotope heater and thermoradiation sterilization systems when they learned that such devices would not require refueling for five or more years, that they were safe and that they could probably be designed for minimal maintenance.

- One agency was interested in using RTGs for extended periods of time in powering unattended lighthouses and various other marine navigational systems for their "port of refuge" concept. This concept is being promoted by some as a means for reducing fatalities from marine storms by providing secure, well-lighted havens using an array of dependable navigational aids along the shore in notoriously stormy areas (such as the Shelikof Strait between Kodiak Island and the Alaskan Peninsula).

- An educational group was interested in exploring conceptually the possibility of storing nuclear wastes in one of the Alaskan Fiords. Their concept was to use the decay heat from the storage containers to cause an upwelling of water sufficient to break thermal gradients in the fiords. This would bring bottom waters, rich in nutrients, near the surface where these nutrients would have an optimum effect on marine growth and would make fish farming possible.

- Officials in other agencies were interested in exploring the possibilities of using isotope power units as backup navigational devices for systems currently in use. This expression of interest is probably based primarily on curiosity at the present time rather than on any well-defined needs.

- Responsible State agencies expect to be active in assessing any potential environmental problems that may be involved in the demonstration or operational use of isotope systems. No antinuclear biases were detected in any of these organizations and recent indications are that these groups would discharge their responsibilities in an impartial and realistic manner.

- State agencies were not as concerned about capital costs as were commercial organizations. Those groups involved in trying to improve the 
"quality of life" for native villages encourage a further examination of total costs for capital, operation and maintenance for isotopes and conventional systems. Although no one promised outright support, they wanted us to proceed with the program development because it potentially offers a means for avoiding many of the problems with fuel supplies and reliability in conventional systems.

Federal Agencies

Interest in Federal agencies varied markedly from one to another, between regional and headquarters offices and even between the offices, in one case, within the region. Some of these differences can be ascribed to poor communications, different views on proposed services, and a heavy reliance on traditional procedures. A summary of the survey results for Federal agencies follows:

- The Public Health Service (PHS) and the Environmental Protection Agency (EPA) are strongly interested in the possible use of isotopes for heaters and sewage sterilization. PHS is responsible for providing adequate potable water and sewage systems for a large number of dwellings in many Alaskan native villages. The EPA, through its Arctic Environmental Research Laboratory, is responsible for exploring the feasibility of using centralized potable water, sewage treatment and waste disposal facilities. Both organizations wish to pursue the possibilities of working with ERDA on a demonstration of isotope heater and/or sewage sterilization systems in their respective areas of responsibility.

- The Federal Aviation Administration (FAA) has a large number of landbased devices in Alaska as aids to navigation. Some of these are remote transmitters located in areas where maintenance is difficult and a highly dependable power source is needed. The Alaskan Region FAA is interested in a demonstration of an RTG as alternatives to the propane thermoelectric generator systems now in use in one of their remote sites. 
- The National Weather Service (NWS) in Alaska is focusing most of its engineering efforts on improving the reliability of their measuring systems. There was not much interest in RTGs for remote power because NWS personnel believe they should visit their stations at least once a month and fuel for conventional power systems can be supplied at the time of these visits.

- Power systems for all Coast Guard aids to marine navigation are specified by their headquarters in Washington, D.C. Although there are a large number of potential uses, especially for backup devices in Prince William Sound for the Valdez Shipping Channel, the regional office did not want to explore the possibility of demonstrating an RTG system at the present time.

\section{Military Services}

The nine contacts made with various U.S. Military Service groups and organizations resulted from referrals by ERDA personnel or others who believed particular individuals and/or groups had some contribution to make to the Cold Regions Isotope Applications Program. The specific basis for these referrals and subsequent contacts was to provide input from individuals/ groups who: 1) were, had or soon were expected to use isotope devices, 2) were potential users of these systems or 3) had special knowledge of Cold Regions problems. Contacts with the first group were made to acquire background information and to learn of anticipated developments that might affect applications in Cold Regions. Input from this group was believed to be particularly important because some military groups have used RTGs for one mission or another for well over a decade.

Contacts with potential military users were for the same purpose as contacts made with the other three segments of the market. No classified discussions were held by the author with any of the services in the course of FY-1975 work. This limited the scope of this particular effort. However, ERDA Headquarters personnel were active in the classified areas so ultimately all or most of the potential Cold Regions applications for the immediate future should be uncovered. None of the classified information from the ERDA contacts is contained or referenced in this document. 
Since the military services have been active in Cold Regions for many years their personnel knowledgeable on general problems in those areas were able to play a particularly important role in this program. These people provided general background on the Arctic and identified potential operating problems of isotope and conventional systems. Finally, these people also pointed out certain potential applications for the military services or other segments of the market.

A sumary of important information acquired for the Cold Regions Isotope Applications Program in contact with the military services follows:

- The Naval Facilities Engineering Command (Nav Fac), U.S. Navy, has acquired over 50 RTGs in the past several years. These devices have been used effectively for a large number of different purposes.

- Nav Fac currently has a number of RTGs in storage that are potentially available for interagency programs designed to provide useful information to the Navy.

- Most or all U.S. Navy RTGs have been designed to operate at depths of $20,000 \mathrm{ft}$. Since the Navy is a major purchaser of these devices from commercial manufacturers, this $20,000-\mathrm{ft}$ requirement is believed to have been designed into the units that are generally available for terrestrial use.

- Certain sections of the U.S. Army Corps of Engineers have been active in examining the possibilities of using radioisotopes for heat and sewage sterilization. Responsible personnel in this organization believe that under special conditions there may be opportunities to use decay heat to produce steam for power generation. The service objectives of this organization's sewage sterilization work appear to parallel those of the Biosystems Research Department at Sandia Laboratories in Albuquerque, New Mexico, for ERDA and EPA supported programs.

- The U.S. Corps of Engineers has an interest in septic tank heaters for Cold Regions use. 
- The Army Security Agency, U.S. Army, has several active programs to improve mean-time-to-failure of a wide variety of electronic systems. The results of their programs should be monitored carefully because the failure of ancillary equipment powered by RTGs has been a major factor contributing to their limited use in remote areas as was reported in Appendix D. Significant improvements in the reliability of electronic measuring systems of various types could herald a greater future demand for RTGs.

- The Cold Regions Research and Engineering Laboratory (CRREL), U.S. Army, has been and is involved in a large number of research programs in the Arctic, Antarctic and Alpine Areas. In addition to the outstanding background information and contacts this organization provided, they also indicated a potential need for small, light weight, highly reliable power sources (up to 5 watts) that could be used to run a wide variety of scientific measuring devices. This potential demand should be carefully examined.

- The Navy Arctic Research Laboratory (NARL) located at Barrow, Alaska, has been involved in cold Regions research for over 25 years. They acquired a Sentinel-powered remote weather station in FY-1975 for one of their needs. The NARL staff, composed of University of Alaska personnel under contract to the U.S. Navy, provided the most extreme fuel cost information acquired during the course of this investigation. Calculated fuel costs for Fletchers Ice Island T-3 at 1100 miles from Barrow are in excess of $\$ 5 /$ gal. NARL also has a fine library that contains a wealth of information about various Arctic problems, research programs, etc. Continuing contact with this organization is warranted not only because they currently are using an RTG powered system but for an exchange of information that would be most useful for any ongoing isotope program in Cold Regions.

- The U.S. Air Force (USAF) as well as the U.S. Navy have a number of remote and automatic weather stations that could be powered by RTGs. The Navy has had one such installation in operation since 1966 on Fairway Rock in the Bering Strait. 
- The USAF operates a system of radar stations in the Arctic to provide an early warning of any potential missile attack on the United States. Upgrading or modifying this system could offer opportunities for RTG systems where unmanned but highly reliable operation might be either desirable or optional.

Other Considerations

This section has been placed in the report as a means for providing survey information that would create embarrassing or awkward situations if the sources of such information were to be identified. Because some of this sensitive information is believed to be particularly pertinent to the Cold Regions Program or sister programs on the beneficial use of isotopes, it will be treated here at least circumspectly so that appropriate remedial or follow-up action may be taken. Further information follows as a listing of statements showing some of the dimension of the problem. Finally, a set of short working definitions are advanced based on the informational statements so that later sections of the report can address suggested procedures for handling matters of this nature.

- Leaders/managers for certain operating and technical groups on the regional level were not aware of the successful use by their organization elsewhere of RTGs even though this occurred a decade or more in the past.

- Technical isolation led one responsible technical leader to ask "...can/were any of those isotope devices operate safely?... Haven't they caused contamination problems?..."

- Certain group leaders/managers on the regional level interpreted their role with centralized research groups to be 1 imited to implementary action on recommendations from above. These regional people appear to view their relationship with their R\&D group as being one of only defining problems or trouble shooting procedures/equipment developed by the centralized organization. Apparently no feedback process is attempted or encouraged insofar as recommendations for the solutions of problems are concerned. 
It should be understood that these examples are not found in all organizations; they were 1 imited but not single events. The general problem that the above three statements describe can be considered as consisting of three elements: 1) limitations on the transfer of technology, 2) the need for better communications and 3) the use of traditional rather than "problem solving" operating procedures. Later in this report are recommendations for avoiding and/or overcoming the first two elements of this problem. The last one, although particularly a source of difficulty and certainly a cause of concern for widespread use of isotopic systems, is beyond the purview of this program. Its existence should be recognized, but the author does not see any methods for readily affecting changes in the operating procedures and traditions of other organizations. 
OPPORTUNITY DEVELOPMENT AND DEMONSTRATION 


\section{OPPORTUNITY DEVELOPMENT AND DEMONSTRATION}

In the previous section a number of promising opportunities to use isotopic devices in Cold Regions were identified. These opportunities were found to be primarily in certain Federal agencies and military groups to help them prepare for anticipated future needs or to provide for more reliable and effective operation of existing systems employed by these organizations.

Identification is but the first of several processes involved in translating opportunity into use or demonstration. Development tasks must be identified which would focus on program objectives, costs, design, access, transportation, licensing, availability, etc. Since one of the major objectives for any demonstration of isotope system in Alaska is the generation of reliable cost information, the basic parameters involved in that evaluation will be treated in the first subdivision in this section. Following will be more details on the opportunities to demonstrate RTGs with the FAA and isotopic heaters and sterilization systems in native villages. Other possibilities for use or demonstration are treated and evaluated in the final part of this section.

\section{ECONOMICS}

One of the considerations in the initiation of the Cold Regions Isotope Applications Program was the economic assumption that Cold Regions are characterized by having high transportation costs with resulting high fuel costs, especially for those localities dependent upon air transport of fuels. Other characteristics include the needs for high reliability in those systems that are critical to survival, safety and the health of those who may live and work in isolated areas. These conditions suggested that there may be situations where isotope devices, even with their high capital costs, would be competitive with conventional systems that have and are being used for these critical services. 
During FY-1975 economic study was focused on acquiring general cost information for: 1) operation and maintenance of conventional systems, 2) capital costs for RTGs, 3) isotopic heaters and thermoradiation sterilization systems, and 4) key factors that affected costs in each of the previous three categories. The general information acquired in FY-1975 will be covered in the following three subsections concerned with: 1) conventional system costs, 2) RTG costs and influential factors, and 3) heater and sterilization system costs. A more detailed cost analysis will be made in succeeding years which would be expected to cover specific production, procurement and licensing costs while another part of this effort would be directed at acquiring operating and maintenance costs for isotopic devices functioning under typical Cold Regions conditions. The latter, experimentally derived, would then be compared with those encountered in the use of competitive systems. The generation of these experimental cost figures is a major reason for the demonstration of isotopic devices for a number of missions in the Cold Regions model area, Alaska.

Costs of Conventional System

Most of the comparative cost information for competitive power systems was supplied by the Northern Engineering Services Company, Ltd. (NESC), Calgary, Alberta, Canada. The data given in Table 1 shows the anticipated costs for the continuous generation of $2 \mathrm{~kW}(\mathrm{e})$ by alternative methods in isolated areas in Northern Canada. Similar costs should be expected for Alaska. The data for Table 1 were derived for a situation involving 28 separate but identical stations, each having one unit to carry the power load and one unit on standby. The 1974 capital cost figures shown in Table 1 include equipment, a building to house the power units, transportation of equipment and materials to the site, and labor. Fuel was to be supplied by helicopter four times each year, at which time preventive maintenance would also be handled. In addition to each site visit, which is expected to take 1 day, up to two additional trips were also included with the unmodified diesel unit for unexpected maintenance work that would be anticipated from system malfunctions during sustained operation. NESC 
TABLE 1. Arctic Power System Costs

\begin{tabular}{|c|c|c|c|c|c|}
\hline & $\begin{array}{c}\text { Capital } \\
\text { Cost, } \\
\$ \\
\end{array}$ & $\begin{array}{c}\text { Capital } \\
\text { Recovery, } \\
\$ \\
\end{array}$ & $\begin{array}{c}\text { Fuel, } \\
\$\end{array}$ & $\begin{array}{c}\text { Fuel } \\
\text { Transportation, } \\
\$\end{array}$ & $\begin{array}{l}\text { Maintenance, } \\
\$\end{array}$ \\
\hline Diese 1 & 43,500 & 5,100 & 1,750 & 5,350 & 6,700 \\
\hline $\operatorname{CCVT}^{(a)}$ (diesel) & 48,000 & 5,650 & 7,165 & 21,500 & 1,100 \\
\hline CCVT (propane) & -- & -- & 5,800 & 22,500 & 1,100 \\
\hline CCVT (modified) & -- & -- & 4,300 & 12,500 & 1,100 \\
\hline
\end{tabular}

Notes:

- Cost analysis based on over 25 sites that might be located in Northwestern Canada.

- The power demand was $2 \mathrm{~kW}$ electric continuously.

- A building and necessary transportation, labor and materials were included in the capital cost figures.

- Cost analysis based on fuel costs exceeding maintenance costs.

- Cost analysis based on four visits to each site per year.

(a) CCVT - Closed-Cycle Vapor Turbine System manufactured by Ormat Turbin Ltd. of Yarne, Israel. 
indicated that fuel costs would be greater than maintenance costs as shown in Table 1. However, other Arctic organizations, according to these people, believe the opposite to be true.

Different fuel oil cost data were acquired for different locations in or near Alaska. The variations are dependent upon three factors: 1) source of supply, 2) method of supply, and 3) distance from a primary fuel storage system. Because of the wide variation only a listing of these costs will be given. However, what follows should provide a general indication of fuel costs in Northern Alaska and on the Arctic Icepack.

- Fletcher's Ice Island T-3 was located about 1100 airline miles from Barrow in September 1974. Fuel oil flown to this ice island by a Hercules air transport was reported to cost $\$ 5.66 /$ gal.

- Atkasook is a small, isolated village located about 80 miles south of Barrow. Chartered flights are currently used for a 11 supplies; fuel oil in June 1975 cost $\$ 2.75 /$ gal. (2)

- Barrow and Wainwright are two Eskimo villages in Northern Alaska located on the shores of the Chukchi Sea. Fuel oil is provided during the ice-free period in late August and early September each year by tug-pulled fuel barges. June 1975 fuel $0 i 1$ costs were reported to be 93\$/gal. (3)

- NARL, another source of fuel costs in Northern Alaska, is supplied by the U.S. Navy. The Navy accounting process apparently averages fuel $0 i 1$ costs for a large number or a11 of their installations because NARL costs for this energy source at Barrow in September 1974 were reported to be $32 \$ / g a 1$. (1)

- Anaktuvuk Pass is an isolated Eskimo village in the Brooks Range about 275 airline miles northwest of Fairbanks. A11 of its supplies are provided by air transport. Using April 1975 information from an air freight company based in Fairbanks, fuel oil was calculated to be $\$ 2 /$ gal delivered at this village. 
RTG Costs and Influential Factors

In FY-1975 Divine conducted a preliminary study of RTG costs and the factors that appeared to have the greatest effect on these costs. His work, a part of the Cold Regions Isotope Applications Program effort, was covered in a short report (see Appendix E). This portion of the report summarizes the salient parts and tentative findings resulting from Divine's study. Before proceeding further, however, it is important to remember that his study was preliminary and limited. Its primary purpose was to take a quick look at some of the costs (and factors related to them) and to indicate any new approaches to their analysis.

Divine used an engineering-economics approach to identify the cost factors inhibiting the use of RTGs. He chose to divide his field into three parts concentrating on the technical, economic and socio-political factors that are believed to influence RTG costs. He then conducted an elementary sensitivity analysis to obtain a general indication of the relative influence of these three parts. The heuristic matrix that he developed defines activities in these three areas for RTGs, as given in Figure 5 . It is expected to be useful in establishing a rigorous methodology for identifying all costs that are the result of a variety of nontechnical as well as technical variables.

Divine made several conclusions based on RTG costs reported in the literature or from private sources which he compared with the NESC data on costs associated with the manufacture, installation and operation of conventional power systems. These conclusions are listed below and are further expanded to provide additional perspective and relationship to the cold Regions Program.

- Cost of RTG manufacture appears to be the controlling variable in the total economics governing the use of these devices. This position is also the one taken by industry. (5)

- From the limited available information, production costs can possibly be substantially reduced by increasing production volume. These 
SCOPE OF STUDY

OF ECONOMIC

FACTORS

\begin{tabular}{|c|c|c|c|}
\hline DEPENDENT -INDEPENDENT & TECHNICAL & ECONOMIC & SOCIO-POLITICAL \\
\hline TECHNICAL & $\begin{array}{l}\text { TECHNICAL } \\
\text { FEASIBILITY }\end{array}$ & & $\begin{array}{l}\text { PATENT, } \\
\text { IICENSING } \\
\text { OF OTHER } \\
\text { PROPRIETARY } \\
\text { FACTORS }\end{array}$ \\
\hline ECONOMIC & $\begin{array}{l}\text { TECHNICAL } \\
\text { SUBSTITUTION }\end{array}$ & & $\begin{array}{l}\text { CAPITAL-LAB OR } \\
\text { SUB STIITUTION } \\
\text { INSTITUTIONAL INERTIA } \\
\text { SOCIETAL NEEDS }\end{array}$ \\
\hline SOCIO-POLITICAL & $\begin{array}{l}\text { ENWIRONMENTAL } \\
\text { IMPACTS } \\
\text { AND } \\
\text { ECOLOGICAL } \\
\text { CONCERNS }\end{array}$ & & $\begin{array}{l}\text { LEGAL-INSTITUTIONAL } \\
\text { FRAMEWORK } \\
\text { WITHIN WHICH } \\
\text { TECHNOLOGY } \\
\text { WILL OPERATE }\end{array}$ \\
\hline
\end{tabular}

FIGURE 5. Engineering-Economic Systems Classification of Factors Affecting Addition of Technology

potential reductions would likely result from improved designs that would evolve from "on line" observation, user feedback, etc., as well as streamlining the use of human resources, inventories, well-defined marketing channels, etc.

- A substantial improvement in overall costs would also result from any "buy back" arrangement for used units. This might evolve to make further use of equipment and the residual heating values remaining in the isotope capsules. Another approach would be leasing. This implies a market sufficient for a leasing operation to function profitably. Some of the other aspects related to the "buy back" arrangement will be covered in the report section treating needed technology development for they have to do with developments that may help achieve a better utilization of the heaters and ancillary equipment that constitute elements of RTGs. 
Costs of Heater and Sterilization Systems

The elementary cost analysis presented in this subsection on the factors influencing the cost of using isotopes for septic tank heaters and sterilization systems is based on use of Waste Encapsulation and Storage Facility (WESF) capsules. (6) These capsules contain either strontium fluoride $\left(\mathrm{SrF}_{2}\right)$ as a compact powder or melt cast cesium chloride ( $\mathrm{CsC} 1$ ). Although a standard $\mathrm{SrF}_{2}$ capsule contains about $150,000 \mathrm{Ci}$ of ${ }^{90} \mathrm{Sr}$ while a $\mathrm{CsCl}$ capsule has $80,000 \mathrm{Ci}$ of ${ }^{137} \mathrm{Cs}$, costs are reported to be 10 to $20 \notin / \mathrm{Ci}$ for both types of capsules. Since the $\mathrm{SrF}_{2}$ capsules would be used for heat, one method of providing cost information would be to compare Btu costs with costs for conventional fuels to accommodate comparable heating loads. A quick calculation shows that one $\mathrm{SrF}_{2}$ capsule will generate about $1.3 \times 10^{8}$ Btu's in 5 years, the energy equivalent of about 24 barrels of fuel oil. A comparison of heat costs, assuming continuous operation for 5 years, at Hughes, a small village on the Koyukuk River in Central Alaska, is enlightening. If fuel oil is assumed to cost about $\$ 1 /$ gal in this village, then heat for a small septic tank to promote anaerobic digestion would run $\$ 1000$. However, $\mathrm{SrF}_{2}$ heat costs of 10 and $20 \$ / \mathrm{Ci}{ }^{90} \mathrm{Sr}$ with shipping charges of $2 \$ / C i$ are $\$ 18,000$ and $\$ 36,000$, respectively. Al though the lower of the two isotope costs exceeds the conventional source by a factor of about 18, this comparison does not include the substantial savings in operations and maintenance costs with the isotope system as well as costs for those factors not easily definable such as improved reliability. It is recommended that more detailed costs be acquired on capita requirements, maintenance and operations. Implementation of this recommendation is discussed in the "Heater and Sterilization System Demonstrations" Subsection.

If the sewage from the entire village of Hughes (about 65 people) were to be treated by a thermoradiation sterilization process, a system using both ${ }^{90} \mathrm{Sr}$ and ${ }^{137} \mathrm{Cs}$ capsules would be involved. The former would be employed to provide the necessary heat for the process while the latter would be the source of the gamma radiation needed for sterilization. A 
reasonable assumption would place capsule requirements at one each and this would result in costs of 10 and $20 \$ / C i$ isotopes with shipping charges of $2 \nsubseteq / C i$ at $\$ 25,200$ and $\$ 50,400$, respectively. A direct comparison of fuel costs can no longer provide even a simplified means for showing what a conventional process, analogous to the isotope system, would cost. It is believed that the effluent from the isotopic system would be at least as good as secondary sewage treatment system effluent and perhaps approaching that achieved by tertiary treatment. The specific cost numbers to make this comparison are not presently available but should be acquired in this program in FY-1976. Certain cold regions characteristics place restrictions on these systems and may limit their applicability (i.e., septic systems are probably incompatible with permafrost). These factors and further discussion of these systems is presented in the "Isotopic Heaters and Sterilization Systems" subsection.

\section{RTG DEMONSTRATION WITH FAA}

The Regional Office of the Federal Aviation Administration (FAA) in Anchorage was contacted in September 1974 since this organization used a large number of navigational devices that could be powered by RTGs. These navigational devices must be very reliable and operate for extended periods of time without maintenance or attendant personnel. In the course of the contact it was learned that the Regional Office had an active, on-going program to examine and, when warranted to demonstrate alternative power generation systems. Since this FAA regional objective coincided nicely with the objectives of the Cold Regions Isotope Applications Program, exploratory discussions were directed toward defining potential methods for cooperations. Letter and telephone contact was maintained over a period of months as well as by another visit in June 1975 to further elucidate the possibilities of demonstrating an RTG system with the Alaskan Region, FAA. It has been an iterative process in which much progress was made in FY-1975, but further work remains to bring to fruition such a demonstration project. Additional information on this opportunity to demonstrate an RTG with the FAA will be covered in three subsections that follow on the current situation, the proposed demonstration and other considerations. 
Current Situation

This subsection will summarize existing procedures used by the Alaskan FAA to provide line-of-sight air/ground communication support systems in a particular part of Alaska, the problems attendant with current modes of operation and efforts to provide alternative systems.

In the upper part of the Alaskan Peninsula lies Lake Clark Pass, an opening in the Chigmit Mountain Range, that is used by light airplanes to travel between Anchorage and the Bristol Bay Area of Southwest Alaska; the location of these mountains and the Pass is shown in Figure 6 . Several years ago the Alaskan FAA embarked upon a program to provide remote transmitter stations in this pass to help the light planes find their way safely through a series of tortuous canyons with high flanking mountains. Since these remote transmitters would be unattended, a high degree of reliability was required for a successful operation. Following certain investigations by the research group at FAA Headquarters, Washington, D.C., a propane thermoelectric generator (TEG) system was recommended for use in that area. (7) The TEG system is an analog of the RTG. Instead of decay heat from an isotope capsule, the static heat generator is operated from heat supplied by the combustion of propane. As with RTGs the heat not used in the conversion process $(295 \%)$ is used by the FAA system to maintain a reasonable temperature in an enclosure to operate various instruments and attendant equipment.

Three TEG powered remote transmitter stations were installed in Lake Clark Pass in 1970. After a period of shakedown operation, these devices have provided satisfactory service, and an additional four TEG units are to be installed in the next 1 to 2 years to complete coverage to Lake Clark. When this is done, Lake Iliamna and Bristol Bay may be reached with relative ease when proceeding from Anchorage by this route.

Although the Lake Clark Pass units have been successful there are certain problems involved in their operation. Since the transmitter sites are located high on sinall level spots on the sides of the mountains, helicopters are used to ferry fuel and maintenance personnel to these sites; 


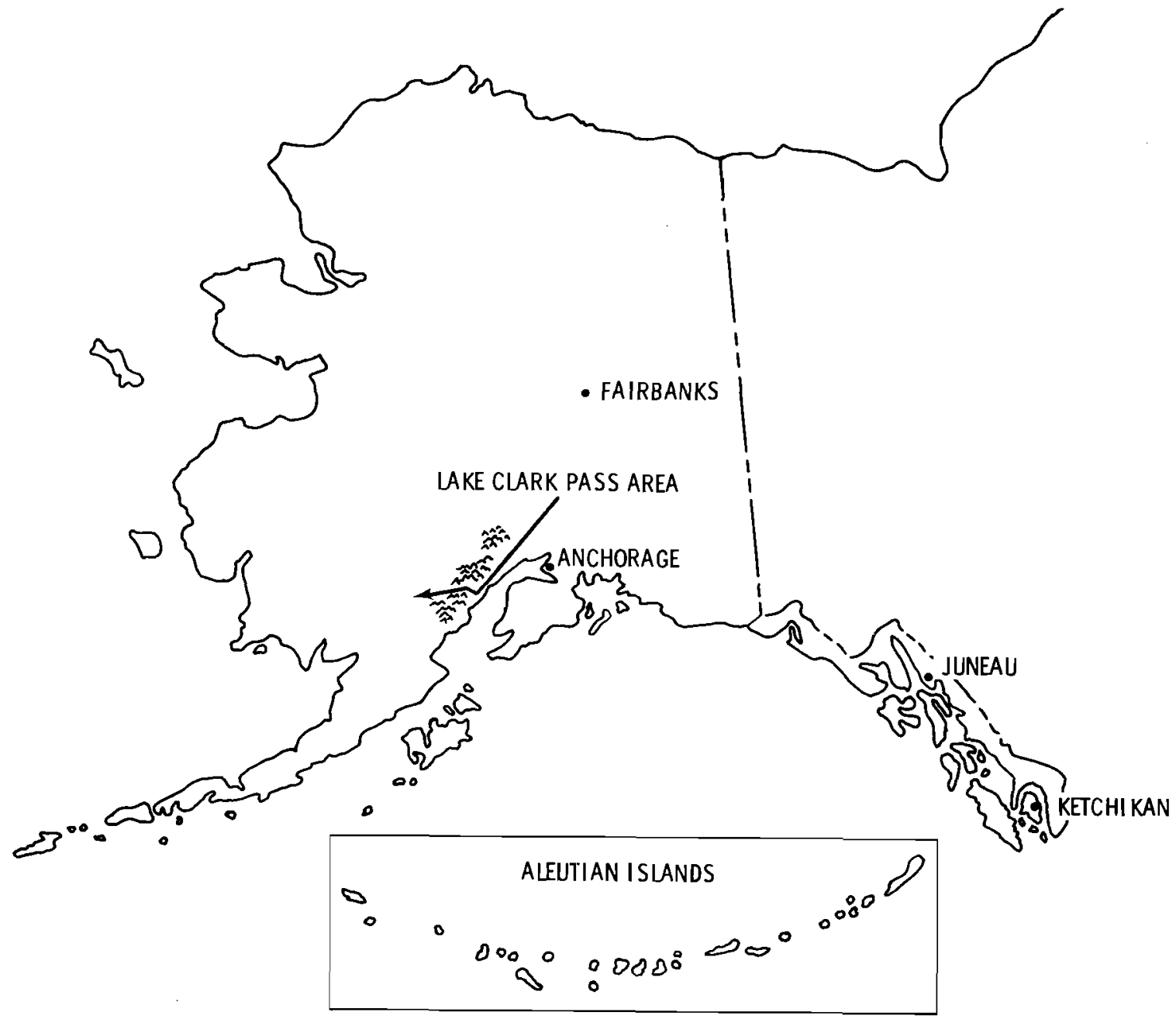

FIGURE 6. Lake Clark Pass Area in Alaska

these craft were also used when the units were originally installed. This means that refueling depends on good weather including reasonable wind conditions. Even after maintenance personnel are landed there are potential safety problems involved in the refueling operation, such as swaying propane tanks that are suspended from the helicopter before being positioned by the ground crew. Figure 7 shows a propane tank being lowered into position at a TEG unit in the Lake Clark Pass Area, while Figure 8 shows 


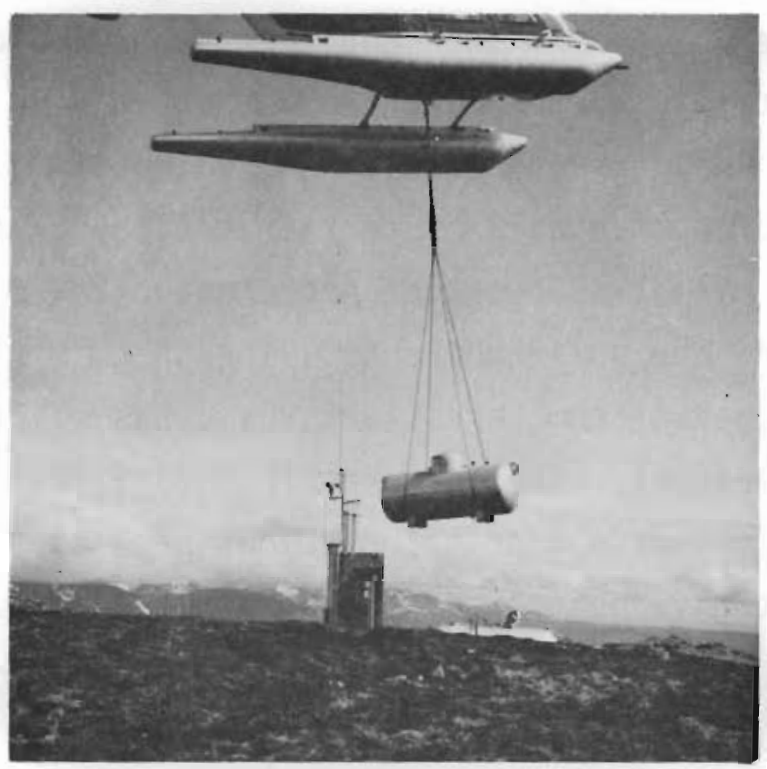

FIGURE 7. TEG Refueling by Helicopter

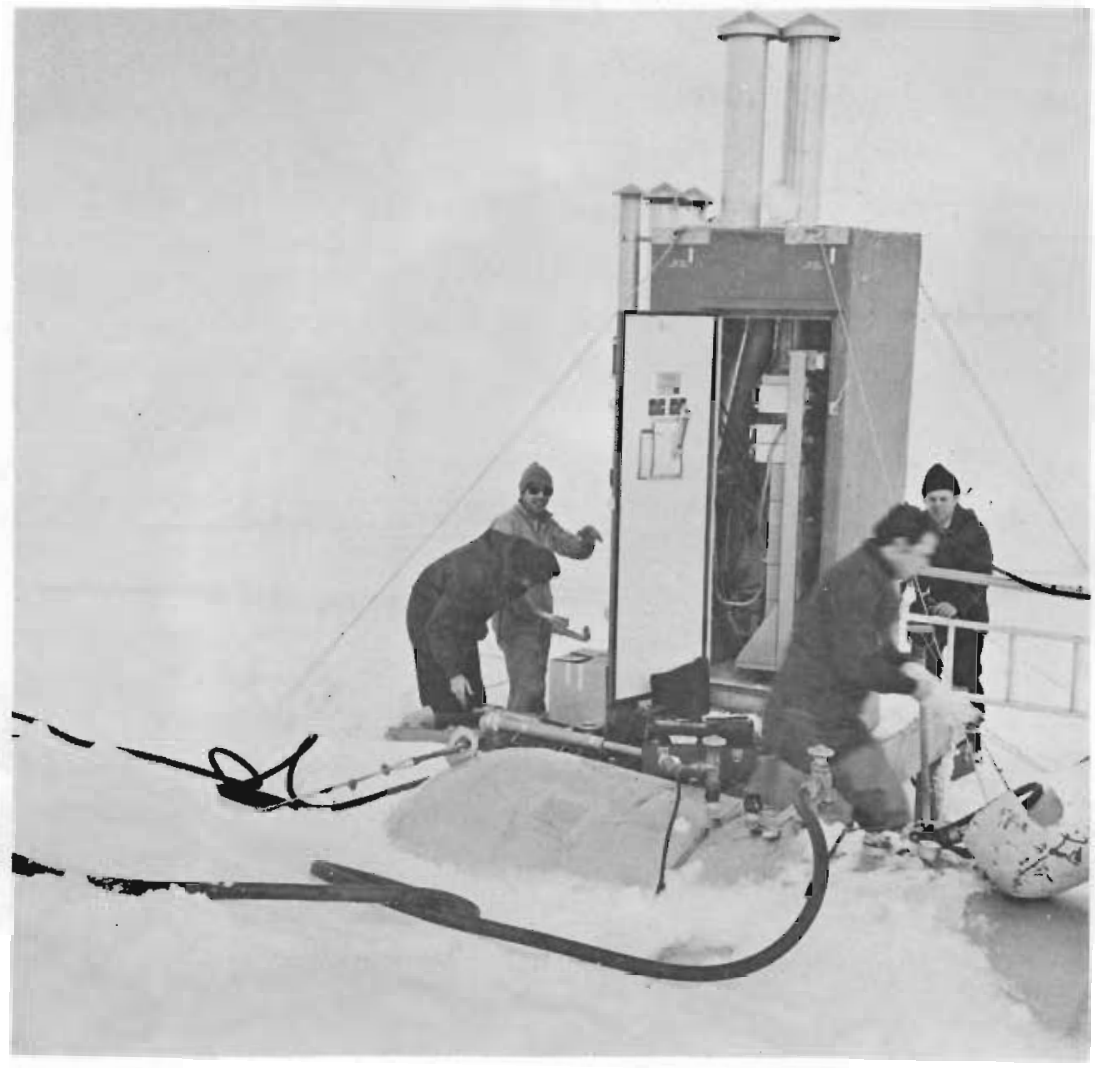

FIGURE 8. Refueling and Maintenance Work on a TEG 
some other activities involved in the refueling and maintenance of a TEG. Note the snow coverage and weather conditions where clouds or fog have obscured the mountains in the background. Figure 9 is a photograph (a11 three photographs are courtesy of Alaskan Region, FAA) of a Lake Clark Pass TEG showing some of the details of terrain. Although these TEGs are located about 100 miles southwest of Anchorage, they are in an isolated area in which there are no inhabitants. The Chigmit Range, running to the southwest and northeast from Lake Clark Pass, has glacier-covered peaks as well as active volcanoes. The only reported difficulties at the TEG sites other than mechanical or electrical problems were those experienced with porcupines ${ }^{(8)}$ that have destroyed some wooden flooring, stands, etc.

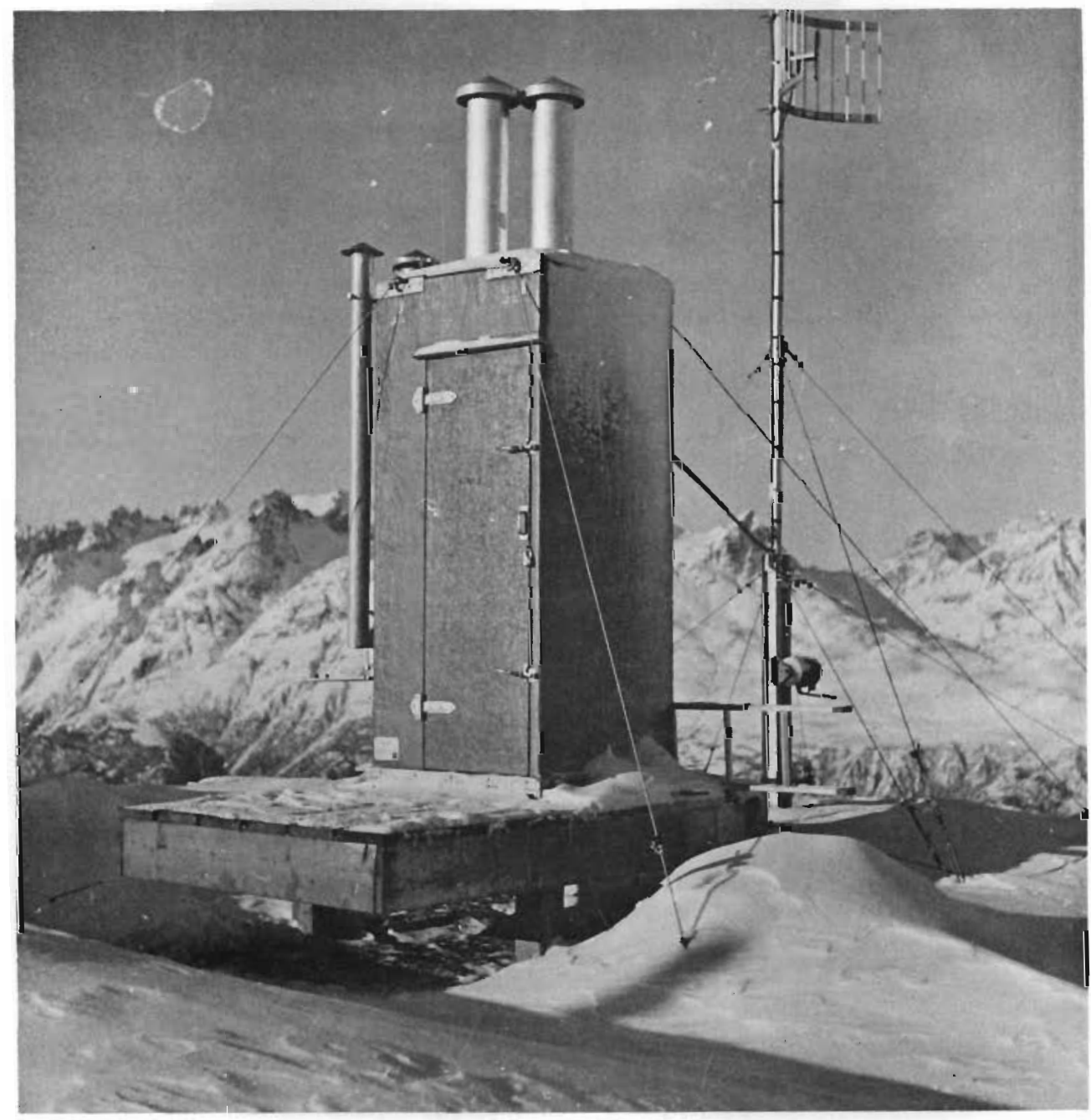

FIGURE 9. A TEG Site in the Lake Clark Pass Area 
The Alaskan office also provided some general cost and related information associated with the operation of TEGs in the Lake Clark Pass Area. Fuel costs were reported to run about $\$ 5000 /$ year/site; ${ }^{(7)}$ this includes transportation costs from the staging area at Kenai on the Kenai Peninsula. FAA manpower costs for planning refueling and maintenance, and following the general operation of TEGs in the Chigmit Range are not known. About $75 \%$ of all TEG outages (total not known) are caused because of propane pile/burner problems. ${ }^{(8)}$

Proposed Demonstration

At the present time two opportunities are potentially available to demonstrate RTGs with the Alaskan Region, FAA. The first of these opportunities involves substituting an RTG for an existing TEG in the Lake Clark Pass Area. The second is to use an RTG to power one of the new remote transmitter devices that are to be installed in 1 to 2 years. One major factor involved in deciding between these two opportunities for demonstration purposes is time. With diligent work and close coordination with the Alaskan FAA it may be possible to place an RTG and begin the demonstration in the summer of 1976. This approach also allows the RTG to be compared directly with a TEG-powered system that has been in operation for several years. If the second option is chosen demonstration might be delayed until the summer of 1977 because the new transmitter units may not be installed until that time. Either option would satisfy the general criteria for conducting such a demonstration such as: 1) the FAA's interest in operating an RTG-powered system to acquire operating experience on alternative systems to the TEG power units now used for remote power, 2) ERDA objectives of acquiring specific operating costs for remote areas in Cold Regions, and 3 ) fostering a wider understanding in other Federal agencies of the high reliability and advantages inherent in the use of RTGs.

Another factor also bears additional scrutiny. In the subsection on economics information was presented that indicated that high fuel costs might not ever be sufficient to rationalize RTG use for terrestrial applications. At this time that consideration is only an indication that has 
resulted from the analysis of limited and incomplete data. The proposed demonstration with the FAA is one method for acquiring the needed information. If demonstration data substantiates Divine's preliminary findings, then there is support for additional emphasis on evolving methods for reducing manufacturing costs.

Some specific activities that should be undertaken in FY-1976 to guarantee such a demonstration with the Alaskan Region, FAA, are listed below.

- An interagency agreement between the FAA and ERDA must be developed and signed to confirm this suggested joint venture.

- Licensing and environmental impact requirements must be defined in FY-1976 if an RTG is to be substituted for a TEG at an existing transmitter in the summer of 1976.

- Once it appears that an interagency agreement will be signed, formal action must be taken to arrange for the use of one of the devices believed to be currently in U.S. Navy storage.

- Once the interagency agreement is signed, PNL and Alaskan FAA personnel must clearly define plans for the demonstration, procedures for a cooperative program and the various items to be studied, examined and evaluated.

- Specific site selection should be a joint undertaking between PNL and the Alaskan FAA. The same time constraints impinge upon this activity that were mentioned earlier with regard to licensing and an environmental impact statement. Other factors involved in the selection process are Lake Clark Pass climate and geography. If there is a particular need to have the greatest access possible to the RTG demonstration, then the selection process should consider a location with: 1) the greatest probability for favorable weather, and 2) the greatest accessibility by helicopter so that necessary observation and measurements can be taken.

- Specific power requirements for the operation of a remote transmitter device in the Lake Clark Pass Area must be defined. 
For the sake of emphasis it should be stated that the proposed demonstration of an RTG with the Alaskan FAA is to acquire detailed economic data for operation in remote Cold Regions. Its demonstration is also needed to broaden the understanding of its reliability and usefulness in other Federal agencies. The technical feasibility of RTGs was firmly established well over a decade ago as indicated in Appendix $D$.

\section{Other Considerations}

As was discussed earlier it would be desirable to work with an established and well-known organization in Alaska so that many of the complaints about the "Lower 48" telling Alaska what to do could be avoided. The proposed arrangement for the demonstration of an RTG with the FAA should fit these more desirable conditions. The Alaskan Regional office has been in operation for many years and its staff members are considered to be permanent residents of the state.

Although the isolation of the area where RTG demonstration is proposed has certain very definite advantages, this isolation makes it difficult to show key Alaskan residents the operation of the isotopic heat engine. The concept in having a demonstration where visitors could see the operation would promote a better public understanding of RTG and other isotopic systems. In all likelihood a well-planned public relations campaign, involving key technical people, would overcome this particular problem. It is recommended that effective liaison be maintained during the entire course of the demonstration with cognizant governmental groups on all levels. Additionally, a thorough program of reaching the public through service clubs, schools, the local media and the business community is mandatory. Care taken when developing effective channels of communication at the onset of the demonstration with proper use during the program should:

1) help avoid any unnecessary fears, and 2) promote a better understanding of the beneficial uses of radioisotopes.

\section{ISOTOPIC HEATERS AND STERILIZATION SYSTEMS}

Contacts in the "Lower 48 " as well as Alaska indicated that there was a strong interest in improved sewage disposal procedures for Cold Regions. 
This interest encompassed all four market segments and was a response to a particular need where isotopic heaters may be substantially used. Existing sewage disposal ranges from the primitive to the very sophisticated. On one end of the scale is the "honey bucket" disposal process while on the other end is the tertiary sewage treatment system used by the Alyeska Pipeline Company. For many systems beyond the primitive type, heat is needed to promote digestion reactions at ambient temperatures below $50^{\circ} \mathrm{F}$. In some areas large collection systems are used to hold sewage until the heat in 2 to 3 summer months is sufficient to digest the solids. In some other situations incineration is used. The possibility of having a well-insulated collection tank, where isotopic heat is continuously supplied to maintain digestion throughout the year, is a potential solution for a major Arctic problem. For more elaborate systems a heater could be used in series with a ${ }^{137} \mathrm{Cs}$ sterilization source to completely deactivate the sewage effluent.

A major impetus for directing program attention to Alaskan sewage disposal is the State- and Federal-agency programs attempting to improve the quality of life for the natives residing in rural Alaska. Currently, the average life expectancy of the Alaskan native is about half of the life expectancy for a resident in the "Lower 48". A significant factor in this lower life expectancy is disease. One method for combating rural Alaskan disease is to improve sewage disposal procedures. Another means for reducing disease problems is to use sanitary drinking water. Two Federal agencies were interested in exploring the possibilities of using isotopic heaters to keep potable water storage and supply systems in a fluid state during those months when ambient temperatures are below freezing.

Additional information on the possibilities for the demonstration of isotopic heaters and sterilization systems in Alaska will be covered in three subdivisions: 1) isotopic heaters, 2) isotopic sterilization units, and 3 ) other considerations.

Isotopic Heaters

At the present time there are several opportunities to demonstrate the use of isotopic heaters in Alaska. All but one of the opportunities 
are concerned with supplying heat for potable water or sewage systems in Alaskan Native Villages. The one non-village possibility is with the U.S. Corps of Engineers, although they too are interested in heat for sewage treatment.

Before additional information on opportunities to demonstrate heaters in Cold Regions is presented, the assumptions governing the type and availability of the isotopic devices that could be used for such purposes must be discussed. This portion of the program was based on the belief that the Hanford Waste Encapsulation and Storage Facility (WESF) SrF 2 capsules would be available and used for such purposes. Each of these capsules contains about $150,000 \mathrm{Ci}$ of ${ }^{90} \mathrm{Sr}$ and generates about $1 \mathrm{~kW}$. These capsules, each $2.625 \mathrm{in}$. in diameter and $20.1 \mathrm{in}$. 1ong, are being produced at the Atlantic Richfield Hanford Company (ARHCO) from separation wastes at Hanford; a diagram of the WESF capsule is given in Figure 10. Although these capsules store the ${ }^{90} \mathrm{Sr}$ (and ${ }^{137} \mathrm{Cs}$ ) component(s) of the separation wastes that have been accumulated at Hanford over a period of years, they may also be used for other purposes. The early 1976 inventory of SrF 2 capsules is about 120 and the annual production is estimated to be $133 .(\hat{6})$ There is expected to be a substantial supply of these capsules that may be used for various heater demonstrations and for various Cold Regions applications.

The heat generation rate of these capsules is dependent upon ${ }^{90} \mathrm{Sr}$ half 1ife. Since half of the ${ }^{90}$ Sr activity disappears in 29 years the heat output will drop by a similar percentage in the same period of time. After 29 years the rate $w 111$ be $500 \mathrm{~W}$ instead of $1 \mathrm{~kW}$. Another factor related to heat output affects the potential purpose for which these devices may be used. A $1-k W$ output is a small generation rate when compared to many conventional heat sources. With a $1 \mathrm{~kW}(3413 \mathrm{Btu} / \mathrm{hr}$ ) output, most applications will be limited to those needed to affect sensible heat changes rather than those involving phase changes such as are required for melting ice or boiling water which take 144 and 970 Btu/lb of water, respectively. More than one capsule could be used in a heat source; however, the numbers will be limited by the costs of the isotopes and the size and weight of the required radiation shielding. 


\begin{tabular}{|c|c|c|c|c|c|c|c|}
\hline & \multirow{3}{*}{ torm } & \multirow{3}{*}{ IOADIMG } & \multirow{3}{*}{ 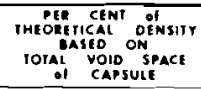 } & \multicolumn{4}{|c|}{ IEMFinatuet: } \\
\hline & & & & \multicolumn{2}{|c|}{ AIE } & \multicolumn{2}{|c|}{ wate } \\
\hline & & & & CENTER LINE & SURFACE & CENIII IINE & SURAAC \\
\hline $\begin{array}{l}\text { stromitium } \\
\text { favoriog }\end{array}$ & $\begin{array}{l}\text { Compactio } \\
\text { powoet }\end{array}$ & $150 \mathrm{kCi}$ & 10 & $100^{\circ} \mathrm{c}$ & $430^{\circ} \mathrm{c}$ & $800^{\circ} \mathrm{c}$ & $110^{\circ} \mathrm{c}$ \\
\hline $\begin{array}{l}\text { CESIUM } \\
\text { CHLORIDE }\end{array}$ & mert-cast & oo kc & os & $430^{\circ} \mathrm{C}$ & $200^{\circ} \mathrm{c}$ & $327^{\circ} \mathrm{C}$ & $30^{\circ} \mathrm{c}$ \\
\hline
\end{tabular}

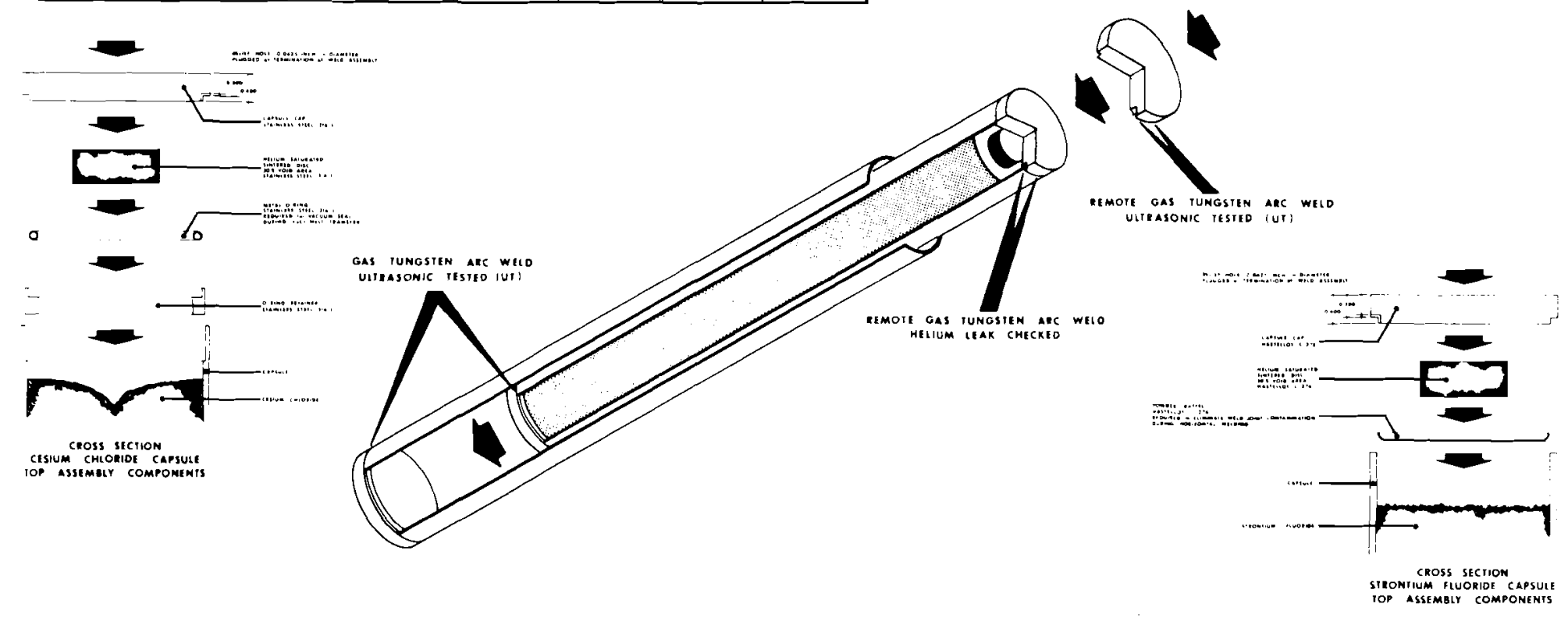

\begin{tabular}{|c|c|c|c|c|c|c|c|c|c|c|}
\hline & \multicolumn{10}{|c|}{ capsule } \\
\hline & \multicolumn{5}{|c|}{ INNER } & \multicolumn{5}{|c|}{ outen } \\
\hline & MAIERIAL & $\begin{array}{c}\text { WALI } \\
\text { THICKNESS }\end{array}$ & $\begin{array}{c}\text { OUISIDE } \\
\text { DiAmEter }\end{array}$ & $\begin{array}{l}\text { rotal } \\
\text { IINGGHM }\end{array}$ & $\begin{array}{l}\text { POTAL CAP } \\
\text { THICKNESS }\end{array}$ & mateniat & $\begin{array}{c}\text { WALI } \\
\text { THICKNESS }\end{array}$ & $\begin{array}{l}\text { OUTSIDE } \\
\text { Diamerte }\end{array}$ & $\begin{array}{l}\text { TOAAL } \\
\text { IINGTH }\end{array}$ & $\begin{array}{l}\text { ROAL CAP } \\
\text { THICKNESS }\end{array}$ \\
\hline 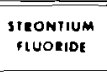 & $\begin{array}{l}\text { Hasitior } \\
\text { c.276 } \\
\text { (uII) }\end{array}$ & $\begin{array}{l}0.130 \\
\text { (UII) }\end{array}$ & 3.230 & 19.050 & 0.400 & $\begin{array}{l}\text { Hasritior } \\
\text { c.27ro } \\
\text { inti }\end{array}$ & $\begin{array}{l}0120 \\
0 \quad 0 r:\end{array}$ & 2.625 & 20.100 & 0.400 \\
\hline $\begin{array}{l}\text { CEsium } \\
\text { chloridit }\end{array}$ & 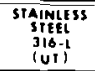 & $\begin{array}{l}0.095 \\
\text { iuti }\end{array}$ & 2.230 & 19.723 & 0.400 & 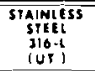 & $\begin{array}{l}0.809 \\
\text { ivil }\end{array}$ & 2.625 & 20.775 & 0400 \\
\hline
\end{tabular}

FIGURE 10. Hanford Waste Encapsulation and Storage Facility Capsules(32) 
To understand the opportunities identified for Cold Regions demonstrations one must also understand the methods currently being used to promote and provide sanitary potable water and effective sewage treatment in Alaskan Native Villages. There are two primary approaches. One of these attempts, generally fostered by PHS, to supply water and sewage service to each dwelling. The other method uses a centralized facility to disperse drinking water and collect treated sewage in each village. The centralized method is being demonstrated by the EPA and is under consideration for the Village Safe Water Program sponsored by the State of Alaska.

In its fullest development the PHS concept is to make these services as convenient as possible for each village dwelling to foster broad acceptance which would have the highest and most immediate impact on disease reduction. However, this method results in certain demands for heat and ancillary services. For instance, the potable water must be stored in the summer in a large tank that is heated during freezing weather to keep it in a liquid state. Water is also pumped from a well to a heated storage tank as demand requires. Sufficient heat must also be supplied in the storage tank or at heater stations in the highly insulated supply systems to ensure that the water going to each dwelling stays in a liquid state.

Similar heat requirements are necessary for the sewage system to ensure that the waste water does not freeze before it reaches a lagoon or septic tank. Currently, lagoons and septic tanks are biologically active for only 2 to 3 months each year in Central Alaska. However, systems to be installed in Northern Alaska would require the addition of heat to promote digestion reaction under any conditions. The septic tank systems now in use in the Interior (a) have notoriously 1 imited lives. (9) Because anaerobic activity is so limited, the tile fields plug rapidly requiring either new fields or the installation of an entirely new system every 1 to

(a) Terminology used to describe Central Alaska or that part of the state north of the Alaskan Range, south of the Brooks Range, and east of the Bering Sea. 
2 years. Lagoons are oversized to provide for adequate storage. Figure 11 shows an aerated lagoon that was installed by PHS at Fort Yukon (Latitude $66^{\circ} 33^{\prime} 45^{\prime \prime} \mathrm{N}$, Longitude $145^{\circ} 16^{\prime} \mathrm{W}$ ). This lagoon covers over a half acre and handles the sewage generated by a village of about 450 . (a)

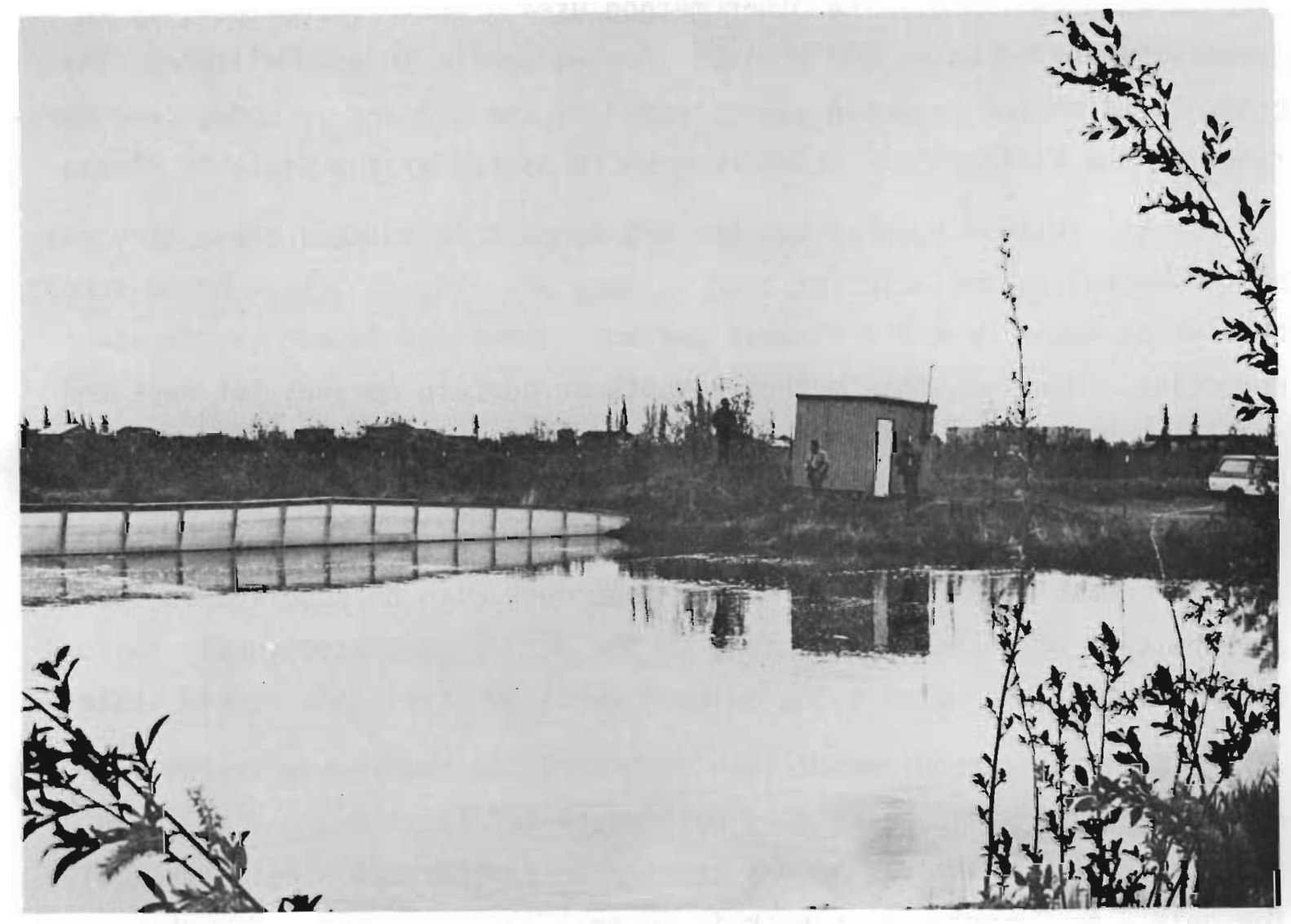

FIGURE 11. Sewage Lagoon at Fort Yukon, Alaska

Another aspect of the problem can be understood by examining Figure 12 . Anaktuvuk Pass (Latitude $68^{\circ} 8^{\prime} 37^{\prime \prime} \mathrm{N}$, Longitude $151^{\circ} 43^{\prime} 50.5^{\prime \prime} \mathrm{W}$ ), as shown from the air in Figure 12, runs for about $1 / 2$ mile along the west bank of the Johns River. (b) The extremes in the other direction are about $1 / 4$ mile.

(a) For detailed topographic information for this village that 1 ies in the center of the Yukon Flats, use should be made of the U.S. Geological Survey Map entitled "Fort Yukon (C-3) Quadrangle".

(b) For topographical information on Anaktuvuk Pass and vicinity, use U.S. Geological Survey Map entitled "Chandler Lake (A-3) Quadrangle". 


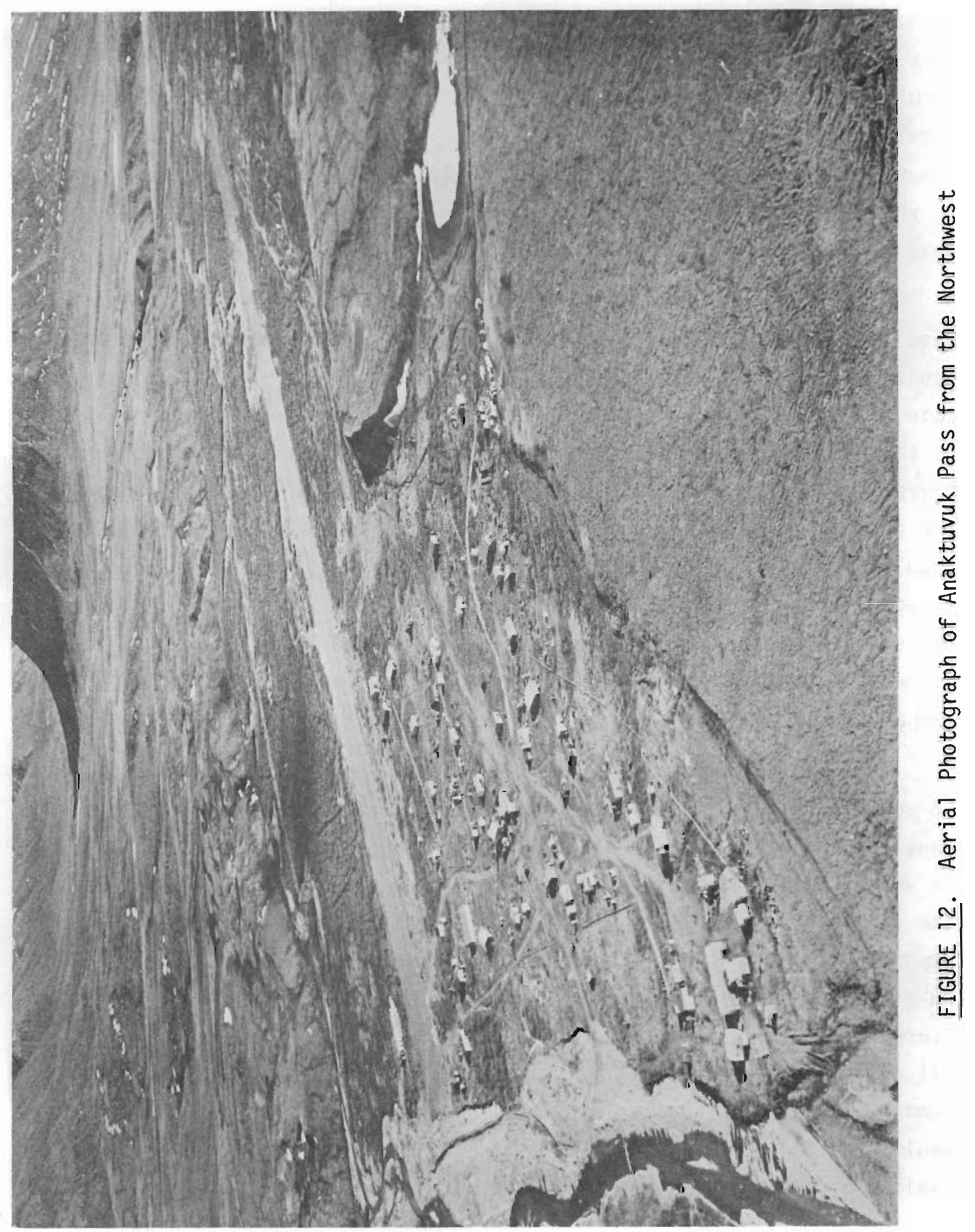


These distances become significant when one realizes that only 139 people reside in this village in about 35 dwellings. Although Anaktuvuk Pass does not have a sewer system at the present time, the dwellings scattered across this area shows some of the problems attendant with providing such service in Alaskan Native Villages. Once discharged from the houses, the sewage may have to be directed to small surge/collection tanks before it is routed on to the treatment system. At these intermediary points enough heat could be added to avoid freeze-up in the sewers.

Another aspect of Cold Regions conditions also bears on the demonstration and possible use of isotopic heaters in Alaska. Permafrost, a ground condition where the subsurface soil remains frozen year round, places certain constraints on the design of systems employing these devices as well as those using conventional heaters. If the subsurface is not rock or a gravel base, designs must be used that avoid any heat loss to the ground for those structures housing the heater. otherwise, ground heat dissipation would result in melting and subsequent loss of structural and system integrity. This restriction is particularly relevant to the demonstration of isotopic devices where great care would be used in the placing of heaters and with stringent requirements imposed for the easy and safe retrieval of these systems.

Conceptually, isotopic heaters could be used to supply sensible heat to potable water systems in Alaskan Native Villages as well as to septic tanks or lagoons. The approach and constraints are similar to those found in any village that would be on the single dwelling service regime. In the very unlikely event that a capsule failed and the multiple barriers imposed between this system and the water tank also failed, there would be an almost inmediate and very deleterious impact on the safety of the water users. Even though this possibility is very remote and essentially beyond all reasonable expectation, this opportunity should not be tried until demonstrations with sewage systems are well underway. Such an arrangement would provide information in addition to the mass of background data now available that would show that: 1) such a possibility is essentially 
beyond reason, and 2) that ancillary safety systems are such that reliable shutdown would occur before such an event would have any undesirable effects.

The other major approach to supplying potable water and sewage services to native villages involves the use of a centralized facility such as that considered by EPA. This concept, described recently in the open literature by Wright, ${ }^{(10)}$ has one large building in a village where drinking water is stored and dispensed and sewage collected by vehicles in the village is treated or incinerated. These facilities (at Emmonak and Wainwright) also contain saunas, showers and laundries. The EPA reports that the natives readily adapt to the use of a combined system of this type and that operation was quite satisfactory. There are three possible uses for isotopic heaters at such a facility: 1) to promote the degradation of sewage, 2) to keep shower, sauna and laundry water in a fluid state, and 3) to maintain potable water ice-free. The second and third fall into the same category as the potable water heating opportunity mentioned earlier and, as stated then, should not be considered actively at this time. The successful demonstration for sewage purposes should precede demonstration in these areas.

At the present time two approaches are or will be used in treating centralized facility sewage. One of these is incineration, and Reid ${ }^{(3)}$ reports that it takes one gallon of fuel oil for every 3 gallons of sewage that is incinerated. The other approach involves the use of a lime treatment process. Isotopic heat appears to offer a viable third alternative that could be, depending upon local conditions, either: 1) septic tank treatment, 2) lagoon disposal, or 3) treatment by a thermoradiation process with subsequent disposal of the effluent. The first two of these approaches would have the same advantages and constraints as discussed earlier. The last one will be discussed in the next subsection.

One of the many missions of the U.S. Army Corps of Engineers is to develop advanced procedures for handling sewage at military installations, 
small or large, in Cold Regions and elsewhere. Isotopic heaters, of course, are an optional source of heat for sterilization systems (to be covered in the next subsection) and septic tanks. In all likelihood the latter Army requirements are quite similar to those that would be encountered in most Alaskan Native Villages where this technique may be a viable alternative for sewage disposal. For Army installations, however, the layout of facilities would be expected to be more near the optimum than are found in most native villages. This would reduce the need for surge/collection tank heaters to ensure that sewers are not clogged with ice so that the sewage would not flow to the septic tank. The factors involved in initiating a demonstration of isotopic heaters for the Corps of Engineers will be treated in the listing of specific tasks that must be undertaken for all heater opportunities identified in Cold Regions.

Some specific activities that should be undertaken in FY-1976 to bring about the demonstration of isotopic heaters in Alaska follow:

- The demonstration opportunities should be prioritized so that the limited resources available in FY-1976 can be best applied to those situations that will provide the information to best satisfy overall program objectives. Some preliminary prioritization has already taken place such as the earlier suggestion that demonstration with potable water systems should follow successful demonstration with sewage systems. As will later be discussed the use in septic tanks should precede demonstrations of the more advanced and sophisticated thermoradiation sterilization process. Even with this preliminary narrowing of the options there remains a significant amount of effort in deciding upon optimum conditions, access, etc., that are important considerations in achieving overall objectives.

- Following or as part of the preceding task must come the selection of joint venture partner(s) in the demonstration of an isotopic heater system in Alaska. Important considerations in making this decision are: 1) the ability of the potential partner to contribute resources in one form or another to the demonstration, 2) as appropriate, have 
a favorable standing with the native and state organizations that will be involved in approving the proposed undertaking, 3) flexibility in responding to the budgetary and approval processes inherent in the demonstration of isotope systems, and 4) the interest and ability in and to conduct a sophisticated demonstration to provide realistic information on the economics involved in the use of these systems in Cold Regions.

- Once a joint venture partner(s) has (have) been selected an interagency agreement should be developed and signed so that means would exist to handle the various procedural matters involved in such an undertaking.

- Licensing and environmental impact requirements must be defined and the appropriate action initiated to handle these matters.

- It is expected that PNL would be responsible for the evaluation of the isotopic heater system performance in Alaska for ERDA. Once the interagency agreement is signed, PNL and the personnel from the Alaskan based agency or group must clearly define plans for the demonstration, procedures for a cooperative program and the various items to be studied, examined and evaluated.

- Specific site selection should be a joint undertaking between PNL and the joint venture partner(s). The matter of selecting a remote site or one having all of the physical characteristics of a remote site must be reconciled and a decision made on what would be most desirable for the program.

- Specific heat requirements for the demonstration must be defined so that preliminary design work may be undertaken. It is expected that the heater device would be integrated into a conventional heat transfer circuit and sewage treatment system insofar as possible. Close coordination with the joint venture partner is mandatory in the pre1 iminary design stages as well as subsequent periods devoted to detailed design, procurement, fabrication, installation, shakedown operation and demonstration. 
Although the technical feasibility of using isotopes for heat was demonstrated sometime ago, economic data is now needed for operation in Cold Regions. Further, demonstration is needed to increase the awareness of other agencies and organizations in the usefulness, reliability and safety of these devices.

Radiation Sterilization

Several potential opportunities were uncovered in Alaska to demonstrate radiation sterilization processes. The same groups and organizations interested in the use of isotopic heater systems were also interested in radiation treatment of sewage and in one case the purification of laundry and shower effluent.

It should be understood that the radiation sterilization technique discussed with possible joint venture partners in Alaska was the Sandia Laboratories process called thermoradiation. This process is reported to be significantly more effective than the additive effects of using heat and ionizing radiation. The synergistic effect is tentatively attributed to the increased susceptibility of DNA to radiation and free radical effects as heat promotes uncoiling of the helixes typical of these complex compounds. The deactivation of a number of species found in sewage sludge (such as aerobic and anaerobic spores, vegetative cells, viruses, bacteria, parasites and enzymes) has been reported. (11) At the present time this work is being jointly sponsored by ERDA and EPA. Soon a large-scale demonstration of technical feasibility is to be undertaken at Albuquerque, New Mexico. The sludge from half of the sewage plant can be deactivated continuously by this process. Cobalt-60 is to be used at Albuquerque to produce the ionizing radiation necessary for this process. For possible use on the Cold Regions Program, WESF or modified WESF CsCl capsules would be the candidate radiation source. More detailed information on these capsules can be found in Figure 10.

A preliminary analysis of the opportunities to demonstrate this sewage treatment process in Alaska gave results indicating that it could be used for either the centralized or individual dwelling systems. Cold Regions 
heaters would be required to have sufficient heat for operation and, conceptually, these would be WESF capsules containing $\mathrm{SrF}_{2}$. A flow diagram, showing the basic elements of a thermoradiation sewage treatment process as might be employed in an Alaskan Native Village, is given in Figure 14. It should be recognized that the process described in Figure 14 calls for the treatment of all of the effluent from the sewage system, not just the sludge. Because of the small volumes that are generated in most native villages this is believed to be a feasible approach technically and perhaps economically.

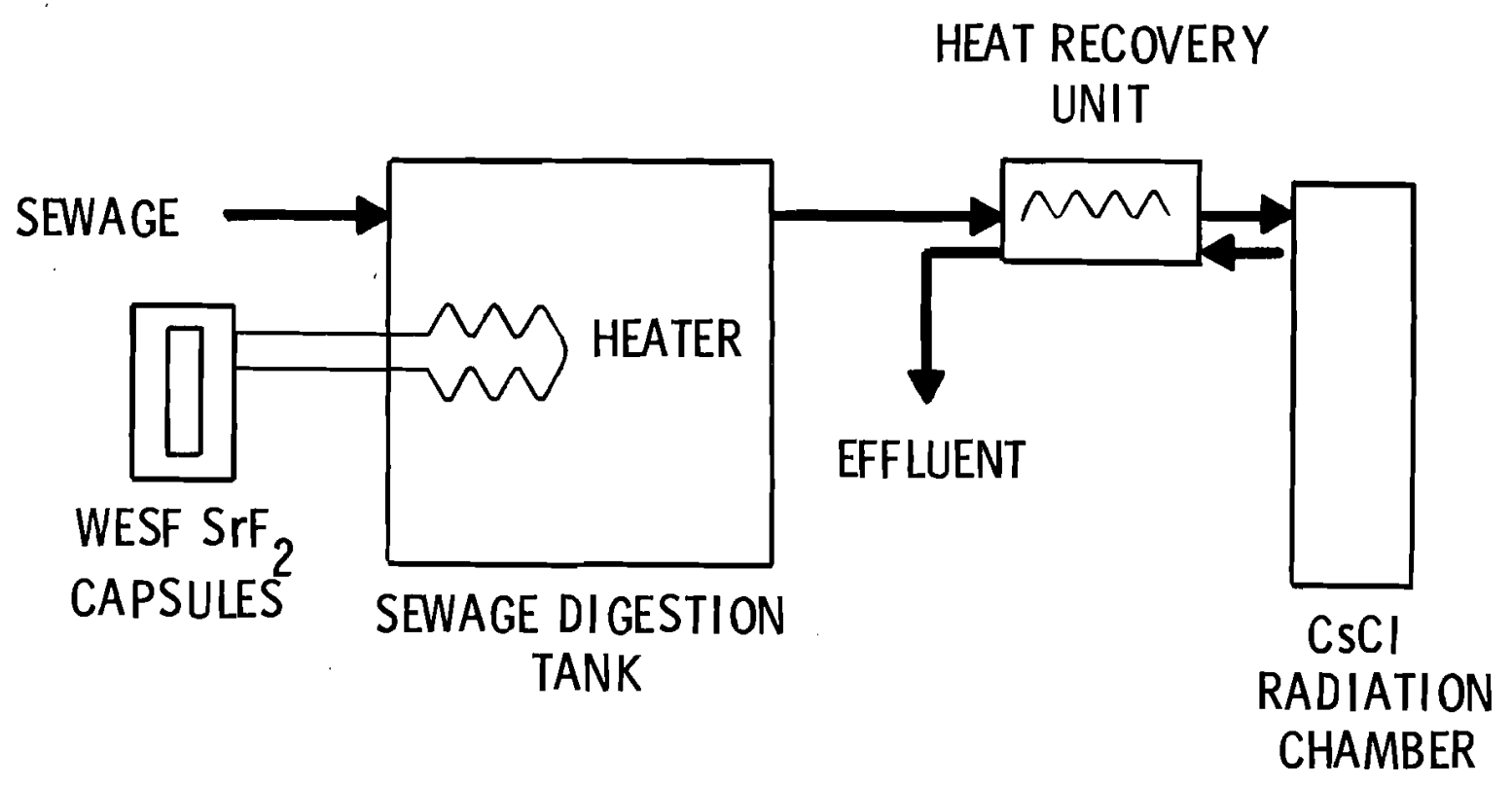

FIGURE 14. Conceptual Flow Diagram for an Alaskan Native Village Thermal Radiation Treatment Process

The current position of the thermoradiation treatment process and action needed in the near future is described below.

- Technical demonstration of the process at Albuquerque, New Mexico, is expected to start in FY-1976. Information on the effectiveness, 
reliability and safety of this process is needed before a formal proposal to demonstrate a similar process in Alaska is made to any of the native corporations.

- Specific opportunities to demonstrate the thermoradiation sewage treatment process in Alaskan Native Villages should be discussed and tentative $\mathrm{plans}$ made to follow up in 2 to 3 years with a formal program contingent upon positive results from the Albuquerque program.

- Joint venture partner selection will be needed in about 2 years assuming favorable results on the currently planned demonstration.

- A well planned program to supply information on the program and results of the Albuquerque demonstration to all potential joint venture partners, interested Federal and State agencies as well as the Corps of Engineers should be developed and initiated in the immediate future. An effective program of providing such information will have a favorable impact on any demonstration of this concept that may be warranted in the future.

Other Considerations

The constraints mentioned in a similar section on RTGs for the need to have a clearly identified organization resident in Alaska as a joint venture partner is true for isotopic heater and radiation sterilization demonstrations also. The PHS and EPA groups in Alaska are well-established and work through one or both should help avoid the "Lower 48" syndrome. Furthermore, these organizations have a substantial expertise that can be brought beneficially to bear on the demonstration of these isotopic devices. In all likelihood, cooperation with either or both would help avoid a significant number of problems in Cold Regions logistics, operation and maintenance that, unrecognized, would result in serious program delays and perhaps even failure to achieve overall objectives. A joint effort with an Alaskan State Agency working in this field would also result in the same benefits. The corps of Engineers has worked in Alaska for decades and doubtlessly would be better recognized in that state than would "outsider" groups or organizations. 
Another important factor in achieving program objectives is the development and maintenance of an effective working relationship with cognizant native organizations. As discussed in Appendix $D$ these groups have an alert and aggressive leadership with substantial political power. Working with joint venture partners such as PHS, EPA and/or the State of Alaska on any programs involving native villages would also take advantage of established relationships obviating the need to set up new ones where neither party would have any earlier understanding of the other's way of doing business or his objectives.

Suggestions for near-term demonstrations were focused on those systems or uses that have been firmly established by earlier technical feasibility studies. This approach should avoid creating a feeling with Alaskan natives that the purpose of the proposed work is to make them the subject of experiments. In keeping with this approach is the suggested delay in seeking a demonstration of the thermoradiation sterilization process. It is believed that after demonstration at Albuquerque, New Mexico, to establish technical feasibility and to focus attention in the Cold Regions on economic considerations, usefulness and reliability, this technique will overcome or avoid what could be a significant negative response to the demonstration concept for isotopic heaters and sterilization units.

A1 though not of paramount importance in the next year or so, the longterm availability of $\mathrm{SrF}_{2}$ and $\mathrm{CsCl}$ capsules could become a very important consideration. PHS personnel have already raised the question about availability assuming economic demonstration of concepts using these capsules. The author does not see any means for providing such an assurance at the present time for time horizons of 5 or 10 years. A logical argument can be advanced that such capsules will be made available as one means of beneficially using what obviously will be a vastly increasing inventory of fission product wastes. That argument is rather tenuous, however, for the philosophy and/or emphasis placed upon the disposal of these fission products continues to be in a state of flux. The availability or the lack of $\mathrm{SrF}_{2}$ and/or $\mathrm{CsCl}_{2}$ capsules in the intermediate or long-term future can 
be minimized by the development of designs for the demonstration system heater units and ancillary equipment that could be readily modified to accept conventional heat exchange and sewage treatment equipment. In the eventuality that capsules would no longer be available after demonstration was successfully completed, the appropriate changes could then be made to the system to continue service to the village.

\section{LATENT OPPORTUNITIES}

The phraseology of latent opportunities is used in this report to describe those situations where the technical feasibility of isotope devices has already been established, but a specific effort or new approach will be required to provide for such usage in the near future. This barrier to application or demonstration is found for a number of reasons, such as other agency/organization programs which have such high priority that little if any time is available for the examination and exploration of a new but proven technology. Another reason for this situation is a traditional approach to services where only those techniques or procedures are used that have been thoroughly established or been under long use. In still other situations the barrier is a financial one where there is not sufficient money to carry through the program at the level necessary to warrant a change to another approach. On some occasions these barriers may be the result of a breakdown in communications within large organizations, and the results of earlier work in other geographic areas are not transmitted to those responsible for operations in Alaska.

Several latent opportunities for the use of RTGs were discovered in the course of conducting Cold Regions work in FY-1975. No attempt will be made in this report to identify the reasons for latency; this identification should be a complementary activity to future efforts to promote broader usage of these isotopic devices.

- There are an appreciable number of remote weather stations in Alaska that are used to supply meteorological data. At the present time these are powered by conventional power sources. Over a decade ago 
a remote weather station was successfully operated with an RTG on Axel Heiberg Island in the High Arctic of Canada. Also, the U.S. Navy has successfully operated a similar system on Fairway Rock in the Bering Strait since 1966. Other examples from the Antarctic and elsewhere as to the reliability and usefulness of RTG powered weather stations could also be cited. With certain prominent Alaskan officials and the literature calling for additional data, especially for Northwest Alaska, the possibilities for using isotopic systems should be carefully examined and appropriate efforts made to promote consideration and hopefully use of these devices.

- There are over 500 lighted buoys in Alaskan waters as well as other aids to navigation that are operated and maintained by the U.S. Coast Guard. In the early 1960s successful demonstration programs were conducted by the AEC with this organization showing the technical feasibility of using RTGs to power such systems. Future attention should be directed by the Cold Regions Program to identify specific conditions where current procedures for supplying navigational aids would be better accomplished by power units capable of unattended operation for 5 or more years. The most likely conditions are those where replacement and servicing of the battery operated units is difficult because of geography, terrain and/or climatic conditions. Furthermore, there are probably situations where a strong argument can be developed that human safety would be better served if RTGs were used. The uncertain condition of servicing these navigational aids could be reduced from a yearly to quinti-annual occurrence.

- As indicated in the Appendix D, continued development of Alaska for the exploration of its natural resources should be expected. Currently, we have the North Slope oil development, but before 1ong, it is anticipated that similar interest will develop in mining the large Alaskan coal deposits. This oil development has led to the need for extensive port development of Valdez and its approaches. Also, increased needs for better remote communication systems have been 
identified and are generally supplied by conventionally powered devices. Similar impacts on shipping, navigational and communications will accompany the mining of coal for export to the "Lower 48" and elsewhere. Before these services are needed attention should be directed toward a careful examination of RTGs for remote power sources; the economics and the need for extreme reliability may favor these isotope devices. The scope of investigation should be expanded to include an examination of the "port of refuge" concept to see if RTGs have a role to play in that area.

- Some time ago the U.S. Navy demonstrated the technical feasibility of powering underwater sound systems or sonar devices with RTGs. Conceptually, such underwater devices could be used as a backup navigational system. Placing these powered RTG devices at key positions (such as the seaward approaches to the Hinchenbrook Entrance to Prince William Sound where there are the two well-known hazards, the Seal Rocks and Wessel Reef) ${ }^{(a)}$ could serve as another means for avoiding a marine oil spill or some similar problem.

The scope of this particular section was limited to latent opportunities. That limitation precluded analys is and discussion of fission product storage devices to promote movement of botton waters in fiords. That is a concept that would require substantial amounts of R\&D to establish technical feasibility and, therefore, it will be treated in another part of the report.

(a) More detailed information in Hinchenbrook Entrance and its approaches can be acquired from National Geodetic Survey Nautical Charts 16709 and 16700 entitled respectively "Prince William Sound--Eastern Entrance" and "Prince William Sound". 
COMMUNICATIONS AND TECHNOLOGY TRANSFER 


\section{COMMUNICATIONS AND TECHNOLOGY TRANSFER}

The plan for the Cold Regions Isotope Applications Program originally called for, among other things, an examination of the factors affecting the transfer of isotope technology to potential users. However, the scope of this phase of the program was expanded to include communications when it became apparent that the four market segments as well as the general public had various degrees of understanding about the possibilities for beneficially using isotopes. Some difficulties in promoting wider usage of RTGs and isotope heaters were expected because of uncertainties about economics. However, we were unable to anticipate the degree of general unawareness about the possible use of isotope devices and systems. For example, the public accepts the use of ${ }^{60} C_{0}$ therapy units as an important and integral part of a modern medical capability. But, much of the public is unaware or does not understand that ${ }^{60} \mathrm{Co}_{0}$ is a radioisotope and a member of a large family of radioisotopes that might be beneficially used. Such is the case with the potential uses of other isotopes.

Another reason for adding communications to the program is based on input from various people in Alaska who feel they are poorly informed about Federal programs conducted in Alaska. Further, they feel that they are not given an opportunity to learn more about these programs. Although some aspects of this problem have been treated earlier in this report, they will be discussed again in this section to emphasize and provide a better perspective on the communication needs and implications in the forty-ninth state.

More information on communication and technology transfer needs and current status will be presented in the following two sections. The first section, "The Current Situation", provides more details on the lack of public awareness about the isotope possibilities and the special communication considerations involved in Alaska. The second subsection, "Alternatives", suggests how to beneficially change present conditions in Alaska. 


\section{CURRENT SITUATION}

Several techniques will be used to establish the current situation on communications and technology transfer as it pertains to the Cold Regions Program. Certain discussions have been paraphrased to convey the general content and, in some cases, direct quotes have been used. Sometimes the source of information is identified while others are not when close identification with the reported material might create an awkward situation for one or more individuals who provided the information. Statistical data are also used to establish that certain informational materials have been used and short statements, tables of data and descriptive material are used to present information, establish implications, provide assumptions, etc.

Communications

Many individuals in commercial organizations and State agencies initially equated isotopes with nuclear reactors, weapons and/or contamination; occasionally some civilian support personnel to the military services held similar views. Additional details on this situation as well as its implications and the special communications conditions found in Alaska follow:

- A responsible technical leader's misunderstanding (previously discussed) about the proposed contamination problems involved in the use of RTGs is indicative of the failure to get useful information on isotopes into certain parts of Federa 1 agencies.

- Some time ago various Federal agencies were involved in cooperative programs with the AEC to demonstrate the effectiveness, reliability and safety of RTGs for a variety of applications. However, without exception, responsible operating personnel on the regional level of these agencies, who were contacted in the course of FY-1975 work, were unaware of these earlier demonstration programs.

- Lt. Thomas J. Holleman, USN, now on assignment with SNS, ERDA, Germantown, Maryland, advised the author that his nuclear engineering course work at Annapolis and experience on active duty (until his current assignment) had a11 provided information or material on nuclear 
reactor systems and none on the possible applications of isotopes. Similar course emphasis is believed to be found at West Point and the Air Force Academy.

- Many Alaskans were reported to have responded negatively to the underground testing of a nuclear device on Amchitka Island in the Aleutians. A significant factor for this response was believed to be the failure to advise the Alaskan citizens of the need for such an endeavor as well as the safety analyses that had been involved in the siting of the experiment and related data before major commitments and site preparatory work were underway. One commercial leader believes that most of the local antagonism could have been avoided by early and freer information. (13)

- A responsible official suggested that the careful and we11-planned demonstration of peaceful applications was a way of overcoming what he perceived to be psychological barriers that many Alaskans have with nuclear systems. (14)

- The contacts made with two people employed at two Alaskan banks revealed that these institutions were unaware that radioisotopes could be used for power or heat. $(15,16)$ Although this information was only obtained from two people, it is significant because these two were involved in and/or responsible for business development in their institutions. If the possibilities for isotope applications are not known or recognized by such people it would be difficult for commercial groups to arrange financing for any undertaking involving such devices.

- Alaskans want to know what is going on in their state and are reportedly sensitive to the development of projects in their State by people and/ or institutions in the "Lower 48" that do not permit visiting, briefings, and open discussion of the needs, implications and potential benefits of such activities. (13)

- Most of the officials in Alaskan State Agencies who were contacted in FY-1975 were unaware that isotopes could be used for heat and power generations. $(17-19)$ 


\section{Technology Transfer}

The record of RTG technology transfer is both positive and negative. In the past several years the U.S. Navy has acquired over 50 RTGs that have been used for a variety of purposes, many of which have been discussed elsewhere in this report. (20) However, Starr and various other sources report that a significant number of these devices are in storage because the Navy has not systematically applied them to applications for which they have been shown to be well suited. (20-22) The Corps or Engineers has a few RTGs that they use to power remote flood warning systems ${ }^{(23)}$ and a few Sentinel systems have also been sold to various branches of the government. ${ }^{(5)}$ The Air Force is also believed to use a few RTG for various military purposes, and the possibilities of using isotope heaters for down hole well heating is also under investigation. (24)

In all likelihood the total number of RTGs in workable condition for terrestrial and/or marine purposes in the U.S. is around 100; this number does not represent a significant penetration into what appears to be a sizable market. Doubtlessly, wel1-defined economics are a major consideration in this situation, but lack of awareness about their potential usefulness in the four segments of the market used in this study are also believed to be major factors. The same situation prevails with isotope heaters. Statements earlier in this section relating to viewpoints and knowledge of isotope applications support the latter position.

Background information was presented in an appendix that indicated that the present and proper functioning of an information system was a necessary ingredient in effective transfer of technology. In another background appendix, information was presented that showed that ERDA had published extensive scientific and technical results of isotope power and heater systems. This literature is only a fraction of the available information on the scientific and technical aspects of isotope research sponsored in the U.S. by ERDA and other agencies abroad. It can be stated safely that there is an existing system that transmits this type 
of information even if it is a passive system that requires a general understanding of the purposes and procedures involved in gleaning useful scientific and technical information.

ERDA $^{(a)}$ has sizable programs devoted to the dissemination of information to the public. These programs, commonly referred to as public relations efforts, use a number of different techniques to reach the public, commercial organizations and other Federal agencies. Characteristically, these programs are designed to disseminate information in a form that does not require any positive procedures for forcing the flow of material into various sectors of the economy. For example, ERDA produces excellent movies describing particular facets of nuclear technology for the general public and other agencies. However, the data shown in Table 2 indicate that movies are not a well-used medium. It should be understood though that both movies in Table 2 were relatively old and may have covered areas of less interest than others in the ERDA film 1 ibrary. Further, ERDA's Office of Public Affairs does not push the use of films such as "Pax Atomis" and "Atomic Weatherman". Instead, they provide listings of available films to 1 ibraries, educational institutions, etc., and respond to requests for use of particular movies. Even with these possible limitations, the data in Table 2 may be indicative of the need to carefully examine this mode of transmitting information. As can be seen from Table 2, grade school and high school viewers were predominant with the percentage of total viewers in this category ranging from 66.6 to $93 \%$. Perhaps the types of viewers who did not see these movies in FY-1973 or 1974 were more important though, such as commercial organizations or contractor groups. These groups are the ones who would be expected to take the lead in exploiting the beneficial properties of isotopes. Other nonviewers include civic or service club members and only 1 group of 30 professional society members saw these two movies. Only 177 members of Federal, State and municipal agencies saw one or both of these movies in the 2 years covered by Table 2 , while one showing of "Pax Atomis" on television was estimated to have been watched by about 500 viewers.

(a) Many programs were conducted by the former Atomic Energy Commission, ERDA's predecessor. 
TABLE 2. Usage of Two ERDA Movies on Beneficial Use of Isotopes

\begin{tabular}{|c|c|c|c|c|}
\hline \multirow[b]{2}{*}{ Audience Type } & & \multicolumn{2}{|c|}{$\begin{array}{c}\text { Viewers of } \\
\text { Atomic Weatherman }\end{array}$} \\
\hline & $\overline{F Y-1973}$ & $\overline{F Y-1974}$ & $\overline{F Y-1973}$ & FY-1974 \\
\hline $\begin{array}{l}\text { Colleges/Junior Colleges/ } \\
\text { Universities }\end{array}$ & 254 & 225 & 389 & 30 \\
\hline $\begin{array}{l}\text { High Schools/Elementary } \\
\text { Schools }\end{array}$ & 812 & 1917 & 6012 & 164 \\
\hline Federal Agencies & 44 & 0 & 30 & 0 \\
\hline $\begin{array}{l}\text { State and Municipal } \\
\text { Agencies }\end{array}$ & 68 & 0 & 35 & 0 \\
\hline Contractor Groups & 0 & 0 & 0 & 0 \\
\hline Professional Societies & 30 & 0 & 0 & 0 \\
\hline Civic and Service Clubs & 0 & 0 & 0 & 0 \\
\hline Television & 0 & 500 & 0 & 0 \\
\hline Commercial Organizations & 0 & 0 & 0 & 0 \\
\hline Other Groups & 11 & $\underline{0}$ & $\underline{0}$ & 0 \\
\hline TOTAL & 1219 & 2642 & 6466 & 194 \\
\hline
\end{tabular}

(a) See Appendix D, p. D-8.

ERDA also prints a number of excellent educational booklets (such as "Power from Radioisotopes", Corliss and Mead, and "Direct Conversion of Energy", Corliss) that are very useful in explaining to many people the principles involved in power generation by radioisotopes. Although not done in FY-1975, it would be useful to determine the demand for these booklets and the type of groups or individuals to whom they were sent. Such information might also be useful in helping to identify how well isotope information is being communicated to the public.

\section{ALTERNATIVES}

The alternative approaches to communications and technology transfer discussed in this subsection have been suggested to help achieve overall program objectives. Since these suggestions are the result of a limited effort in this particular field of inquiry, they are not exhaustive, nor should they rule out subsequent modifications or additions that may 
provide newer or more innovative methods. A listing of ideas for promoting better Cold Regions communication and technology transfer follows:

- A missing link in more effective transfer of isotope technology to Cold Regions usage appears to be the lack of an entrepreneur. A1though one particular member on the SNS staff has been very effective in creating a broader awareness of isotopes and in promoting interest in their application, he has a number of other duties and activities as wel1. These other functions and his particular position in a Federal agency probably reduce his overall efficiency. What is needed is one or more contractor representatives who would have full-time assignments in facilitating communications and technology transfer for Cold Regions isotope applications. For emphasis it should be stated that this person (these persons) should have no other research duties and that he (they) should be funded adequately to cover time, necessary travel and attendant publication and communication activities. The individual $(s)$ should be market-oriented and enterpreneurs, but with strong scientific or technical backgrounds.

- To increase the military services' awareness about the beneficial uses of isotopes, the curricula at the various academies should be modified. The nuclear engineering courses should devote some time to explaining radioisotope thermoelectric generators, isotopic heaters and their potential military applications. Similarly, a more intensive, but short duration course, for officers on active duty is suggested to overcome what appears to be at present a lack of knowledge by many officers of potential military uses for isotope systems. Such an intensive course could be conducted as a separate educational activity by each service, possibly as a joint service function, or as an addition to courses now conducted on nuclear engineering or allied technology. A strong argument can also be developed to establish an ongoing demonstration at some military base of an RTG and an isotopic heater system that could be used to support course work on military application of isotope systems. Such a concept might be attractive at 
the present time to the U.S. Navy since they are reported to have a large inventory of RTGs that are not being used. The school may be a means for promoting greater immediate as well as intermediate and long-term use of such devices. Also, with a change in emphasis and course content such an ongoing demonstration system could be the basis for enlisted as well as officer training programs.

- Another procedure for increasing awareness of the beneficial uses of isotopes and increasing the opportunities is to foster a different philosophy in cognizant contractor groups and by key ERDA personnel. It is proposed that these people be encouraged to promote the use of appropriate ERDA Office of Public Affairs Materials with various commercial, civic, professional, educational, governmental agencies and the media to improve the public understanding of isotopic systems. For such an arrangement to be directly effective new material must be developed to focus more directly on potential applications and previous experience in Cold Regions. The active use of these public relations and educational materials should overcome some of the problems believed to be existent today where people are not aware of beneficial isotope applications. The author, for example, used about 50 copies each of the two brochures mentioned earlier to give contacts in the four market segments a better understanding of the principle of RTG use and a history of their previous demonstrations and application. These brochures, although not specifically designed to address Cold Region problenis, were found to be particularly useful in providing general background information.

- If a demonstration(s) of isotope systems is/are undertaken in Alaska a carefully constructed public relations program should be designed and implemented to avoid a negative reaction from the residents of that state. As was stated earlier in this report, such a program should be initiated before demonstration is started. Part of this effort should involve onsite visits by key Alaskan business and public leaders to create a broad base of awareness and to help avoid unpleasant 
surprises. Aamot ${ }^{(25)}$ and Behlke ${ }^{(26)}$ have both mentioned vandalism problems at certain installations and experimental sites in Alaska. The public relations effort and the demonstration programs must be developed in such a manner as to reduce or avoid problems of this nature.

- Substantial progress has been made in FY-1975 in identifying potential demonstration and application opportunities in Cold Regions. In the future a much better understanding of general Arctic conditions and problems will be required to maintain momentum and to identify additional opportunities. One means for acquiring part of this background is to initiate close association with various professional and commercial groups that are active in the north. We should be simultaneously conducting a vigorous and well planned campaign to foster a greater awareness in those groups of the beneficial use of radioisotopes. A particularly important group is the Arctic Institute of North America. Key contractor and ERDA personnel should be encouraged to become active in this professional society. We should be able in a period of time to make a substantial and useful contribution to that organization. 
NEEDED NEW TECHNOLOGY 


\section{NEEDED NEW TECHNOLOGY}

One of the FY-1975 milestones for the Cold Regions Isotope Applications Program called for the identification of needed new technology development. When the program was initiated it was anticipated that certain problems would be discovered that would require newer or better isotope systems to supply required services. However, this scope was slightly expanded to include an examination of needed improvements in ancillary systems when these systems were found to have detrimental effects on the acceptance or reliability of isotopic devices in Cold Regions. New technology development needs, identified in FY-1975, will be covered in four subsections concerned with capital costs, mean-time-to-failure in support systems, thermal aging problems and logistics.

\section{CAPITAL COSTS}

The development of designs to reduce the capital cost of RTGs is a priority need in any new technology development effort. Invariably, commercial groups complain about these costs and, with their methods of financing equipment, capital costs for RTGs pose a real constraint on their wider use for Cold Region power units. Some reduction should result according to Divine (see Appendix E) from "learning curve" effects that would come from production scale rather than custom manufacture of these devices. 0thers that merit particular attention in a capital cost reduction campaign are listed below; these three areas are not intended to be inclusive, but rather to serve as examples of some of the things that might be considered in reducing RTG capital costs.

- 'Some attention has already been devoted to refueling as a means for reducing capital costs. This approach is based on the concept of reusing the remaining equipment and systems that are integral parts of an RTG. In all likelihood a refueling capability would require the development of semiconductors with longer effective life. 
- Conceptually, a shift from static- to dynamic-cycle RTGs could reduce kW-hr capital costs. With current static efficiencies remaining about $5 \%$ an increase to 15 to $20 \%$ is attractive. One of the unknown quantities at this time is the magnitude of the cost increase of moving hardware used in these heat engines. It is conceivable that such increases might exceed the benefits that would accrue from increased thermal efficiency.

- The author has been advised by one of the manufacturers of RTGS that an appreciable cost for most units now being considered for terrestrial use is the material and design needed to make them useful at depths down to $20,000 \mathrm{ft}$ in the sea. If this is indeed true, then designs for use at atmospheric pressure should be somewhat less costly than those associated with marine service.

\section{MEAN TIME-TO-FAILURE}

The useful life of an RTG is dependent upon the proper functioning of the non-nuclear as well as the nuclear parts of the system. From experience we have learned that the most probable failures are in the non-nuclear components which, in many cases, limit the duration of the missions. It is not sufficient for the isotope source to be able to supply enough heat to provide rated power for 5 years if other parts of the system have an expected service life that is significantly less.

In the early 1960's a remote weather station, powered by an RTG, was placed in the High Arctic on Axel Heiberg Island. Thirteen months later the wind speed indicator failed necessitating a visit to the site for repairs. Several months after this problem, there was a failure in an ancillary electrical system. Even though both of those failures were in non-nuclear components, they doubtlessly influenced many people about the reliability of RTG systems. Another example is the recent experience of the Naval Arctic Research Laboratory at Barrow, Alaska. This laboratory acquired an RTG-powered remote weather station to be used for some of their 
studies on the north slope. However, the unit was not deployed in the field because the electronic and mechanics supporting systems would not function properly. (27)

The problems described above are similar to those encountered by other Federal and private groups that need extended service from devices installed in remote or unfrequented 1ocations. The Army Security Agency is focusing considerable attention on increasing the useful life of various communication devices employed on their missions. They hope to increase the meantime-to-failure in some of their electrical/electronic packages from 500 to $10,000 \mathrm{hr}$ with an intermediate future objective of 20,000 hr. A similar program is needed for terrestrial RTG supporting components to ensure that these have a life expectancy similar to the useful power rating of the unit. In summary, it accomplishes no useful purpose in promoting RTG application if our devices become inoperable in a year or so from ancillary equipment failures when we forecast a useful isotope unit life of 5 years or more. The reliability of the RTG will be questioned if any of the supporting components fail.

\section{LOGISTICS}

The handling and movement (logistics) of radioactive isotopes to and from the Cold Regions are important considerations in their successful applications. Not only are the cormon problems of long distances, high transportation costs and inclement weather controlling variables in the Cold Regions, but those having to do with the transport of radioactive materials impose still other constraints that must be handled expeditiously if the potential benefits of isotopes are to be fully exploited.

The logistic considerations that require followup on the Cold Regions Program are those concerned with: 1) casks, 2) transportation, and 3) loading and unloading. More detailed information on each of these needs is contained in three following subsections concerned with these topics. 
Casks

At the present time, even though it is a matter of taking the limited action necessary to capitalize on demonstration opportunities, it is obvious that the availability of acceptable shipping casks is an important consideration. There are many casks available to contractors for a variety of local transfers or short-duration storage. These casks were not designed to meet safety regulations for the transport of isotope capsules by commercial carriers. They also serve as vehicles for the loading and unloading of isotopic systems such as RTG capsules and heaters in the field. If the RTGs and/or the ${ }^{90} \mathrm{Sr}$ heaters are found to be viable systems in Cold Regions, casks will be needed in 2 to 5 years to readily move these materials to and from the field. This need implies that there should be more than one size cask available to transport radioisotopes such as WESF capsules, for example, which are the candidate sources for the heater studies proposed earlier in this report. Although a cask, designed and constructed for 10 WESF capsules, could be used to transport one capsule to a small, remote Alaskan Native Village, the transportation costs would be unnecessarily high and the unloading/loading operations needlessly complicated at the site in handling a very large cask. Also, if a demand for WESF capsules is established, the logical site for the control and storage of these transfer casks would be the WESF Operation at Hanford, WA.

\section{Transportation}

Concurrent with the need to thoroughly examine cask needs is the implementary task of transporting such casks. This matter is extremely important for such transfer operations because: 1) the contents are radioactive, and 2) suitable carriers must be available to effectively carry the cask to the site where the isotopic devices are to be used. The first of these considerations is amply covered by existing regulations and is mentioned here only for emphasis. However, follow-up on the recommendation made in this section will require a detailed analys is of those regulations.

The heavy dependence upon air transport for the delivery of most (or in some cases all materials) to many Alaskan Native Villages imposed some 
severe constraints on delivery to the point of use. Cormercial carriers, such as sea and rail, and air cargo service can be used to deliver materials to Fairbanks or Barrow. The transfer from these towns to the villages will be the controlling link in the transportation network. Helicopters can carry loads of the size that will probably be involved with isotope systems, but their range is limited with any appreciable load. Hercules Aircraft can readily carry these devices also, but there are sites that do not have runways capable of handling that size of plane. There are smaller planes (the single and two engined aircraft) that routinely go to these villages although they have load limits. These 1 imits may be the controlling variable on the design of certain casks.

Loading and Unloading

The limiting cases insofar as loading and unloading are concerned are the remote sites where RTGs may be installed or the small isolated native village. In the remote sites there may be little if any area in which a helicopter can land. In this case the device will have to be lowered to the ground. If an isotopic capsule is to be loaded and unloaded the equipment to effect that operation must be lightweight, mobile and simple. For the isolated village a heavier hoisting device might be used but it too should be simple and straightforward to use.

The items discussed in the previous subsections are not a comprehensive analysis of the logistic factors involved in the movement of isotopic devices to and from Cold Regions. They were provided to give a general overview of the problems involved in effectively utilizing isotopes in Cold Regions. What is needed now is a systems study of all the logistic factors involved in their movement to and from the site where they are to be used. If viable opportunities for use are demonstrated by the program identified earlier follow-up and implementation should provide for design and fabrication of casks, identification of the specific constraints involved in transport and the fabrication of the appropriate loading and unloading equipment. 
THERMAL AGING

Containment of ${ }^{90} \mathrm{Sr}$ for terrestrial heat source applications has generally involved the use of nickel-base or cobalt-base alloys. Unfortunately, many nickel- and cobalt-base alloys undergo long-term thermal aging reactions which affect their mechanical properties. Work at $\operatorname{ORNL}(28,29)$ and elsewhere $(30,31)$ has shown that thermal aging of some alloys at 600 to $900^{\circ} \mathrm{C}$ for extended periods can result in a serious loss of impact strength, toughness and ductility. These reactions do not present any apparent problems if the alloy containing ${ }^{90} \mathrm{Sr}$ is used for sewage or potable water heaters, but could have significant implications when the radioisotope is used with static or dynamic power generators. Additional studies are needed to demonstrate that nickel-and cobalt-base alloys, which are compatible with the ${ }^{90} \mathrm{Sr}$ fuel, will provide the mechanical properties needed to meet source safety requirements after extended use at elevated temperatures. 


\section{REFERENCES}

1. Private Communication with Dr. Warren Denner, Director, Naval Arctic Research Laboratory, Barrow, Alaska, September 1974.

2. Private Communication with George C. Schwarderer, Barnhoff and Associates, at Atkasoak, Alaska, June 12, 1975.

3. Private Communication with Barry H. Reid, Research Engineer, Arctic Environmental Research Laboratory, Environmental Protection Agency, College, Alaska, June 10, 1974.

4. Letter from Alaska Internationa1, February 1975.

5. Private Communication with John H. Morrison, Marketing Manager, Teledyne Isotopes, Timonium, MD, August 1974.

6. Private Communication between C. L. Johnson, Richland Operations Office, ERDA, and W. E. Sande, PNL, March 1976.

7. Private Communication with G. W. Boedecker, Alaskan Region Office, Federal Aviation Administration, September 1974.

8. Private Communication with G. W. Boedecker, Alaskan Region Office, Federal Aviation Administration, June 1975.

9. Private Communication with William L. Ryan, Chief, Sanitation Facilities Construction Branch, U.S. Public Health Service, Anchorage, Alaska, June 9, 1975.

10. D. J. Wright, Integrated Utilities for Remote Alaskan Villages, Proceedings: Waste Water Treatments on Cold Climates, Symposium by Environmental Canada and the University of Saskatchewan, Saskatoon, Saskatchewan, August 22-24, 1973.

11. H. D. Sivinski, "Treatment of Sewage Sludge with Combinations of Heat and Ionizing Radiation (Thermoradiation)," paper presented at IAEA Symposium on the Use of High Fuel Radiation in Waste Treatment - Status and Prospects, IAEA-SM-194/303, Munich, Germany, March 17-21, 1975.

12. Private Communication with Lt. Thomas J. Holleman, USN, who is on duty with SNS, ERDA, Germantown, MD, May 1975.

13. Private Communication with Don Dickey, General Manager, Alaska State Chamber of Commerce, Juneau, Alaska, September 1974.

14. Personal Communication with Dr. Y. R. Nayudu, Science Advisor to the Governor, Juneau, Alaska, September 1974.

15. D. A. Atlee, Director, Marketing and Business Development, Alaska National Bank of the North, Fairbanks, Alaska, September 8, 1974.

16. Personal Communication with H. E. Slezinger, Alaska State Bank, Anchorage, Alaska, September 6, 1974.

17. Personal Communication with Jerry Sargent, Department of Environmental Conservation, Juneau, Alaska, June 19, 1975.

18. Personal Communication with Katherine L. Allred, Division of Planning and Research, Office of the Governor, Juneau, Alaska, June 19, 1975. 
19. Personal Communication with Kevin Waring, Department of Community and Regional Affairs, Juneau, Alaska, June 19, 1975.

20. Personal Communication with Maurice D. Starr, Head Nuclear Programs, Nuclear Power Division, Naval Facilities Engineering Command, Department of the Navy, Alexandria, VA, August 13, 1974.

21. "Operating Report for Radioisotope Power Generators of the U.S. Navy," U.S. Naval Nuclear Power Unit, Fort Belvoir, VA, vol. 7, no. 2, Apri1 1, 1973.

22. "Operating Report for Radioisotope Power Generators of the U.S. Navy," U.S. Naval Nuclear Power Unit, Fort Belvoir, VA, vol. 8, no. 1, January 1, 1974 to September 30, 1974.

23. Private Communication with Homer Musselman, MERDC, U.S. Army Corps of Engineers, Fort Belvoir, VA, August 1974.

24. Private Communication with G. P. Dix, SNS, ERDA, Germantown, MD, November 1974.

25. Private Communication with Dr. H. W. C. Aamot, U.S. Army Cold Regions Research and Engineering Laboratory, Hanover, NH, August 1974.

26. Private Communication with Dr. Charles E. Behlke, Dean, University of Alaska, College, Alaska, September 1974.

27. Letter from Dr. Larry Underwood, Naval Arctic Research Laboratory, July 1975.

28. D. T. Bourgette, Effects of Aging Time and Temperature on the Impact and Tensile Behavior of L-605-A Cobalt Base Alloy, ORNL-TM-3734, Oak Ridge National Laboratory, Oak Ridge, TN, Apri1 1973.

29. H. E. McCoy and D. T. Bourgette, Influence of Aging on the Impact Properties of Hastelloy N, Haynes Alloy No. 25 and Haynes Alloy No. 188 , ORNL-TM-4380, Oak Ridge National Laboratory, Oak Ridge, TN, December 1973.

30. Personal Communication with H. T. Fullam, Battelle Northwest, Richland, WA, August 1975.

31. Personal Communication with S. J. Matthews, Cabot Corporation, Kokomo, IN, September 1975.

32. L. M. Knights, Operational Safety Analysis Report, Waste Encapsulation and Storage Facility, ARH-2967, March 15, 1974. 
APPENDIX A

ISOTOPIC HEATERS AND THERMOELECTRIC POWER SYSTEMS 


\section{APPENDIX A}

\section{ISOTOPIC HEATERS AND THERMOELECTRIC POWER SYSTEMS}

Radioisotopes are unstable particles that undergo a decay process which involves the emission of alpha, beta and/or gamma radiation. Since these emissions possess significant amounts of kinetic energy, this decay process results in appreciable amounts of thermal energy when the various particles are absorbed in containers or in the supporting matrix of radioactive materials. Radioisotope heaters and thermoelectric generators or power systems operate by using thermal energy that is converted from the kinetic energy of these decaying particles (radioisotopes). Brief statements on how this thermal energy is used for heaters and power generators will be treated in the following subsections.

\section{ISOTOPE HEATERS}

Since all radioactive processes produce heat when the emitted particles are absorbed, the preparation of heaters depends on: 1) the selection of an isotope having a sufficient power density and half-life, and 2) providing the isotope in appropriate amounts in a container that can be used as a heat source. A brief summary of the characteristics of the isotopes most commonly used as heat sources is given in Table A-1. These heat sources are nothing more than high integrity cans or containers in which the radioactive materials are held in some type of concentrated form. In this report most of the isotopic systems were based on ${ }^{90} \mathrm{Sr}$ so the material in the container would be either the compacted powder $\mathrm{SrF}_{2}$ or the solid $\mathrm{SrTiO}_{3}$. In many respects this container of ${ }^{90} \mathrm{Sr}$ will function much like an electrical heater where the unit is at a higher temperature than its surroundings. This thermal difference results in a flow of heat from the warmer to the cold body. In contrast to its electrical counterpart, once the isotope heater is installed it requires no external energy input to promote its operation. 
TABLE A-1. Characteristics of Radioisotopic Heat Sources (a)

\begin{tabular}{|c|c|c|c|c|c|c|c|c|c|c|c|c|}
\hline \multirow[b]{2}{*}{1.} & & ${ }^{60} \mathrm{Co}$ & ${ }_{905 r}$ & ${ }^{100} R u$ & ${ }^{11} \mathrm{Cs}$ & ${ }^{144 \mathrm{Ce}}$ & ${ }^{10} \mathrm{Pm}$ & ${ }^{170} \mathrm{Tm}$ & $210 \mathrm{Po}$ & ${ }^{238} \mathrm{Pu}$ & ${ }^{242} \mathrm{Cm}$ & ${ }^{244} \mathrm{Cm}$ \\
\hline & Watts/Gram (100\% Basis) & 17.8 & 0.933 & 33.1 & 0.416 & 25.6 & 0.333 & 13.6 & 144 & 0.56 & 120 & 2.84 \\
\hline \multicolumn{2}{|c|}{ 2. Half-Life Years } & 5.24 & 28.6 & 1.0 & 30 & 0.78 & 2.62 & 0.35 & 0.38 & 87.8 & 0.45 & 18.1 \\
\hline \multicolumn{2}{|r|}{ 3. Curies/Gram (100\% Basis) } & 1141 & 139 & 3394 & 87 & 3180 & 928 & 6048 & 4500 & 17 & 3320 & 81 \\
\hline \multicolumn{2}{|c|}{ 4. Curies/Watt } & 64.2 & 149 & 102 & 209 & 124 & 2786 & 445 & 31 & 30 & 28 & 29 \\
\hline \multicolumn{2}{|r|}{$\begin{array}{l}\text { 5. Estimated Isotopic } \\
\text { Purity } \%\end{array}$} & $10^{(a)}$ & $61^{(\mathrm{b})}$ & $3.6^{(b)}$ & $45^{(b)}$ & $5.5^{(b)}$ & $95^{(b)}$ & $10^{(a)}$ & 95 & 80 & 90 & 95 \\
\hline \multicolumn{2}{|r|}{ 6. Compound Form } & Metal & $\mathrm{SrTiOs}$ & Metal & $\mathrm{CsCl}$ & $\mathrm{Ce}_{2} \mathrm{O}_{3}$ & $\mathrm{Pm}_{2} \mathrm{O}_{3}$ & $T m_{2} 0_{3}$ & Metal & $\mathrm{PuO}_{2}$ & $\mathrm{Cm}=0$ & $\mathrm{Cm}: 0$ \\
\hline \multicolumn{2}{|r|}{$\begin{array}{l}\text { 7. Melting Point of } \\
\text { Compound }{ }^{\circ} \mathrm{C}\end{array}$} & 1495 & 2040 & 2310 & 645 & 2190 & 2320 & 2375 & 254 & 2232 & 2230 & 2230 \\
\hline \multicolumn{2}{|r|}{$\begin{array}{l}\text { 8. Active Isotope in } \\
\text { Compound }\end{array}$} & 10 & 27.0 & 3.6 & 34.5 & 4.23 & 82 & 8.8 & 95 & 70 & 75 & 83 \\
\hline \multicolumn{2}{|r|}{ 9. Watts/Gram Compound } & 1.78 & 0.252 & 1.19 & 0.143 & 1.08 & 0.273 & 1.2 & 137 & 0.39 & 90 & 2.35 \\
\hline \multicolumn{2}{|r|}{$\begin{array}{l}\text { 10. Density of Compound, } \\
\mathrm{g} / \mathrm{cm}^{3} \text {, actual or } 90 \% \text { TD }\end{array}$} & 8.8 & 5.03 & 12.4 & 3.8 & 6.9 & 6.6 & 8.0 & 9.2 & 10.3 & 11.7 & 11.7 \\
\hline \multicolumn{2}{|r|}{$\begin{array}{l}\text { 11. Power Density, } W / \mathrm{cm}^{3} \\
\text { Compound }\end{array}$} & 15.7 & 1.27 & 14.8 & 0.545 & 7.47 & 1.8 & 9.6 & $1260^{(\mathrm{d})}$ & $4.0^{(\mathrm{d})}$ & $1053^{(d)}$ & $27.5^{(\mathrm{d})}$ \\
\hline \multicolumn{2}{|c|}{$\begin{array}{l}\text { 12. Dimension of capsule for } \\
50 \mathrm{~W}_{1} \mathrm{~cm}^{(e)}\end{array}$} & 2.2 & 4.3 & 2.2 & 5.5 & 2.6 & 3.9 & 2.5 & 1.7 & 3.1 & 1.7 & 1.9 \\
\hline \multicolumn{2}{|c|}{ 13. Availability } & Avail. & Avail. & $\begin{array}{l}\text { Poten. } \\
\text { Avail. }\end{array}$ & Avail. & Avail. & Avail & Avail. & Avail. & Avail. & $\begin{array}{l}\text { Poten. } \\
\text { Avail. }\end{array}$ & Avail. \\
\hline \multicolumn{2}{|r|}{ 14. Major Types of Radiation* } & $\gamma B$ & $B \times \bar{Y}$ & $Y \overline{B X}$ & $B \overline{Y X}$ & $\overline{8 x}$ & $B$ & $B x$ & $\alpha x$ & $\alpha$ & $\alpha n$ & $\alpha n_{1}$ \\
\hline \multicolumn{2}{|c|}{$\begin{array}{l}\text { 15. Spontaneous Fission } \\
\text { Half-Life, Yr. }\end{array}$} & - & - & - & - & - & - & - & - & $4.9 \times 10^{10}$ & $7.2 \times 10^{6}$ & $1.4 \times 10^{7}$ \\
\hline \multicolumn{2}{|c|}{$\begin{array}{l}\text { 16. Shielding Required } \\
\text { (inches of lead) } \\
\text { [MeV of significant } \\
\text { B orY] }\end{array}$} & $\begin{array}{l}\text { Heavy } \\
(9.5) \\
{[1.33 y]}\end{array}$ & $\begin{array}{l}\text { Heavy } \\
(6) \\
{[2.268]}\end{array}$ & $\begin{array}{l}\text { Heavy } \\
\text { (9) } \\
{[3.35 \mathrm{~B}]}\end{array}$ & $\begin{array}{l}\text { Heavy } \\
(4.6) \\
{[1.17 B} \\
0.67 \gamma]\end{array}$ & $\begin{array}{l}\text { Heavy } \\
(10.2) \\
\mid 2.98 \mathrm{~B} \\
2.18 \mathrm{\gamma} \mid\end{array}$ & $\begin{array}{l}\text { Minor } \\
(1) \\
{[0.238]}\end{array}$ & $\begin{array}{l}\text { Moderate } \\
(2.5) \\
{[0.97 \mathrm{~B}]}\end{array}$ & $\begin{array}{l}\text { Minor } \\
(1) \\
{[0.8 \gamma]}\end{array}$ & $\begin{array}{l}\text { Minor } \\
(0.1) \\
{[0.04 \mathrm{Y}]}\end{array}$ & $\begin{array}{l}\text { Minor } \\
(0.4) \\
{[0.04 \gamma]}\end{array}$ & $\begin{array}{l}\text { Moderate } \\
\text { (2) } \\
{[0.04 \gamma]}\end{array}$ \\
\hline \multicolumn{2}{|c|}{$\begin{array}{ll}\text { 17. Bio. Haz., MPC, } & \mathrm{Ci} / \mathrm{m}^{3} \\
\text { Total Body, Air, } & \mathrm{W} / \mathrm{m}^{3} \\
\text { Sol. Continuous } & \mathrm{g} / \mathrm{m}^{3} \\
\text { Exposure } & \end{array}$} & $\begin{array}{l}10^{-7} \\
1.6 \times 10^{-9} \\
8.8 \times 10^{-11}\end{array}$ & $\begin{array}{l}3 \times 10^{-10} \\
2 \times 10^{-12} \\
2.2 \times 10^{-12}\end{array}$ & $\begin{array}{l}3 \times 10^{-7} \\
3 \times 10^{-9} \\
8.8 \times 10^{-11}\end{array}$ & $\begin{array}{l}2 \times 10^{-8} \\
9.6 \times 10^{-11} \\
2.3 \times 10^{-10}\end{array}$ & $\begin{array}{l}10^{-8} \\
8 \times 10^{-11} \\
3.2 \times 10^{-12}\end{array}$ & $\begin{array}{l}2 \times 10^{-9} \\
7.2 \times 10^{-13} \\
2.2 \times 10^{-12}\end{array}$ & $\begin{array}{l}7 \times 10^{-8} \\
1.6 \times 10^{-10} \\
1.2 \times 10^{-11}\end{array}$ & $\begin{array}{l}2 \times 10^{-9} \\
6.5 \times 10^{-11} \\
4.5 \times 10^{-13}\end{array}$ & $\begin{array}{l}5 \times 10^{-12} \\
1.7 \times 10^{-14} \\
2.9 \times 10^{-13}\end{array}$ & $\begin{array}{l}2 \times 10^{-10} \\
7.1 \times 10^{-12} \\
6.0 \times 10^{-14}\end{array}$ & $\begin{array}{l}9 \times 10^{-12} \\
3.1 \times 10^{-13} \\
1.1 \times 10^{-13}\end{array}$ \\
\hline \multicolumn{2}{|c|}{$\begin{array}{l}\text { 18. Estimated Future Price, } \\
\$ / g(\text { Pure), IPresent } \\
\text { Price] }\end{array}$} & $\begin{array}{l}285 \\
{[456]}\end{array}$ & $\begin{array}{l}20^{(g)} \\
{[14]}\end{array}$ & $120^{\prime} g^{\prime}$ & $\begin{array}{l}10^{(g)} \\
{[8.70]}\end{array}$ & $50^{(g)}$ & $\begin{array}{l}75^{(g)} \\
{[186]}\end{array}$ & 136 & $2800^{(h)}$ & 300 & $2000^{(i)}$ & 185 \\
\hline \multicolumn{2}{|c|}{$\begin{array}{l}\text { 19. Estimated Future Price } \\
\$ / W\end{array}$} & 16 & 22 & 5 & 24 & 2 & 220 & 10 & 20 & 540 & 17 & 65 \\
\hline \multicolumn{2}{|c|}{$\begin{array}{l}\text { 20. Total } \mathrm{kWh} \text {, released/ } \\
\text { initial gram over a mis- } \\
\text { sion period of }(\mathrm{yr}) \text {. }\end{array}$} & $\begin{array}{l}582 \\
(5)\end{array}$ & $\begin{array}{l}73 \\
(10)\end{array}$ & $\begin{array}{l}209 \\
(1)\end{array}$ & $\begin{array}{l}33 \\
(10)\end{array}$ & $\begin{array}{l}150 \\
(1)\end{array}$ & $\begin{array}{l}6 \\
(3)\end{array}$ & $\begin{array}{l}33 \\
(0.4)\end{array}$ & $\begin{array}{l}350 \\
(0.4)\end{array}$ & $\begin{array}{l}47 \\
(10)\end{array}$ & $\begin{array}{l}310 \\
(0.4)\end{array}$ & $\begin{array}{l}.209 \\
(10)\end{array}$ \\
\hline \multicolumn{2}{|c|}{$\begin{array}{l}\text { 21. Minimum Cost, } \\
\$ / \mathrm{kWh}_{\mathrm{e}}(\mathrm{ji)} \text { for } \\
(\mathrm{yr}) \text { mission }\end{array}$} & 15 & 6.5 & 23 & 7 & 9.5 & 320 & 165 & 235 & 133 & 240 & 22 \\
\hline \multicolumn{2}{|r|}{$\begin{array}{l}\text { 22. Grams per ton (at } 25000 \\
\text { MWD/t) Recoverable from } \\
\text { Reactor Fuels. }\end{array}$} & - & 360 & 53 & 835 & 89 & 60 & - & - & $(345 \mathrm{~Np})$ & - & $\begin{array}{l}9.6(204 \\
\text { for } \mathrm{Pu} \\
\text { recycle) }\end{array}$ \\
\hline \multicolumn{2}{|c|}{$\begin{array}{l}\text { 23. Production in Power } \\
\text { Reactors } \\
\text { kg/1000 MWY }\end{array}$} & & 18 & 2.1 & 42 & 5.3 & 2.9 & - & - & $(18 \mathrm{~Np})$ & - & $\begin{array}{l}0.5(10 \\
\text { for } \mathrm{Pu} \\
\text { recycle })\end{array}$ \\
\hline \multicolumn{2}{|c|}{$\begin{array}{l}\text { 24. Est. Availability in } \\
\text { 1980, } \mathrm{kW}_{\mathrm{L}}^{(\mathrm{m})}\end{array}$} & $M W_{s}$ & 1100 & 6000 & 1100 & 10,000 & 54 & $M W_{s}$ & $M W_{s}$ & $232^{(k)}$ & - & $\begin{array}{l}119 \\
185^{(1)}\end{array}$ \\
\hline
\end{tabular}

(a) Prepared by C. A. Rohrmann, PNL, for the U.S. Atomic Energy Commission, March 1973. 


\section{THERMOELECTRIC POWER}

The heater units described in the previous subsection can be used to produce electric power by either dynamic or static conversion processes; since this report has focused on the possibilities of static units, that approach will only be discussed in this summary. The information on the static or thermoelectric conversion process that follows was taken from a brochure by Corliss and Mead; ${ }^{(a)}$ it is a short but informative discussion:

"... The thermoelectric principle was used in ... (most) ... radioisotope generators used to date. It is not a new principle but was discovered almost 150 years ago by a German scientist named Thomas Johann Seebeck. He observed that an electric voltage is produced when two junctions are kept at different temperatures. Such pairs of junctions are called thermoelectric couples or thermocouples. In a typical temperature-sensing thermocouple, two ordinary metals or alloys are used. For power production, it has been found that some semiconductor materials, 'doped' by the addition of impurities to produce a deficiency or an excess of electrons, offer far greater efficiency. A very large number of semiconductor compounds exhibit the 'thermoelectric effect'. The power output of a thermoelectric material is a function of its operating temperature; some materials are better than others at certain temperatures.

A thermoelectric couple used in a radioisotope generator is composed of one so-called positive type element and one negative type element. In positive elements the flow of electrons is toward the hot junction. In negative ones it is away from the hot junction. Isotopic power generators using thermoelectric elements are commonly called RTGs (Radioisotope Thermoelectric Generators)."

(a) See Reference 15, Appendix D. 
Figure A-1 shows the basic principles of how a radioisotope thermoelectric generator works.

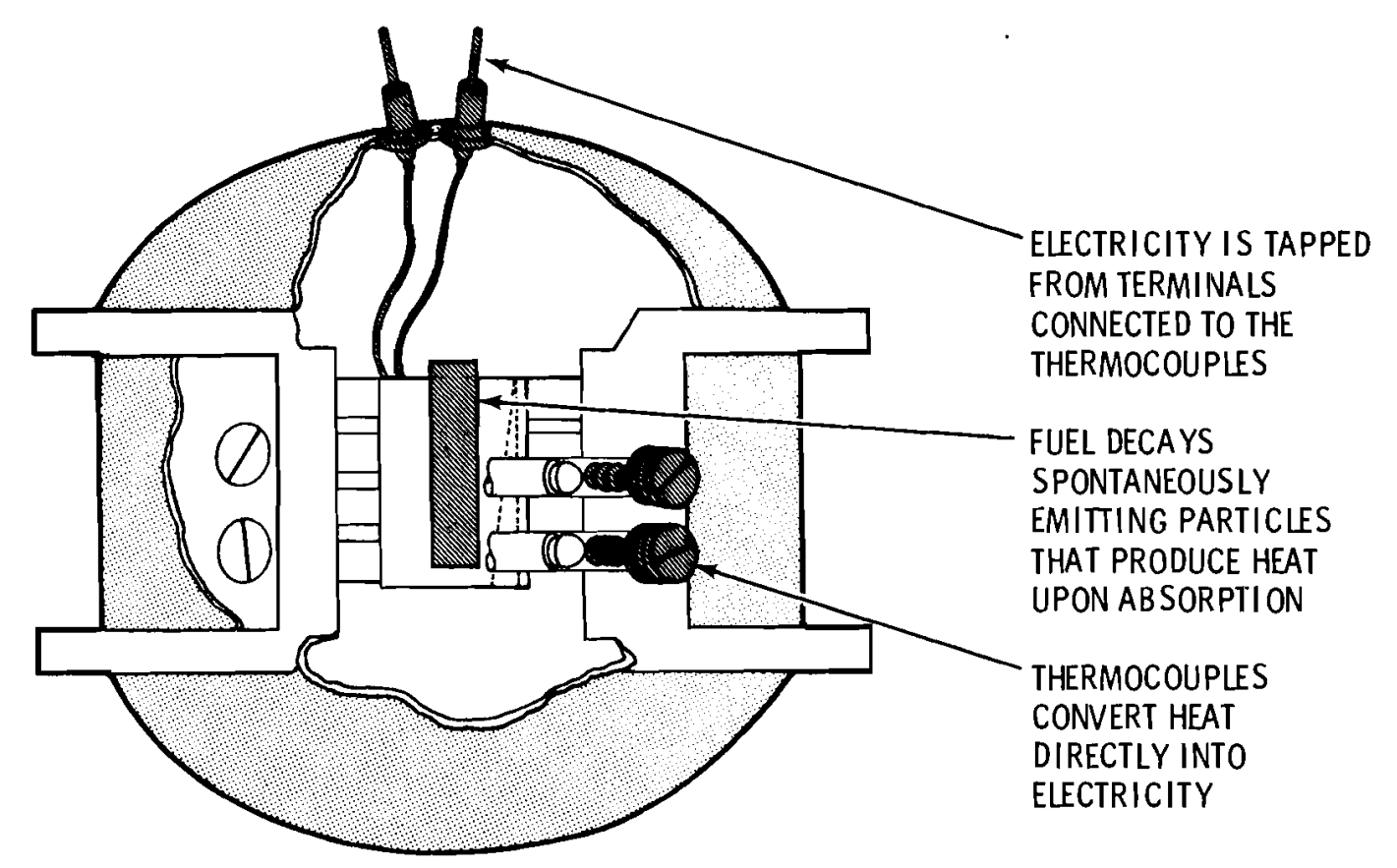

FIGURE A-1. How a Radioisotope-Powered Thermoelectric Generator Works (From Corliss and Mead) 
APPENDIX B

COLD REGIONS PROGRAM CONTACTS

IN FY-1975 


\section{APPENDIX B}

\section{COLD REGIONS PROGRAM CONTACTS}

IN FY-1975

In Appendix C of this report on FY-1975 Cold Regions Isotope Applications Program, activity information is presented on: 1) the methodologies used to make contacts and 2) the results of making such contacts. The purpose of this appendix is to provide backup information in the form of a detailed listing of al1 pertinent contacts made in FY-1975. This backup information may be useful in a number of ways including: 1) determinirg the specific groups that have been covered, 2) developing leads for the follow-up and/or further elucidation of material presented in this report, and 3) extending the coverage on this subject to groups not contacted in FY-1975. The divisions used to present information on these contacts and the assumptions made to assign various groups to one of the four market segments used in the FY-1975 Cold Regions Study were discussed earlier in the section on Opportunities and Problems. Those divisions and assumptions are also integral to the listing that follows:

COMMERCIAL ORGANIZATIONS

In the course of the past years' research, 20 contacts were made with commercial groups. Distribution within geographic areas is given in Figure $C-1$ of Appendix $C$. The organizations were:

Alaska

1. Merric, Inc. 3852 University Avenue

- (Aircraft and helicopter charter)

P. 0. Box 3149

Fairbanks, Alaska

2. Marketing and Business Development

Alaska National Bank of the North

Alaska National Bank Building

Fairbanks, Alaska 
3. Alaskan Resource Sciences Corporation 2550 Spenard Road Anchorage, Alaska

4. Alyeska Pipeline Service Company 1835 South Brogan Street

P. 0. Box 4-Z Anchorage, Alaska

5. Bomhoff and Associates 1020 West International Airport Road Anchorage, Alaska

6. Kenai Native Association Wildwood Air Force Base Kena i, Alaska

7. Alaska State Bank 5 th and $E$ Street Anchorage, Alaska

8. Mr. Bill Ogle, Consultant 3801 West 44th Anchorage, Alaska

9. Mr. David Katzuk Katzuk and Associates Juneau, Alaska

10. Dr. Charles Konigsberg Anchorage, Alaska

11. Alaska State Chamber of Commerce 208 National Bank of Alaska Building Juneau, Alaska

12. Associates of Pacific Fisheries Juneau, Alaska

13. Alaska Internationa1 Air, Inc. P. 0. Box 3029 Fairbanks, Alaska

Elsewhere

1. Teledyne Isotopes 110 West Timonium Road Timonium, Maryland

2. Northern Engineering Services Company, Ltd. 635 6th Avenue S.W. Calgary, Alberta Canada 
3 and 4. The Arctic Institute of North America 3426 North Washington Boulevard

Arlington, Virginia

and staff from AINA office at

1020 Pine Avenue West

Montrea1, Quebec H3A 1 A2

Canada

5. Personnel from

United Kingdom Atomic Energy Authority

Harwe11, Oxfordshire

U.K.

\section{STATE AGENCIES}

In FY-1975 13 contacts were made with various State agencies to help achieve program objectives. Twelve of these contacts were in Alaska and one in 0lympia, Washington. Details follow in two subdivisions:

\section{Alaska}

1. Mayor of Homer

Homer, Alaska

2. Seward Marine Laboratory

Institute of Marine Science

University of Alaska

Seward, Alaska

3. Institute of Marine Science University of Alaska

College, Alaska

4. Arctic Environmental Information and Data Center University of Alaska

707 A Street

Anchorage, Alaska

5. College of Mathematics, Physical Sciences and Engineering University of Alaska

College, Alaska

6. Department of Environmental Conservation

419 Sixth Street

State of Alaska

Juneau, Alaska

(September 1974) 
7. Department of Environmental Conservation

419 Sixth Street

State of Alaska

Juneau, Alaska

(June 1975)

8. Community Planning Division

Department of Community and Regional Affairs

State of Alaska

Juneau, Alaska

9. Division of Planning and Research

Office of the Governor

State of Alaska

Juneau, Alaska

10. Department of Highways

State of Alaska

Juneau, Alaska

11. Department of Economic Development

State of Alaska

Juneau, Alaska

12. Science Advisor to the Governor

Office of the Governor

State of Alaska

Juneau, Alaska

Elsewhere

1. Industrial Development Division

Department of Commerce and Economic Development

State of Washington

$01 y$ mpia, Washington

FEDERAL AGENCIES

Twelve contacts were made with Federal agencies in FY-1975 with six of these contacts being with Alaskan Offices of these agencies. One Federal contact was with a Canadian Government Group.

Alaska

1. Alaska Region Office

Federal Aviation Administration

632 Sixth Avenue

Anchorage, Alaska 
2. Office of Environmental Health

U.S. Public Health Service

Anchorage, Alaska

3. National Weather Service - Alaskan Region

National Oceanic and Atmospheric Administration

U.S. Department of Commerce

632 Sixth Avenue

Anchorage, Alaska

4. Arctic Environmental Research Laboratory

Environmental Protection Agency

Col lege, Alaska

5. Anchorage Office U.S. Coast Guard 632 Sixth Avenue Anchorage, Alaska

6. Aids to Navigation Branch

Seventeen Coast Guard District

U.S. Coast Guard

Juneau, Alaska

\section{Elsewhere}

1. Senator Ted Stevens' Office 01d Senate Office Building Washington, D.C.

2. Federal Aviation Administration

Buzzard Point Building

2100 2nd Street, S.W.

Washington, D.C.

3. Control and Treatment Integration Branch

Municipal Pollution Control Division

Environmental Protection Agency

Waterside Mall

Washington, D.C.

4. Technology Division

National Oceanic and Atmospheric Administration

Rockville, Maryland

5. Health Research Division

University of California

Los Alamos Scientific Laboratory

Los Alamos, New Mexico

6. Industrial Products Group

Atomic Energy of Canada, Ltd.

Ottawa, Canada 


\section{MILITARY SERVICES}

Nine contacts were made with various branches or groups in the U.S. Military Services in FY-1974. Particulars follow:

\section{Alaska}

1. Naval Arctic Research Laboratory

Barrow, Alaska

2. Engineering Branch

1931st Communications Group

U.S. Air Force

Elmendorf Air Base

Anchorage, Alaska

3. Alaskan District

U.S. Army Corps of Engineers

Anchorage, Alaska

\section{Elsewhere}

1. Cold Regions Research and Engineering Laboratory

U.S. Army Corps of Engineers

Hanover, New Hampshire

2. Army Security Agency

Arlington $\mathrm{Hall}$

4000 Arlington B1vd.

Arlington, Virginia

3. $R$ \& D Division, FESA

U.S. Army Corps of Engineers

Fort Belvoir, Virginia

4. Nuclear Power Division

Naval Facilities Engineering Command

Department of the Navy

200 Stoval1 Street

Alexandria, Virginia

5. Scientific and Technical Liaison Office

U.S. Air Force

Andrews Air Force Base

Maryland

6. MERDC

U.S. Army Corps of Engineers

Fort Belvoir, Virginia 
APPENDIX C

MARKET METHODOLOGY 
APPENDIX C

\section{MARKET METHODOLOGY}

Several factors were considered during the selection of a market methodology. A major factor was the problem arising from earlier, broad spectrum-type attempts to promote extensive usage based on the technical merits of radioisotope systems without regard for economical factors. Conceptually, a different approach with a different perspective might yield information, contacts and plans that could achieve greater beneficial use of radioisotope systems with a sound economic base. This approach is believed to be particularly useful because it emphasizes economic considerations and customer acceptance factors which have not been treated systematically in earlier studies. Another factor considered when the program methodology was selected was that well-developed marketing methodologies existed which could be readily adopted to examine the opportunities for using radioisotope systems in Cold Regions. This made the new approach a reasonable course to follow.

The impending generation of vast quantities of radioisotopes that could be used in the manufacture of various devices also had its impact on the methodology selection. If there is a reasonable market for such systems, current use of a conventional market methodology would lay the groundwork for such an approach in the future. Furthermore, this approach normally requires a customer-oriented view of the market which can be beneficial in many ways. Perhaps the most promising way would be in structuring information programs and demonstrations in such a manner that the economic and technical benefits are better understood by potential system users as well as a broader cross section of the public.

Adopting a marketing methodology and approach to generate information has significant program implications. Marketing, in the sense used here, means attempting to maintain a perspective of all aspects bearing on the 
program, not separately but as a unified whole. Specifically, the Cold Regions Isotope Applications Program involves the following considerations:

- Consumer Orientation. This approach involves examining the present and anticipated needs of a potential consumer to do his job better at the same cost or with a reasonable and justifiable increase in cost.

- Service Orientation. This approach recognizes that a potential consumer is not really interested in hardware, as such, but in what it can do for him.

- Accommodation to Existing Technology. The accommodations with existing technology for this program resulted in narrowing candidate systems that might be offered to consumers of radioisotope thermoelectric generator, heater and radiation systems. Although other potential applications were technically possible, experience, availability and accommodation to existing and expected conditions in the nuclear community dictated that these three applications be the ones selected for emphasis in this study. Radiation usage was narrowed to a preliminary assessment of application in sewage sludge treatment. This investigation of sewage sludge was bel ieved warranted to accommodate apparent advances in this area of technology at Sandia Laboratories, Albuquerque, New Mexico.

- Approach Anticipating Change. Market opportunities increase or decrease for particular systems and their competitors as technological advances are made. Thus, important factors related to anticipated and recommended work on promoting change were included.

- Planning Aid. Data generated in the assessment of market opportunities is a valuable resource that can be used beneficially in planning. This factor was considered when establishing a market methodology and a work plan for the program. Significant factors that are believed to affect the future options available to sponsors are identified as such in the report. 
Additional information on the rationale for using the above factors in developing a market research approach for the Cold Regions Isotope Applications Program can be found in the literature. (1) More information on the market methodology used for this program will be covered in the following subdivisions.

\section{AREA OF STUDY}

Alaska was chosen as the area of study because we believe that conditions in that state would provide the type of examples needed to carefully examine opportunities for radioisotope applications. Also, Alaska has a large land area, a small population and widely dispersed commercial and governmental activities. These characteristics, combined with those related to harsh weather conditions, create situations that might be favorable to the economic feasibility, technical feasibility and of overall societal benefit of using radioisotope systems. The recent interest in recovering North Slope oil and the long-standing interest in the tactical, as well as strategic location of the state, were also important factors. Another important consideration is the location of Alaska relative to PNL; it is close and readily accessible to laboratory staff members pursuing this study. Additionally, certain PNL staff members have conducted ERDA sponsored programs in Alaska for many years. These people were able to serve as resources on problems and conditions that could be anticipated in that state.

Once the primary geographic area was chosen, a means for acquiring specific information about conditions, opportunities, and commercial and military activities was needed. An accepted approach (the major trading area concept) ${ }^{(2)}$ was used to provide such a basis. Although the trading areas indicated in Figure $\mathrm{C}-1$ were developed from Rand McNally information on shipping goods, they nevertheless constitute a rational method for gathering information about Alaska. (3) The three major Alaskan trading areas are based on the trading centers of Anchorage, Fairbanks, and the two towns of Juneau and Ketchikan. These centers are the focal points for 
intrastate transportation and communication systems as well. In-state data acquisition was therefore developed to emphasize contacts with representative organizations in Anchorage, Fairbanks and Juneau; no effort was made on working through Ketchikan because its importance as an information center on Cold Regions was limited by its location.

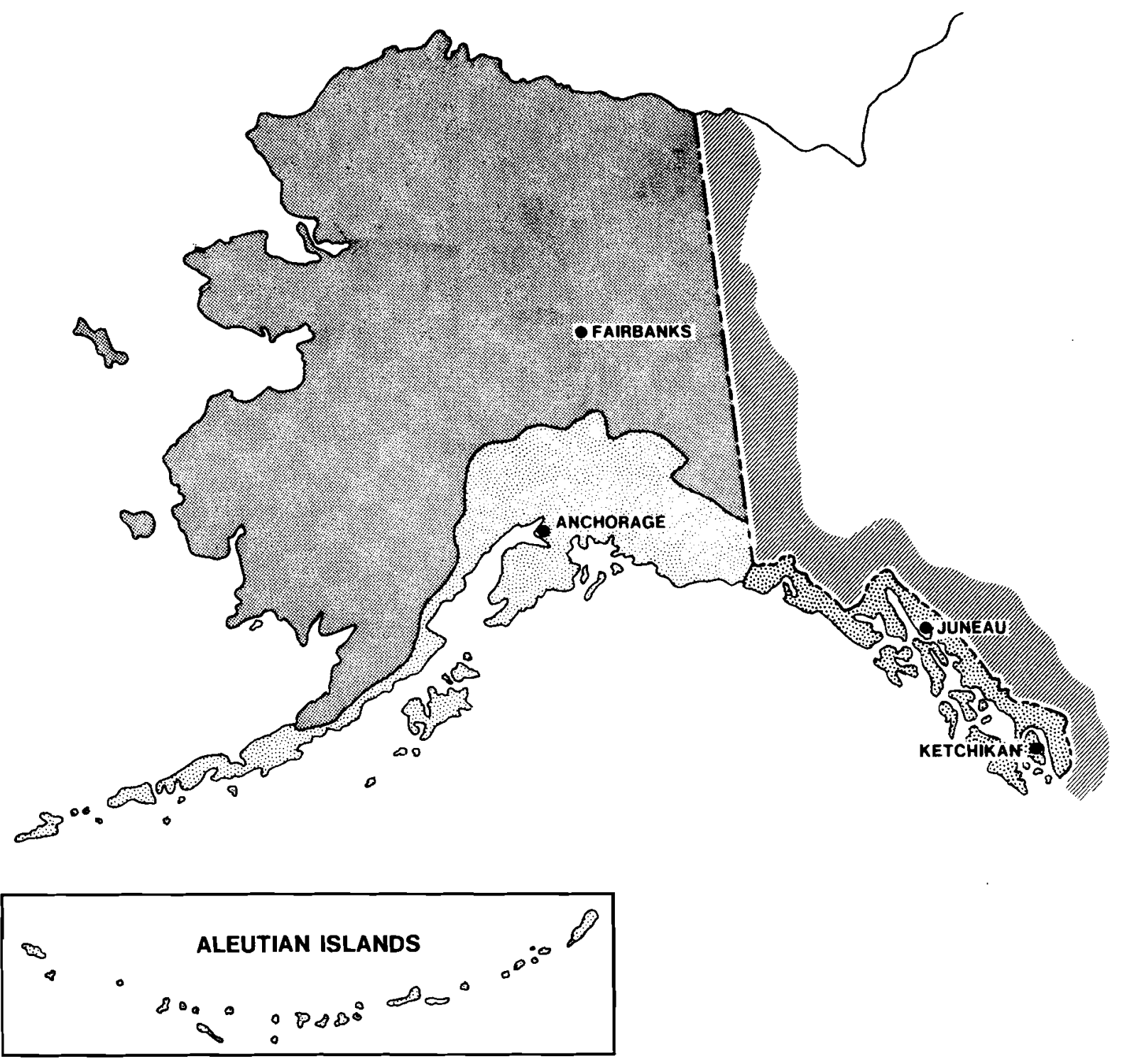

FIGURE C-1. Alaskan Trading Areas 


\section{MARKET SEGMENTATION}

Segmentation is a term used to describe divisions in a market that have common characteristics. These divisions can be made in a number of ways (such as by size of consumers, product applications, industrial location or industrial requirements) and they focus attention on areas where one has advantages in developing a market. This development may be affected by catering to particular servicing needs, product characteristics, cost constraints or regional needs.

For this study an industrial segmentation was used. The major segments were defined as being: 1) resident commercial operations, 2) the military services, 3) other Federal agencies and 4) State agencies. An industrial-based segmentation of the market was believed to be warranted because the objectives of these four elements of the Alaskan market are markedly different in most cases. When these segments are examined from the standpoint of the trading area divisions mentioned previously, one can also obtain information about geographical effects on the market.

Once the segments of the market were defined, we were then able to identify key individuals who could supply useful program information. Such a division also permits a detailed examination of the industrial trade literature and popular publications as well as the scientific/technical journals for additional background information. Additional details on these aspects of the market and how data were acquired for the program from a number of different sources is treated below.

\section{DATA ACQUISITION}

Six different procedures were used to acquire information for the Cold Regions Isotope Applications Program: 1) the open literature, 2) other publications, 3) referrals, 4) surveys, 5) letters and calls, and 6) briefings. These procedures are briefly discussed below to describe the data acquisition efforts for this program. 
- Open Literature. This phraseology is used in its usual sense and the results of a specific search are treated in the report section discussing the results of the program. The literature was also used to acquire general background information on Alaska, the Arctic in general and other aspects bearing on the programs; these details are covered only when they provide some relevant information.

- Other Publications. Extensive use was made of trade publications, government information sheets, industrial literature and commercial reports to acquire background information and data for the program. Subscriptions to the "Fairbanks Daily News - Miner" and the "Anchorage Daily News" were purchased for a month prior to the first field survey of Alaska to provide information on existing issues, beliefs, etc. in that state.

- Referrals. A number of the author's technical colleagues, business associates, and acquaintances in various governmental agencies having contacts in Alaska or the Arctic were called for referrals to knowledgeable people who could either provide background information or specific program data. These referrals were frequently those who were contacted in field surveys.

- Surveys. Direct contacts were made both in Alaska and elsewhere for information about Cold Regions problems and their response to the possibilities of using isotope systems for their solution. In all cases where the identity of these contacts was known prior to the survey the individuals were contacted by letter to explain the reasons for my visit. In many cases AEC booklets on isotope power applications were included with the letters to maximize the potential benefits of each step. These contacts are listed in Appendix B.

- Letters and Calls. Information was solicited by letters and/or telephone for those situations where direct personal contact was not warranted or feasible. These contacts also produced useful information as is discussed in the program results section of this report. 
- Briefings. PNL colleagues and ERDA staff members provided several briefings at the onset and during the program. These briefings provided background information, insight into new developments and reports on current conditions relative to isotope utilization and unique Arctic living and operating procedures. None of these meetings will be referenced directly al though they were of substantial benefit in focusing on program objectives and relevant Arctic problems.

\section{REFERENCES}

1. L. Fisher, Industrial Marketing, Brandon/Systems Press, Princeton, NJ, 1970.

2. J. Goldstucker, "Trading Areas", Science in Marketing, George Schwartz, editor, John Wiley and Sons, Inc., NY, 1965.

3. 1974 Commercial Atlas and Marketing Guide, Rand McNally and Co., Chicago, IL, 105th Edition, 1974. 
APPENDIX D

BACKGROUND INFORMATION 
APPENDIX D

\section{BACKGROUND INFORMATION}

The information for this appendix was obtained from the literature, various publications, internal reports on similar work, and briefings. It was acquired and used to provide a background for work on other parts of the Cold Regions Isotope Applications Program. Three tasks (shown on the Work Plan in Figure 2) provided the data for this portion of the report: "Acquire Isotope Background Information", "Acquire Arctic Background Information", and "Conduct Literature Search". Since these tasks were designed to acquire background data to assist in accomplishing subsequent tasks, the level of effort involved in the work was affected. For example, the literature search of reports and publications on similar work was pursued only to the extent necessary to acquire a "flavor" of the important factors involved in radioisotope power and heater system technology, their recent applications and anticipated developments. The same general constraints were imposed on examining the informational sources on Cold Regions problems and technology transfer. Consequently, the material listed in appendices dealing with these three subject areas should not be considered exhaustive. However, this literature more than adequately provided background for achieving overall program objectives. Additional discussions are presented in the following three subsections: 1) the State-of-the-Art Study, 2) Cold Regions Background Information and 3) Technology Transfer.

\section{STATE-OF-THE-ART STUDY}

In this report "state-of-the-art study" refers to collecting and evaluating existing information on radioisotope applications. The subject of this study was narrowed to those applications having to do with heat and power generation. Although isotopes have been used extensively as tracers or for medical purposes, those applications were considered to be outside 
of the boundaries of this effort because they do not fall into the areas of responsibility assigned to SNS. Although the platinum metals are within the area of responsibility, they were not examined because: 1) little if any opportunity for their use in Cold Regions could be anticipated, and 2) the technology for the separation, packaging and use of these materials was not well-established.

After the Cold Regions Program was initiated attention was directed toward using isotopes for sewage or sewage sludge deactivation. This increase in the scope of research resulted from the promising and ongoing work at Sandia Laboratories in Albuquerque, New Mexico. However, even with this increased scope, care was taken to limit the field of study so that FY-1975 objectives could be achieved within the time and funds available.

Another consideration also governed the acquisition and evaluation of information in the state-of-the-art study. Only enough information was sought that would be required to establish existing status of isotope technology in the areas of interest. This approach was sufficient for the FY-1975 effort since it was essentially a market research program. Consequently, the literature is limited to that necessary to provide a general understanding of the current situation. This material should not be considered an exhaustive treatment of the subject. Further state-of-the-art information is provided in three subdivisions concerned with: 1) informational sources, 2) isotope generator, heater and sterilization technology, and 3 ) educational and popular materials.

\section{Informational Sources}

The Quarterly Technical Progress Review, published by the Isotopes Information Center, Oak Ridge National Laboratory, and entitled Isotopes and Radiation Technology, presented a wealth of information on isotope applications. In its 9 years of publication (1963-1972) there were 28 articles or technical notes on isotope power and heater systems in the U.S. and abroad. Those who wish to acquire a more detailed background on this subject should include the reading of the quarterly reviews in their study. 
The Isotope Information Center also published reports on special sources, selected abstracts and program reviews that also provided useful information. Dr. J. H. Jarrett's 1971 bibliography lists reports covering Hanford Laboratories and Battelle-Northwest research on radioisotopes. (1) The proceedings from two international symposia sponsored by the European Nuclear Energy Agency at Harwel1, United Kingdom, in 1966 and at Madrid, Spain, in $1972^{(2,3)}$ contain sizable amounts of useful information on isotope power generation. For several years the Intersociety Energy Conversion Engineering Conferences have published transactions covering papers on isotope applications technology that are helpful in acquiring a better background for the Cold Regions Isotope Applications Program. Books that were most helpful were those by Corliss and Harvey, ${ }^{(4)}$ Sutton, ${ }^{(5)}$ Dempsey and Polishuk ${ }^{(6)}$ and Wheelwright. ${ }^{(7)}$

Generator, Heater and Sterilization Technology Background

The informational sources identified in the previous subsection provide a sizable amount of background material on the demonstration and application of isotope power, heater and sterilization systems. Significant details on these demonstrations and applications are discussed in the following subsections.

\section{RTG-Powered Weather Stations}

The literature reveals that several Radioisotope Thermoelectric Generator (RTG) powered weather stations have been successfully demonstrated since $1961,(4,8-14)$ under extreme climatic conditions such as in the Arctic and Antarctic or in isolated places such as weather buoys. The first of the weather stations was on Axel Heiberg Island in the High Arctic of Canada. A $5 \mathrm{We}_{\mathrm{e}}{ }^{90} \mathrm{Sr}$ generator and ancillary equipment was installed on this island in August $1961 .(4,9,13)$ The isotope power unit performed wel1, but difficulties were encountered with the meteorological and electrical equipment. After 13 months the anemometer shaft was fouled by an antenna feed line and in July 1963 a bank of motor-actuated electrical switches had failed; the system was returned to the U.S. in August of 1963. $(9,13)$ Another weather 
station, a $10 \mathrm{~W}_{\mathrm{e}}$ SNAP-7C, was shipped to Antarctic in late 1961 and installed on Minna Bluff, some 200 miles from the South Pole on February 8, 1962. $(4,8,9)$ This system like the one on Axel Heiberg Island was plagued with weather equipment problems until it was removed in 1968. (9) Corliss ${ }^{(4)}$ reports that the Navy has used RTGs for power on floating weather stations for years. Shortly after the first SNAP-7D unit was installed in the Gulf of Mexico erratic electric output problems resulted from thermocouple failures caused by differential therma 1 expansion; a design change with modification of the system overcame this problem. Another RTG-powered weather station is the one installed on Fairway Rock in the Bering Strait in August $1966(8,15)$ which is still in operation. ${ }^{16)}$ In summary, ${ }^{90}$ Sr-powered isotope systems can be successfully operated for remote weather stations. Most of these reported problems resulted from various failures in the weather sensors and/or electric units and not with the isotope power units themselves.

\section{Marine Navigational Aids}

The U.S., United Kingdom, U.S.S.R., Sweden, Denmark and France all have, or are using, RTG-powered marine navigational aids, $(4,8-12,15-20)$ including buoys, lighthouses, ocean-bottom beacons, navigational lights and fog horns. The earliest reported demonstration was on a U.S. Coast Guard buoy in Curtis Bay near Baltimore, Maryland. $(4,8,15)$ A SNAP-7A device $\left(10 \mathrm{~W}_{\mathrm{e}}\right)$ was used to provide a flashing light. It was installed in 1961, refurbished in 1963; reinstalled in 1966 and was finally removed in 1967 for disassembly and inspection. ${ }^{(8)}$ Another RTG was installed in a U.S. Coast Guard lighthouse at Baltimore in 1964 and performed perfectly for 2 years. ${ }^{(8)}$ Another example is an ocean bottom beacon which was placed in the deep ocean off of Bermuda in July 1964. Although the signals stopped in November 1968, the RTG was still performing well when recovered in 1969. (8) An English RIPPLE unit fueled with ${ }^{90} \mathrm{Sr}$, which was installed to power a navigational light on some submerged rocks in the Stockholm Archipelago in 1967 was reported to be operating well in 1969. Although the earliest demonstrations encountered problems with diminishing power (rectified by design changes), later studies revealed that the radioisotope systems were highly reliable. 


\section{Ground Navigational Aids and Communications Equipment}

The literature contains information on the possible use of RTGs for ground-located aircraft navigational aids and communications equipment. $(8,9,11,21-23)$ Carpenter reports that RTGs containing ${ }^{238} \mathrm{Pu}$ as the heat generating isotope were used to power communications demonstration devices in the U.S. in the period 1963-1969. (8) RTGs with ${ }^{238} \mathrm{Pu}$ were also employed for telemetry work beginning in September 1969. (8) Sawyer in 1966 reports on the possibilities of using RTGs for supplying power for microwave radio communications. ${ }^{(22)}$ He concluded that power demands of $300 \mathrm{~W}_{\mathrm{e}}$ in those locations where access is difficult and maintenance costs were very high would provide the most promising conditions at that time. At the same time Clark et al. noted that most aircraft communications and navigational systems would best be served by conventional power sources. However, they indicated there may be immediate applications for remote marker beacons and for the ideal siting of radio communication and navigational facilities where conventional means of provisioning conventional systems is impractical. In summary, the literature indicates possible opportunities for RTG use with aircraft navigational aids and communications equipment when they are located in remote areas where maintenance costs are high. Also, the technical feasibility of using RTGs for communications systems and telemetry purposes was demonstrated in the U.S. in the 1960s.

\section{Dynamic Heat Engines}

Over the years there has been a continuing interest in using dynamic heat engines rather than static systems that are commoniy encountered with RTGs. This interest is sparked by the possibilities of higher heat-toelectric energy conversion efficiencies. Dynamic systems may be able to achieve a conversion of $15 \%$ or more while most static RTGs operate with about $5 \%$ conversion. Corliss and Harvey, ${ }^{(4)}$ Corliss and Mead, (15) Corliss, ${ }^{(24)}$ Dunn and Hammerton, ${ }^{(25)}$ and many others have described how decay heat can be converted to power by the Rankine, Brayton and Sterling Cycle Systems. Van Nederveen, ${ }^{(26)}$ van Witteveen ${ }^{(27)}$ and 0ttesen (28) described the state-of-technology of isotope-powered Sterling and Rankine 
engines in 1966; these were either in the conceptual or prototype stage of development. In 1971 Fraas described detailed engineering studies at 0ak Ridge National Laboratory in the period of 1969 to 1970 on organic and steam Rankine cycles to produce kilowatt levels of power from decay heat. (29) Later, Westinghouse built a large ${ }^{60}$ Co fueled dynamic heat engine but it was never fully tested under prototypical conditions in the U.S. or later in Canada. (30) In 1972 Hermans et a1. reported on the development of an isotope heat source and a Sterling cycle engine which could be made available in a relatively short time for marine applications. (31) Holman and Jaspers in 1974 indicated that demonstrated Sterling engine technology was available to design a thermodynamic converter using isotope heat to drive a $400 \mathrm{~W}_{\mathrm{e}}$ generator in space for at least 5 years. (32) They believed that 20 engines could be manufactured for $\$ 50,000$ to $\$ 80,000$ per engine in 3 years and including fuel, shielding, and other isotope system costs, the units should be priced at less than $\$ 500,000$. It should be understood that these dynamic cycle systems using isotopes show great promise, but there is currently no backlog of operating experience with such systems. This situation should be contrasted with the wealth of experience and positive demonstration results for static systems using decay heat. Consequently, FY-1975 application and demonstration opportunities were narrowed to static systems.

Heater Technology

Information on the successful demonstration of RTGs can also be used to establish the feasibility of heater technology. If the RTGs are successful, then the heater was also successfully demonstrated since RTGs operate on the conversion of decay heat from isotope pins or capsules into electrical energy; the heater does not convert the heat to electrical energy (see Appendix B). Bolme ${ }^{(33)}$ and Safonov ${ }^{(34)}$ have reported on schemes for using the decay heat from mixed fission products for power generation purposes; Bolme was not overly optimistic about the economic possibilities of such a process while Safonov was. Further investigation of Safonov's findings are now underway. (35) A number of patents have been issued in the U.S. for using isotopic heaters to increase petroleum recovery from oil wells. The 
patent issued to Triplett and Brauer in March 1970 is indicative of general interest in this area. (36) In this patent ${ }^{90} \mathrm{Sr}$ as $\mathrm{Sr}_{2} \mathrm{TiO}_{4}$ is mentioned as one possible isotope heater than can be used to lower the viscosity of the petroleum in the deposit so that increased recovery is possible. In summary, heater technology has been adequately demonstrated on a technical basis. Because of the low heat output of isotope units compared with the heat from the combustion of fossil fuels and petroleum, the isotope systems would best be used where sensible heat changes are needed and can occur over appreciable periods of time (on the order of weeks or months).

\section{Isotope Sterilization Processes}

Information on the state of technology of isotope sterilization processes will be limited to an investigation of thermoradiation techniques. A wealth of literature can be found in the journal ISOTOPES AND RADIATION TECHNOLOGY and elsewhere on broader aspects of sterilization. The scope of this investigation was narrowed due to input from the sponsor on the economics associated with most radiation sterilization processes. As a result of this narrowed investigation of the literature, a study was made of the recent efforts at Sandia Laboratories in Albuquerque, New Mexico. Sivinski and his colleagues have reported that a combination of heat and radiation is far more effective than the additive effects of each process separately. (37-39) Reynolds et a1. also reported this process to be effective in inactivating spores in sewage sludge. (37) Sivinski indicated good inactivation of spores, bacteria, viruses, vegetative cells such as $E$. Coli, and parasites. (38) A demonstration of this process is planned for the near future $(38,39)$ on half of the sewage sludge generated at Albuquerque, New Mexico. The results of this demonstration should be monitored carefully since a successful effort at Albuquerque could create a significant demand for radioisotopes such as ${ }^{137} \mathrm{Cs}$.

It should be remembered that the information sought and evaluated in this study does not constitute a full coverage of the technical and scientific 1iterature of isotope demonstration and usage even within the narrow 
confines of power generation, heaters and sterilization systems. Only enough information was acquired to provide a general background for the present Cold Regions Program.

Other Background Materials

There is a variety of other background materials that can provide additional information on the state-of-the-art in isotope applications such as: scientific and public information motion pictures; non-technical articles and booklets on isotope applications; and the trade literature prepared and distributed by commercial organizations in the fabrication and marketing of isotope devices. Some of these sources were examined to provide further information for the Cold Regions Isotope Applications Program.

The Energy Research and Development Administration (ERDA) has two motion pictures for loan to the public on terrestrial applications of RTGs. The two, "Atomic Weatherman: Strontium-90 Isotopic Power Applications" and "Pax Atomis: SNAP-7 Terrestrial Isotopic Power Systems", were prepared in 1961 and 1965 respectively to provide general information to the public on RTG usage. Both were viewed in the course of FY-1975 work on this program and were found to provide a broad context for understanding some of the practical demonstrations of these devices. The first motion picture covers the demonstration of a remote weather station on Axel Heiberg Island in the Canadian Arctic which is particularly relevant to the Cold Regions Program. The second presents information on several demonstrations of RTGs to power marine navigational aids. Although such a film is not now known to exist, a movie directed specifically to the spectrum of possible isotope applications in Cold Regions would be of the greatest potential benefit to this program.

Also provided as a public service by ERDA are two booklets in the UNDERSTANDING THE ATOM Series that contained useful information on isotope power generators. These two by Corliss, ${ }^{(24)}$ and Corliss and Mead ${ }^{(15)}$ were referenced and discussed in the previous subsection. 
In FY-1975 trade literature was obtained from three RTG manufacturers. This material was useful in establishing the types of devices they have or intend to market and some general information of the characteristics of these devices such as size, weight and configuration. Use of the trade literature is recommended for future work.

\section{COLD REGIONS BACKGROUND}

The literature has a number of definitions about what can be considered the Arctic which is one part of the Cold Regions. (40) For this study cold Regions are those areas to the north or south of $60^{\circ} \mathrm{N}$ and $60^{\circ} \mathrm{S}$ latitude respectively plus the high mountain areas of the world which are characterized by having essentially year-round snow or ice coverage. It is recognized that there are parts of Europe that probably do not fit well into this $60^{\circ} \mathrm{N}$ latitude definition. However, in Asia and especially in North America the areas above $60^{\circ} \mathrm{N}$ are characterized by sparse habitation, cold climatic conditions and could be considered "frontier" areas even today. Even with these possible drawbacks this definition of Cold Regions has been most useful for the Cold Regions Isotope Applications Program.

Cold Regions background information is presented in three subsections: 1) Information Centers, 2) Stimuli to Isotope Usage, and 3) Stimuli Effecting Operations. As with other parts of the background study, only enough information was sought and acquired to provide a general understanding of the Cold Region opportunities, problems and pertinent operations. This limited approach was believed to be adequate for the effort to be conducted in $\mathrm{FY}-1975$.

\section{Information Centers}

One of the first things accomplished in this part of the program effort was to identify centers containing information on Cold Regions activities and research. Four centers were found in the United States and Canada, although it should be recognized that there are a number of centers located elsewhere in Canada, the U.S. and the world that also have very useful 
information. Visits to these four centers revealed that all who are involved in future activities on this program would be advised to maintain liaison with these institutions as well as encouraged to broaden their contacts to include other groups specializing in Cold Regions research and programs. Another factor affecting the selection of the centers identified in FY-1975 was the decision mentioned in an earlier section that our model region was to be Alaska. Additional information on these centers of information is presented in the following four subsections.

\section{Arctic Institute of North America}

The Arctic Institute of North America (AINA) is a professional society for people who are interested in the North. It also conducts research programs, provides grant monies for research and has a library of books and literature on the Arctic. This organization has been in operation since 1945 and currently has offices in Montreal, Quebec, and Ottawa in Canada, Arlington, Virginia, and Anchorage, Alaska. For AINA members loans of library materials can be arranged through the mail. In addition to a quarterly journal entitled ARCTIC, AINA publishes proceedings of conferences, books, technical papers and project reports. The AINA 1974 Annual Report provides additional information on operations and purposes of this institution. (41) Their staff and publications provided useful background information for the Cold Regions Isotope Applications Program in FY-1975. (a)

\section{Cold Regions Research and Engineering Laboratory}

The purpose of the Cold Regions Research and Engineering Laboratory (CRREL) is reported to be responsible for: $(42)$

"... conducting and monitoring scientific and technological programs in the cold regions of the world."

The main laboratories and facilities of CRREL are located in Hanover, New Hampshire and are under the direction of the U.S. Army Corps of Engineers.

(a) The author of this report is a member of AINA, and others who may be involved on the Cold Regions Program would be advised to become members also. 
CRREL publishes an annual bibliography on Cold Regions Science and Technology, material on pertinent, recent activities in those geographic areas, technical and research reports, monographs, translations and other types of literature. ${ }^{(42)}$

Naval Arctic Research Laboratory

The Naval Arctic Research Laboratory (NARL), operated by the University of Alaska for the U.S. Navy, is located at Barrow, Alaska. ${ }^{(43)}$ The purpose of this laboratory is similar in many respects to the one held by CRREL, but NARL emphasizes marine research and associated problems in Cold Regions. NARL has a small but excellent library that can be used to advantage if suitable arrangements have been made to visit this laboratory when in Barrow.

\section{University of Alaska}

The University of Alaska's Geophysical Institute located in College and its Arctic Environmental Information and Data Center, Anchorage, are excellent sources of information on Arctic research. The former is active in conducting a wide variety of research programs on Arctic phenomena while the latter primarily compiles information on the Arctic and Alaska.

Stimuli for Isotope Usage

The examination of the 1iterature in FY-1975 revealed that there are at least three stimuli that could lead to greater use of radioisotope systems in Cold Regions. These stimuli are: 1) pressures for resource development and exploitation, 2) demands for quality of 1 ife improvements for natives, and 3) demands for increased and improved Cold Regions services. Additional information on those three stimuli is presented in the following three subsections.

\section{Resource Development and Exploitation}

The 1973 petroleum shortage increased the world's awareness of modern technology's dependence on viable energy resources. Attendant with that shortage was the realization that industry is also highly dependent upon 
many different minerals for the production of metals and other materials used throughout the world. Because of this 1973 petroleum shortage and the realization that we are dependent upon minerals, a large effort was focused on the development of new fuel and mineral resources. This new emphasis, coupled with the depletion of some of the better-known deposits in temperate and torrid zones, resulted in greater attention being placed on the identification and/or development of these resources in Cold Regions. (40)

The interest in, and the necessary initial work leading to, the development and exploitation of the Prudhoe Bay Dil Field in Alaska are well-known and preceded the 1973 oil shortage. However, that shortage spurred development of that north slope field and created activity elsewhere. A brief summary of some of these activities and the possible direct and indirect effect on potential use of isotope systems follows: ${ }^{(a)}$

- There is an enormous deposit of sub-bituminous coal north of the Brooks Range in Alaska. $(40,44,45)$ The location and general extent of this field can be seen in Figure $D-1$ as well as the location of other coal deposits in that state. Since this North Slope Field is reported to be the largest untapped coal deposit in North America, the pressure for its development and use can be expected to increase markedly in the near future. When this occurs some special geographic and climatic factors must be handled. For example, no ports that can be used or developed lie beyond Port Clarence on the Seward Peninsula. This means that special arrangements would be needed to ship bulk coal to the United States or elsewhere. One approach is evident from Figure D-2 which shows a number of prospective corridors for the movement of resources in Alaska. ${ }^{(46)}$ Conceptually, North Slope coal could be transported as a slurry to the Bristol Bay or Cook Inlet Areas for shipment in marine bulk carriers. Other options (such as the

(a) Only recent references are used to establish a possible demand for isotope systems from ongoing development activities. This has resulted in no treatment of an appreciable amount of literature that could also be used for this purpose. However, it is believed that recent information readily established the points made in this report. 


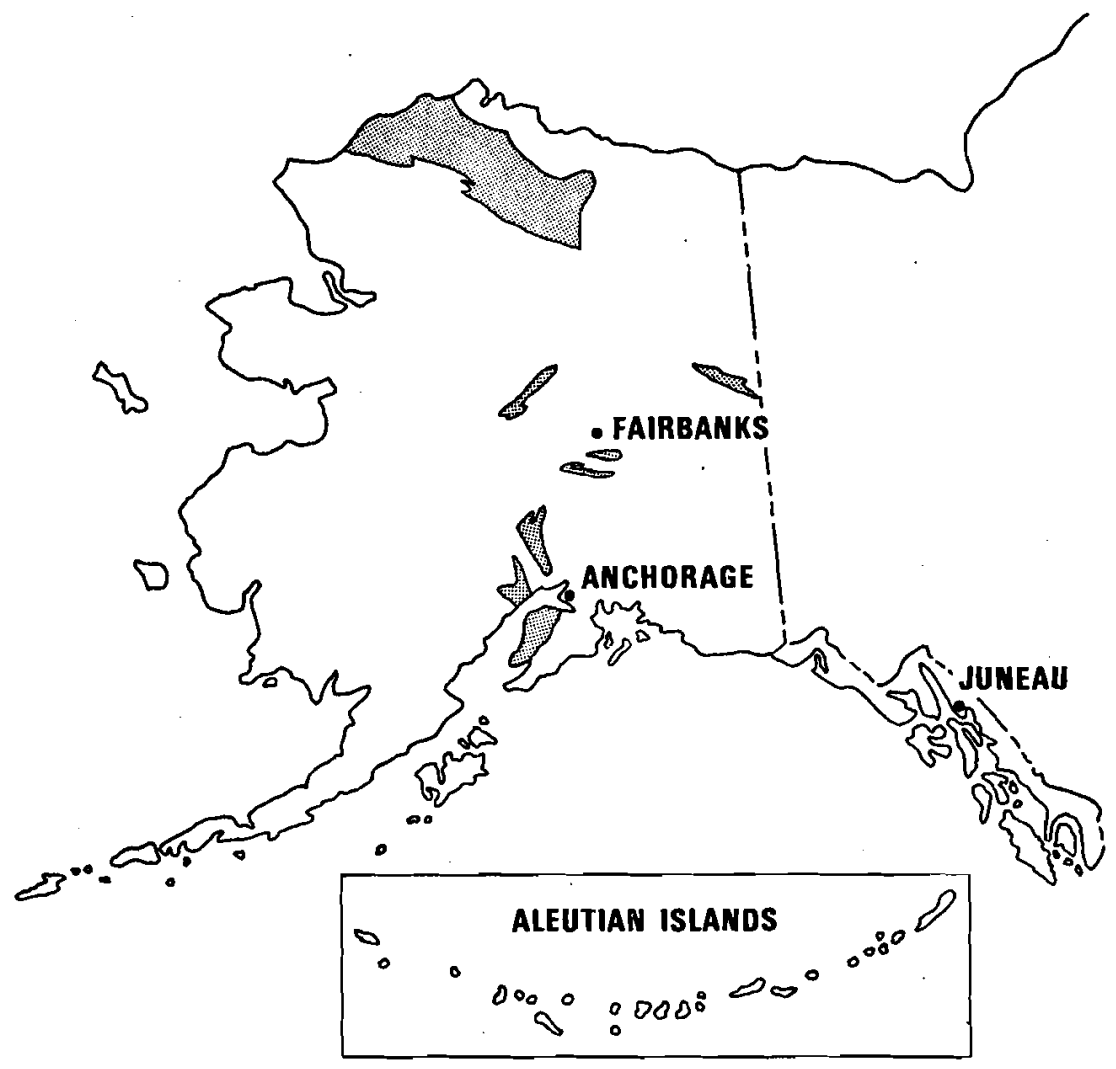

FIGURE D-1. Major Alaskan Coal Fields

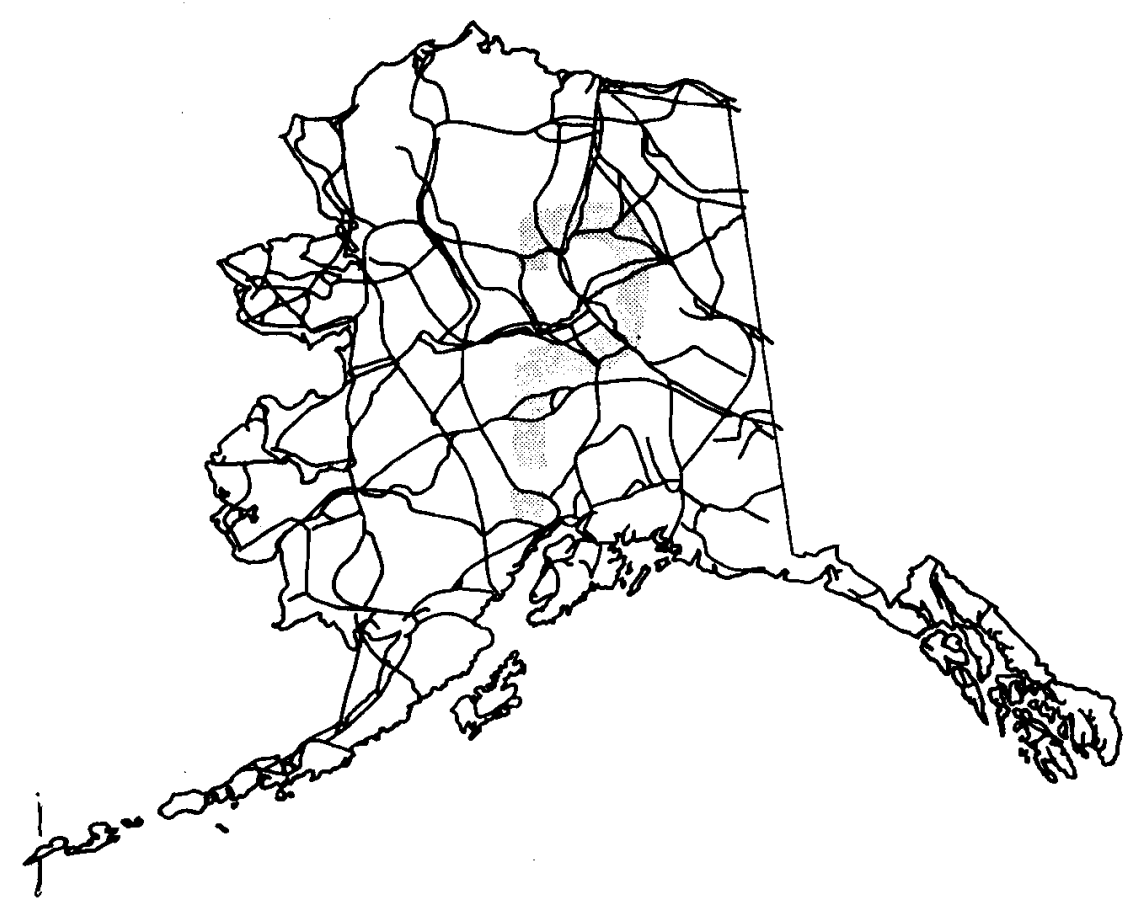

FIGURE D-2. Possible Multimodal Transportation and Utility Corridor Systems in Alaska (Taken from Reference 46) 
construction and use of railroads) are also possible, but they all ultimately need marine transport unless pipelines through Canada are to be used. This increased use of marine carriers will place greater demands on existing navigational devices and the need to install new and/or better ones to ensure safety in constricted areas such as the Cook Inlet and its entrance, the passages between the Aleutian Islands in going to and from Bristol Bay points, etc. RTGs have already been demonstrated in powering remote lighthouses, buoys and lighted buoys. The expected increased demands for navigational aids to help Alaskan resources reach commercial users elsewhere should be monitored carefully so that RTG's possibilities are properly considered.

- Joubin has identified Arctic Navigation and its development as important factors in utilizing the resources in the Arctic and High Arctic portions of Canada. (47) Petroleum is pumped from wells in the Mackenzie River Delta and extensive explorations have been made or are underway in the Arctic Islands. In 1971 estimates placed reserves in these islands at 80 to 120 billion barrels with 20 to 30 billion barrels in the Mackenzie Delta. ${ }^{(40)}$ Deposits of lead and zinc with high assays have been found in the Arctic Islands as well as in the upper reaches of the Northwest Territories. ${ }^{(47-51)}$ Some ores are being shipped in the limited ice-free period each summer. These shipments and anticipated use of the sea lanes for the transfer of ores and perhaps petroleum emphasize the need for reliable navigational systems. (51) Canadian Imperial Bank information shows that value of the output from the Yukon and Northwest Territories grew more rapidly than any other geographic area in Canada in the last 10 years. (52) A similar increase is possible in the coming decade if suitable means are available for coping with problems in the Arctic. As in the previous statements on resource development, particular attention should be directed toward the use of RTG-powered navigational equipment to help speed this development process. 
- In the late 1960 s some 200 to 300 ships were reported to be carrying 1.5 to 2.0 million metric tons of freight along the Arctic coasts of the U.S.S.R. ${ }^{(40)}$ Dark powder melting of fast ice and extensive use of icebreakers keep the Northern Sea route open for about 150 days each year. ${ }^{(40)}$ Since the Soviets are advanced in the development of their Arctic resources, particular attention should be directed toward examining their methods for powering remote navigational systems. They are known to have used RTG-powered unmanned lighthouses and may well have used other RTG systems on the Northern Sea Route. As an indication of Soviet Arctic resource development, in 1965 about 36, 16 and 43\%, respectively, of their petroleum, natural gas and coal came from that geographic area. (40) 0 ther possible uses of isotope systems in the Soviet Arctic development of their natural resources should also be examined.

- Recently, New Zealand reported the discovery of over 2 million tons of $\mathrm{NaCl}$ at the bottom of Lake Bonney in the Antarctic. (53) In the early 1970s when this deposit was discovered it was believed to be the only natural resource available in sufficient quantity or in a suitable location where it might be exploited. However, recent pressures on resources will likely speed efforts to learn more about the resources of the Antarctic. New Zealand also reports the possibilities of drilling for oil in the seas around this southern continent. (53) If Antarctic resources are developed, isotopes could play important roles in supplying power to remote navigational systems for both ships and aircraft; these possibilities should be explored and followed closely. Improved Quality of Life

The provincial/State and Federal levels of the Canadian and U.S. Governments are interested in improving the quality of life for the natives living in the North. A major impetus for this interest comes from the shortened life expectancy of the natives. In Alaska, for example, the natives' life span is about one-half of that of the residents in the "Lower 48". (54) Several agencies are actively trying to improve this situation in our model 
area of Alaska by directly reducing disease through improved medical services or, more indirectly, by eliminating pollution from excreta. The Environmental Protection Agency (EPA) is demonstrating a centralized community facility in Alaska to provide safe water and eliminate pollution. (54-57) These facilities dispense drinking water, provide saunas, laundry services and showers, and dispose of sewage collected in the village. The Public Health Service (PHS) is also involved in providing potable water and effective sewage disposal processes in addition to operating hospitals and treatment centers throughout Alaska for the natives. $(58,59)$ In contrast to the centralized facilities being demonstrated by EPA most of those installed by PHS provide sewage service to each dwelling in a village with disposal by conventional aeration lagoons and septic tanks. The Alaskan Department of Environmental Conservation is another organization involved in supplying safe drinking water to the natives and adequate disposal of sewage.

The activities of these organizations are of interest to the Cold Regions Isotope Applications Program because these agency projects and programs require heat to promote suitable degradation of sewage in most areas of Alaska and to keep potable water storage and transport systems in a liquid state. The heat required for these processes could conceptually be supplied by isotope heaters. Sterilization of the sewage might also be affected by the thermoradiation processes under development at Sandia Laboratories. $(38,60-62)$

\section{Improved Services}

Resource development activities and increased population in Cold Regions have resulted in greater demands for services. These services are provided in part by improved transportation systems, better meteorological information, and better communications networks. Demands of this nature provide potential opportunities for the application of radioisotope systems. For example, the need for increased weather data noted by Johnson and Hartman, ${ }^{(63)}$ and Hickok ${ }^{(64)}$ could provide a basis for using RTG-powered remote weather stations. The Federal Aviation Administration (FAA) provides beacons and transmitter systems to aid in the navigation of aircraft that are used for various commercial and private purposes. These too could 
potentially use RTGs for power in remote and essentially inaccessible areas of Alaska. Some of the remote native villages in Alaska have communications with larger population centers via satellite systems. However, similar service could be provided with terrestrial RTG-powered transmitter units. Early flood warning systems operated by the U.S. Army Corps of Engineers in Alaska as elsewhere in the U.S. could use RTGs for power as is reportedly planned for the Southwest. ${ }^{(65)}$ The opportunities created by demands for improved services in Alaska are not inclusive of all of the stimuli for the possible use of isotope systems created by these demands. The particular opportunities noted are indicative of the general situation resulting from these increased demands for services. It can best be used as a directive to thoroughly explore the implications of such changes so that additional possibilities might be uncovered in direct contact with people in Alaska or in other Cold Regions. It also calls for a more systematic examination of the literature with this perspective. A more detailed look at the literature should include follow-up on developments in the U.S.S.R. and Canada especially.

Factors Affecting Operations

There are a number of conditions that impose severe constraints upon operations in Cold Regions. Also, there are special situations arising from population and ethnic groups that have an effect on how programs may be conducted in parts of the area above $60^{\circ} \mathrm{N}$, especially in Alaska. A brief survey of the literature and other sources was made to provide a background on these factors so that a reasonable assessment of isotope application opportunities could be made. This background should also provide an initial informational base for the development of any follow-up activities in FY-1976 and beyond. The following is a listing of some of the important factors in Cold Regions, especially in Alaska, that would influence the demonstration and/or application of isotope systems:

- The Environment of the northern portions of Alaska and similar areas in the north is fragile. This condition has resulted in a number of 
campaigns by various environmental groups to block recent resource development activities, especially in Alaska. An excellent statement on the scientific and technical aspects of the Arctic environment was made by Sater and his coauthor. $(40,66)$

- Geography, climate, permafrost and a number of other factors impose severe constraints on construction in Cold Regions. Many of these factors are in eight articles by Eb Rice in the Northern Engineer in the period 1972-1974. (67-74) A book entitled The Ideal Arctic House is reported to be in preparation by Mr. Rice and will cover the material (and perhaps more) in the referenced articles. AINA has sponsored two workshops/conferences on building in the north. The reports covering these two conferences/workshops should be consulted for information on Arctic planning, Arctic development, housing design and construction, utilities and services, the physical environment, pollution control, energy conservation, the building process, etc. $(75,76)$ Another perspective on the construction problems in the north is given by Gant and Meeres. (77) They describe the factors involved in large-scale operations such as the construction of the Canadian Arctic Pipeline to deliver natural gas to North American markets from the MacKenzie River Valley. When contrasted with construction practice for more moderate climates, their information will provide useful insight into Arctic construction problems and operations.

- The handling and movement (logistics) of personnel and materials into and from Cold Regions require either special attention or methods that differ considerably from those normally used in the temperate and torrid zones of the world. AINA sponsored a symposium at Hershey, Pennsylvania, in 1971 that presented some of the more advanced concepts that are, or may be, useful in Arctic logistics; the proceedings of that symposium have been published and provide useful background information. (78) The design and modification of industrial vehicles for use in Cold Regions has been discussed and was summarized by the Society of Automotive Engineers (SAE) in 1968. (79) Sater et al. have briefly 
summarized the transportation systems used in the Arctic by various nations. Some of the special problems involved in handling oil spills in Cold Regions were discussed by McLeod and McLeod, (80) while the dependence on helicopters for moving loads in remote areas was described by Matthews. (81) Transportation and living problems (as well as other aspects of Arctic work) were carefully summarized by Schindler in $1974,(82)$ and the National Science Foundation (NSF) has prepared and distributed a handbook on logistics support in the $\operatorname{Arctic}^{(83)}$ to help research groups achieve their objectives.

- Weather and climate is another area of consideration as described by Sater et al. (40) and Johnson and Hartman ${ }^{(63)}$ of the Arctic and Alaska, respectively. Their publications should be consulted to acquire a general overview of climatic conditions in parts of the Cold Regions.

- The native groups, especially in Alaska, have begun to assume important roles in the development of policy, direction of emphasis and development of alternatives as they affect native living conditions, aspirations and resources within their lands. A nontechnical discussion of the Native Claims Act and its influence on Alaskan Natives can be found in a recent issue of the National Geographic Magazine. (84) At the present time native lands in the 49th state are under the control of 12 native corporations. Since these groups were primarily established along tribal lines, ${ }^{(85)}$ knowledge of the ethnic divisions in that state is useful. The information presented in Figure $0-3$ (taken from Reference 86) provides information on major language groups in Alaska. The perception of the natives as to whether they belong to one group or another is important and rests upon a large number of factors including historic relationships between Alaskan tribes. Some of the aspects of working with Canadian Natives are covered in the AINA workshops/conferences on Arctic buildings. $(76,77)$ 


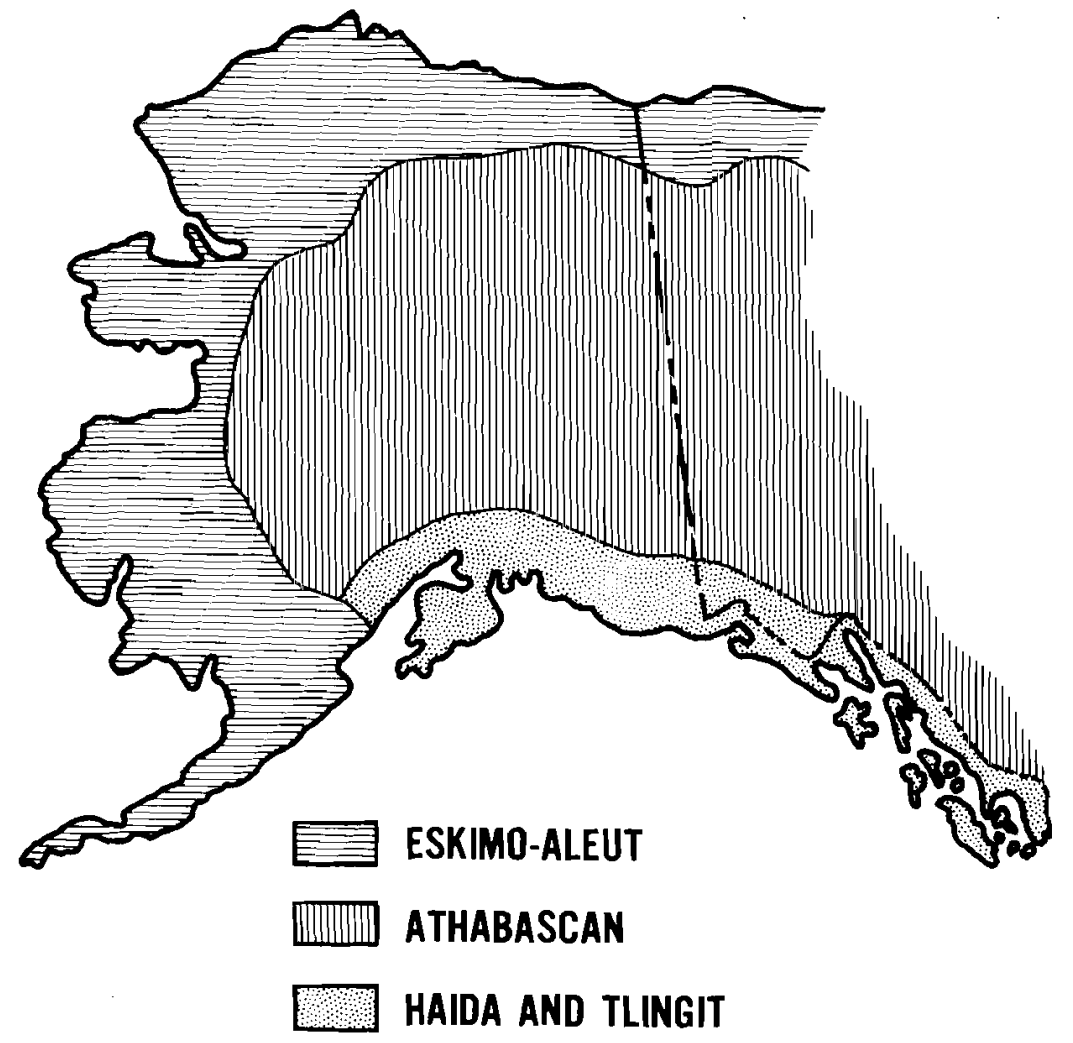

FIGURE D-3. Major Language Groups in Alaska

\section{BACKGROUND ON TECHNOLOGY TRANSFER}

Because technology transfer was expected to be an integral part of one of the research tasks on the Cold Regions Program (see Figure 1 in text), background information on this process was acquired at the same time that similar information was sought on isotopic systems and Cold Regions. The approach to the acquisition of data and the scope of work was also similar. The search of the literature was not exhaustive but rather directed toward finding enough information to define the nature of technology transfer, its key elements and current general usage of the technology transfer process. If these limited points could be achieved it was believed that this information would be sufficient to help achieve FY-1975 program objectives.

The proceedings of a conference sponsored by Battelle Memorial Institute in Seattle, Washington, in 1973 provide an excellent overview of technology 
transfer. (87) Articles discussing various aspects of this and other processes preceding this conference can be found in the literature; these, however, are not treated in this report because Manning's book and a limited number of other references should be adequate to establish the background needed for this study.

One of the definitions noted by Gabor Strasser in the U.S. Senate report on technology transfer in 1967 was selected as a working definition for this subject on the Cold Regions Program. (88) This definition reads:

"... a process of matching solutions in the form of existing science and engineering knowledge to problems in commerce or public programs ..." (89)

Important factors affecting the successful transfer of technology were discussed at the Battelle Conference and elsewhere. Those factors believed to be particularly relevant to the Cold Regions Program are:

- Emphasis should be placed on the "market pull" approach rather than on the "technology push" approach when transferring technology. (88)

This means that people involved in promoting technology transfer should know the particular needs of a potential recipient and should relate the benefits of using the new technique(s) to this need. This is in contrast to the approach of pushing interesting possibilities and asking the potential user to see what he may be able to use.

- Technology transfer should be viewed in the broadest context without limiting it to narrow technical hardware lines, even though many "payoffs" might eventually come from such lines. (88)

- The process is very dependent upon an entrepreneur to deploy the resources necessary to achieve needs. $(90,91)$ In all cases direct person-to-person dialogue is required. (92)

- Although an informational system is necessary in technology transfer, it is not sufficient to insure optimal transfer. An individual committed to the process is needed. (91) 
- A primary mechanism to help transfer technology is publication.

This can range from scientific/technical articles to technical briefs focused on specific commercial or public sector targets. The latter would generally be more effective than the former.

- Conferences involving key personnel from the target sector and the group with the technology are also useful in establishing dialogue and channels of communication. (92) Careful and systematic follow-up is needed for maximum benefit.

It should be understood that the above factors are not inclusive of all that bear on effective technology transfer, but rather those that would probably have the greatest impact on the Cold Regions technology transfer effort.

A recent report by the National Academy of Engineering (NAE) on Federal agency efforts to transfer technology contains information useful to this study. (93) Key statements on inadequacies and methods for overcoming the inadequacies follow:

- "The methods generally used by Federal agencies for transferring technology involve the passive techniques of collecting, screening, indexing, storing and disseminating scientific and technical information upon the specific request of a potential user. These methods are not fully effective because they depend upon: 1) the ability of the prospective user to define the technology he seeks, 2) the procedures used to search and identify the requested information, 3) the format in which the data is provided to the requester, as well as 4) the skill of the user in assimilating the knowledge, evaluating its relevance, and adopting the technology to meet a specific need." (93)

- "More active methods which involve personal interplay between innovators and potential users, frequently assisted by third party change agents or multidisciplinary teams, are used less often by the Federal government. When used, they tend to be more effective than passive methods. (93) 
- A more equitable balance is needed between expenditures for the collection, organization and dissemination of information and implementing technology transfer. Of the $\$ 935$ million spent in FY-1974, on information dissemination only $4.6 \%$ was directed toward the encouragement of technology utilization. (93)

- NAE found that a shift in emphasis in the dissemination of information was needed to create a broader public awareness of the existence and the availability of scientific and technical information. (93)

Al though some of NAE's comments and recommendations were blunt they indicate some of the areas where future emphasis on technology transfer activities should be placed. As such then the NAE report and the earlier information in this subsection should be used to provide a context for cold Regions Program work in this area. 


\section{APPENDIX D REFERENCES}

1. J. H. Jarrett, Radioisotope Bibliography, BNWL-1621, Battelle, Pacific Northwest Laboratories, Richland, WA, September 1971.

2. Proceedings of an International Symposium on Industrial Applications for Isotope Power Generators, AERE, Harwe11, United Kingdom, September 1966, European Nuclear Energy Agency, January 1967.

3. Proceedings on the Second International Symposium on Power from Radioisotopes, Junta de Energia Nuclear of Spain, May 29-June 1, 1972, European Nuclear Energy Agency, Paris, France.

4. W. R. Corliss and D. G. Hawey, Radioisotopic Power Generation, Prentice-Hal1, Inc., Englewood, NJ, 1964.

5. G. W. Sutton, Direct Energy Conversion, McGraw-Hil1 Book Company, NY, 1966.

6. J. G. Dempsey and P. Polishuk, editors, Radioisotopes for Aerospace: Advances and Techniques, part 1, Plenum Press, NY, 1966.

7. E. J. Wheelwright, editor, Promethium Technology, American Nuclear Society, Hinsdale, IL, 1973.

8. R. T. Carpenter, "Status of U.S. Radioisotope Space Power Systems," Isotopes and Radiation Technology, vol. 9, no. 3, Spring 1972.

9. "International Study of Terrestrial Applications of Radioisotope Power Sources," Isotopes and Radiation Technology, vol. 4, no. 2, Winter 1966-67.

10. J. G. Morse, "Isotopic Power in Europe-II," Isotopes and Radiation Technology, vol. 6, no. 1, Fall 1968.

11. F. E. McKinney, "English Colloquium on Isotopic Thermoelectric Generators," Isotopes and Radiation Technology, vol. 6, no. 2, Winter 1968-69.

12. R. P. Cope and T. P. Fleming, "U.S. Navy Radioisotopc Power Generator Program," Isotopes and Radiation Technology, vol. 9, no. 3, Spring 1972.

13. F. V. Kohl, An Isotope-Powered Automatic Weather Station, Weather Bureau, U.S. Department of Commerce Report, Washington, D.C., May 1964.

14. J. H. Morrison, Radioisotope Power Sources in Terrestrial Applications, International Nuclear Industries Fair, Basel, Switzerland, October 1969.

15. W. R. Corliss and R. L. Mead, Power from Radioisotopes, U.S. Atomic Energy Commission Booklet, Revision 1, 1971.

16. Personal Communication with G.P. Dix, DANES, ERDA, Washington, D.C., May 1975.

17. "Isotope Power Development," Isotopes and Radiation Technology, vol. 1, November 1, 1963.

18. D. N. Ness, "Summary of Recent Work by the French in the Development of Isotopic Thermoelectric Generators," Isotopes and Radiation Technology, vol. 7, no. 1, Fall 1969. 
19. "Sweden's Radioisotope-Powered Navigational Light," Isotopes and Radiation Technology, vol. 7, no. 1, Fall 1969.

20. L. Hallingren, C. G. Hjertberg and S. Ulvönäs, "The Use of Radioisotopic Thermoelectric Generators in Aids to Navigation in Sweden," (Proceedings, Reference 2).

21. H. Dolan and N. A. Lockley, "Power Supply Requirements for Low Consumption Communications Equipment," (Proceedings, Reference 2).

22. L. R. Sawyer, "Notes on the Possibility of Utilizing Isotopic Thermoelectric Generators for Powering Telecommunications Equipment," (Proceedings, Reference 2).

23. J. 0. Clark, S. D. Whiddett, R. C. Meadows and R. A. Young, "Prospects for the Use of Isotopic Power Sources in Civil Aviation Communications and Navigation Systems," (Proceedings, Reference 2).

24. W. R. Corliss, Direct Conversion of Energy, U.S. Atomic Energy Commission Booklet, 1964.

25. P. D. Dunn and J. C. Hammerton, "A Survey of Potential Dynamic Conversion Systems of Isotopic Power," (Proceedings, Reference 2).

26. H. B. van Nederveen, "The Nuclear Stirling Engine," (Proceedings, Reference 2).

27. R. A. J. 0. van Witteveen, "The Stirling Engine, Present and Future," (Proceedings, Reference 2).

28. R. Ottsen, "A Survey of the Isotope Fueled Small Rankine Cycle Power Unit," (Proceedings, Reference 2).

29. A. P. Fraas, "ORNL Isotope Kilowatt Program," Isotopes and Radiation Technology, vol. 8, no. 3, pp. 341, Spring 1971.

30. Private Communication with J. W. Anstie, Manager, Industrial Products Group Atomic Energy of Canada Ltd., Ottawa, Canada, November 1974.

31. M. L. Hermans, H. Uhlemann and C. L. Spigt, "The Combination of a Radioisotope Heat Source and a Stirling Cycle Conversion System," Madrid, Spain, 1972 (Proceedings, Reference 3).

32. R. R. Hclman and H. A. Jaspers, "A Stirling Cycle $400 \mathrm{~W}(\mathrm{e})$ Economical Radioisotope Thermodynamic Generator," a paper delivered at the ANS Meeting, Philadelphia, PA, June 24-28, 1974.

33. D. W. Bolme, The Potential of Using Mixed Fission Products as a Source of Energy, BNWL-1115, Battelle, Pacific Northwest Laboratories, June 1969.

34. G. Safonov, Military Facility Steam from Mixed Fission-Products, R\&D Associates, RDA-TR-6800-005, Santa Monica, CA, March 1975.

35. Private Communication with J. H. Jarrett, Pacific Northwest Laboratories, September 1975.

36. W. C. Triplett and W. H. Braner, Solvent Recovery of Petroleum, U.S. Patent 3,500,910, issued by U.S. Patent Office May 17, 1970. 
37. M. C. Reynolds, R. L. Hogengenber and A. C. Zuppero, Thermoradiation Treatment of Sewage Sludge Using Reactor Waste Fission Products, SAND74-100, Sandia Laboratories, Albuquerque, NM, June 1974.

38. H. D. Sivinski, "Treatment of Sewage Sludge with Combinations of Heat and Ionizing Radiation (Thermoradiation)!" paper presented at IAEA Symposium on the Use of High Fuel Radiation in Waste Treatment - Status and Prospects, IAEA-SM-194/303, Munich, Germany, March 17-21, 1975.

39. Private Communication with H. D. Swinski of Sandia Laboratories at a Meeting in Ottawa, Canada, November 1974.

40. J. E. Sater, A. G. Ronhovde and L. C. Van Allen, Arctic Environment and Resources, Arctic Institute of North America, Washington, D.C. 1971.

41. The Arctic Institute of North America Annual Report-1974, Arctic Institute of North America, Montreal, Quebec, Canada, 1974.

42. USA CRREL Technical Publications, Cold Regions Research and Engineering Laboratory Special Report 175, Hanover, NH, June 1972.

43. J. F. Schindler, "NARL-25 and Growing," Alaska (magazine), Anchorage, September 1972.

44. 1973 Keystone Coal Industry Manual.

45. A. B. Caldwe11, "Conquest of the Northwest Frontier," Mining Engineering, September 1971.

46. Multimodel Transportation and Utility Corridor Systems in Alaska - A Preliminary, Conceptual Analysis, U.S. Department of the Interior Report, Washington, D.C., October 31, 1974.

47. F. R. Joubin, "The Future of Canada's North," Engineering and Mining Journa 1, September 1969.

48. "Canada's Northland Boasts Increased Production," Engineering and Mining Journal, September 1970.

49. "World's Most Northerly Mine to Begin Shipments," Engineering and Mining Journal, pp. 44, June 1973.

50. "This Month in Mining: First Canadian Arctic Mine will Benefit Local People," Engineering and Mining Journal, pp. 40, August 1974.

51. G. H. Legg, "Ice and Transport in Arctic Canada," Proceedings of a Symposium on Arctic Logistics Support Technology at Hershey, PA, Arctic Institute of North America, May 1972.

52. "The Canadian Mining Industry," Commercial Letter, Canadian Imperial Bank of Commerce, Issue No. 2, 1975.

53. "Exploration Roundup-Antarctic," Engineering and Mining Journal, Apri1 1974.

54. D. J. Wright, Integrated Utilities for Remote Alaskan Villages, Proceedings: Waste Water Treatments on Cold Climates, Symposium by Environmental Canada and the University of Saskatchewan, Saskatoon, Saskatchewan, August 22-24, 1973.

55. Alaska Village Demonstration Projects, EPA Report to the Congress, July 1, 1973. 
56. B. Puchtter, Social and Economic Implications of the Alaskan Village Demonstration Projects, EPA Working Paper No. 20, College, Alaska, 0ctober 1973.

57. B. H. Reid, Alaska Village Demonstration Projects, First Generation of Integrated Utilities for Remote Communities, EPA Working Paper No. 22, College, Alaska, October 1973.

58. Personal Communication with Fred Reiff, Director, U.S. Public Health Service, Anchorage, Alaska, September 1974-June 1975.

59. Personal Communication with William Ryan, Director, U.S. Public Health Service, Anchorage, Alaska, September 1974-June 1975.

60. J. P. Brannen, D. M. Garst and S. Langley, Inactivation of Ascaris Lumbricoides Eggs by Heat Radiation and Thermoradiation, SAND-75-0163, Sandia Laboratories, Albuquerque, NM, JuTy 1975.

61. Progress Report: Waste Resource Utilization Program Period Ending June 30, 1975, SAND-75-0436, Sandia Laboratories, A1buquerque, NM, August 1975.

62. Progress Report: Beneficial Uses Program Period Ending June 30, 1975, SAND-75-0435, Sandia Laboratories Report, ATbuquerque, NM, September 1975.

63. P. R. Johnson and C. W. Hartman, Environmental Atlas of Alaska, University of Alaska, College, Alaska, 2nd Edition, January 1971.

64. Personal Communication with David Hickok, Director, Arctic Environmental Information and Data Center, University of Alaska, Anchorage, Alaska, September 1974.

65. Personal Communication with Homer Musselman, MEROC, U.S. Corps of Engineers, Ft. Belvoir, VA, August 1974.

66. Man's Impact on Arctic and Subarctic Environments, Arctic Institute of North America in Cooperation with the American Institute of Biological Sciences, Washington, D.C., June 1974.

67. E. Rice, "Permafrost: Its Care and Feeding," The Northern Engineer, University of Alaska, Fairbanks, Alaska, vol. $\overline{4, \text { no. 2, Winter } 1972 .}$

68. E. Rice, "Northern Construction: Siting and Foundations," The Northern Engineer, vol. 5, no. 1, Spring 1973.

69. E. Rice, "The Ideal Arctic House - II: Walls, Windows, Doors and Floors," The Northern Engineer, vol. 5, no. 2, Summer 1973.

70. E. Rice, "Heating the Ideal Arctic House - III," The Northern Engineer, vol. 5, no. 3, Fall 1973.

71. E. Rice, "Vapor Barriers," The Northern Engineer, vol. 5, no. 4, Winter 1973-1974.

72. E. Rice, "Windows," The Northern Engineer, vol. 6, no. 1, Spring 1974.

73. E. Rice and A. Otter, "Water Supply in the North," The Northern Engineer, vol. 6, no. 2, Summer 1974.

74. E. Rice and A. Otter, "Waste Management in the North," The Northern Enqineer, vol. 6, no. 4, Winter 1974-1975. 
75. M. Glover, Editor, A Report on a Conference - Workshop: Building in Northern Communities, held at the Université de Montreal, May 7-11, 1973, AINA, Montreal, Canada, January 1974.

76. M. Glover, Editor, A Report on a Conference - Workshop: Building in Northern Communities, held at Inuvik, N.W.R., Canada, February 10-15, 1975, AINA, Montreal, Canada, June 1974.

77. W. Gant and R. Meeres, "Construction Problems Facing the Canadian Arctic Gas Pipeline," Pipeline and Gas Journal, vol. 200, no. 8, July 1973.

78. B. F. Slocum, Editor, Proceedings of a Symposium on Arctic Logistics Support Technology, he1d at Hershey, PA, November 1-4, 1971, Arctic Institute of North America, Alaska, May 1972.

79. Design and Modifications of Industrial Vehicles for Operation at Low Temperatures, SAE Construction and Industrial Machinery Technical Committee Report No. SP-346, New York, NY, December 1968.

80. W. R. McLeod and D. L. McLeod, "Measures to Combat Arctic-Subarctic 0i1 Spills," Journal of Petroleum Technology, March 1974.

81. S. Matthews, "Helicopters: The Arctic Workhouses," Pipeline and Gas Journal, July 1974.

82. J. F. Schindler, "What's It Like to Live and Work in Arctic Alaska," Pipeline and Gas Journal, July 1974.

83. Arctic Research Logistics Support Handbook, National Science Foundation, Washington, D.C., December 1972.

84. J. Judge, "Alaska Rising Northern Star," National Geographic, vol. 147, no. 6, June 1975.

85. Comments in an address by P. Eaton, The Alaskan Native Foundation, Anchorage, Alaska, at the Annual Meeting of AINA, Toronto, Ontario, Canada, May 20, 1974.

86. A. Arlotto, Introduction to Historical Linguistics, Houghton Mifflin Company, Boston, 1972.

87. G. K. Manning, Editor, Technology Transfer: Successes and Failures, San Francisco Press, Inc., San Francisco, CA, 1974.

88. G. Strasser, "Keynote Address - Technology Transfer Revisited," Technology Transfer: Successes and Failures, San Francisco Press, Inc., San Francisco, CA, 1974.

89. The Science Policy Research Division, Legislative Reference Service, Library of Congress, Policy Planning for Technology Transfer, Report of the Subcommittee of science and Technology to the Select Committee on Smal1 Business, U.S. Senate, April 6, 1967.

90. L. A. Cox, "Transfer of Science and Technology in Successful Innovation," Forest Products Journal, vol. 24, no. 9, September 1974. 
91. W. T. Knox, "Information Systems in Technology Transfer, Technology Transfer: Successes and Failures, San Francisco Press, Inc., San Francisco, CA, 1974.

92. J. M. Carlson, "Technology Transfer - the NASA Perspective," Technology Transfer: Successes and Failures, San Francisco Press, Inc., San Francisco, CA, 1974.

93. National Academy of Engineering, Technology Transfer and Utilization: Recommendations for Redirecting the Emphasis and Correcting the Imbalance, PB-232-123, National Science Foundation, February 1974. 


\section{APPENDIX E}

COLD REGIONS RADIOISOTOPE GENERATOR PROGRAM PRELIMINARY ECONOMIC ANALYSIS 
APPENDIX E

\section{COLD REGIONS RADIOISOTOPE GENERATOR PROGRAM - PRELIMINARY ECONOMIC ANALYSIS \\ by}

T. E. Divine

This preliminary economics analysis is a first attempt to identify and characterize the reasons why radioisotope generators are expensive to produce and use. The scope of the inquiry is based on an engineeringeconomic system's approach. Specifically, it is a first order analysis of estimated costs of use as they are related to power ratings of the generators and to generic types of competing power units (diesel-electric generator sets, etc.). Estimated capital, operating and total annual costs of production and use have been identified. Selected cost elements have also been analyzed in terms of their sensitivity to improvements which would bring the costs of using isotope generators in line with those of competing systems. This approach provides an economic measure of the improvements required in the production and use of this technology before its market acceptability can be insured.

The present analysis must be considered only as an example. Any choice of systems should be made on a more detailed analysis which would include important factors such as the following:

- System Purchase Price: The purchase price of a $500 \mathrm{~W}$ radioisotopic thermoelectric generator (RTG) in the present example was taken as $\$ 500,000$ from a 1972 report. (1) Since 1972, increased regulations for licensing an RTG and increased fuel costs may have forced this figure upward significantly.

- Method of Payment: The present example is based on private industrial purchase and use of these systems which implies interest charges and 
profits. Governmental use of these devices may have significantly different economics if cash were paid or no profit were required. (Since an RTG has a relatively high initial purchase price, governmental use may make RTGs more economically competitive.)

- Transportation: The present example is based on 600-mile transport by chartered carrier (plane, helicopter, etc.). The report by McCoy, (1) from which the transport cost data was taken, considers other distances and indicates RTGs are more cost competitive at longer distances due mainly to the refueling charges of the organic-fueled systems. A detailed analysis would need to be location/transport mode specific.

\section{ENGINEERING-ECONOMIC SYSTEMS PHILOSOPHY}

We wish to answer the question, "Why don't people use more radioisotope generators?" One method of developing suitable answers to this question is to analyze this technology in terms of three groups of factors affecting its adoption: 1) technical, 2) economic and 3) sociopolitical. This grouping of factors is arbitrary and is selected because this is one usefur method of classifying various aspects of our technological activities. These independent-dependent relationships are best characterized as shown in the matrix format of Figure E-1.

The three components that make up our concept of the economics of adoption of technology are identified in the cross-hatched column of the matrix. These components consist of: 1) the costs of production of isotope generators, 2) the relative costs of using isotope generators in competition with other small-unit power systems and 3) the licensing and regulatory costs associated with the new technology. These are, respectively, the technical, economic, and socio-political variables to the economic function of technology. Each of these components will be discussed in the following analysis. 


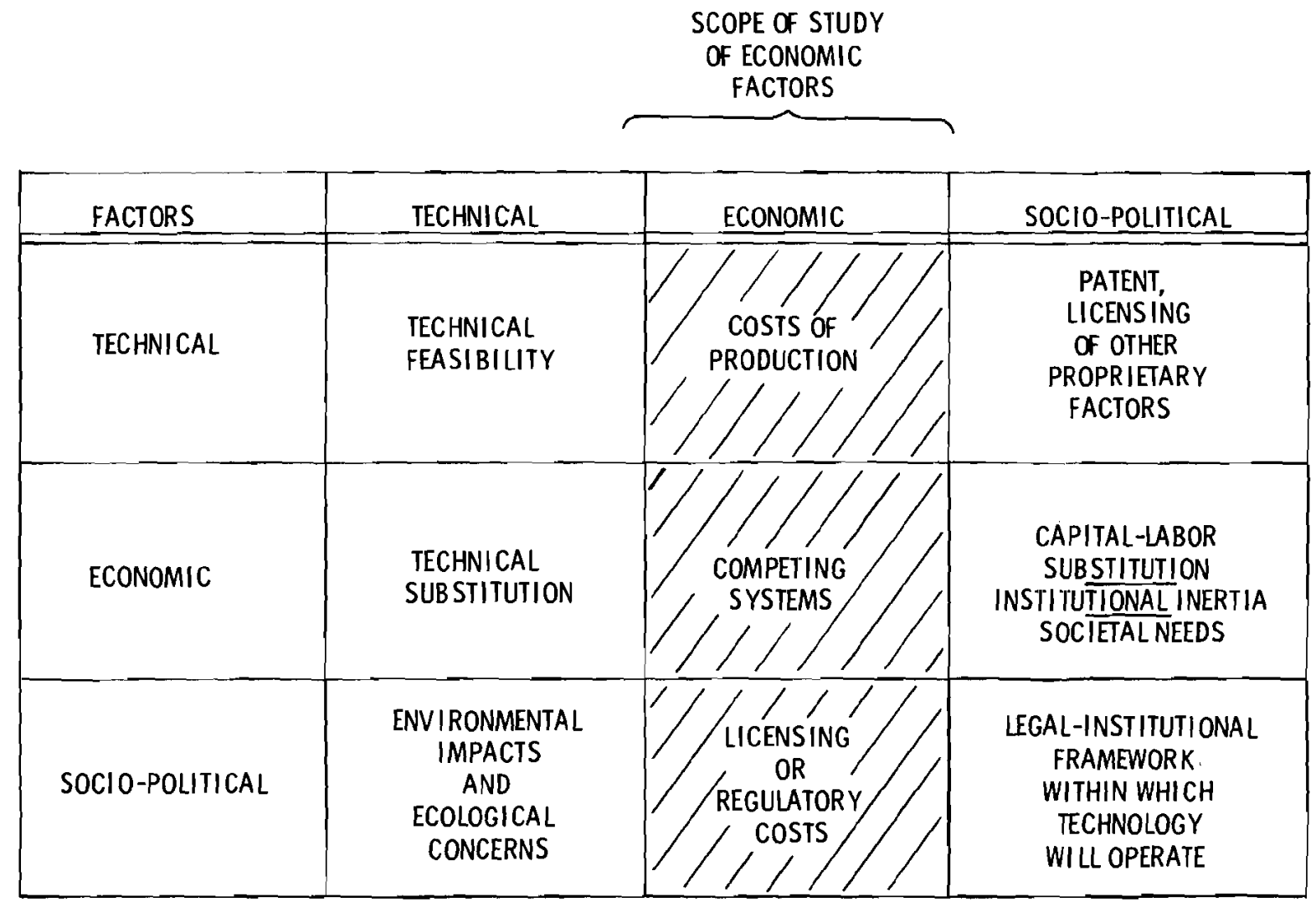

FIGURE E-1. Engineering-Economic Systems Classification of Factors Affecting Adoption of Technology

\section{ENGINEERING-ECONOMIC SYSTEMS ANALYSIS}

Specific objectives to be achieved as a result of our analysis are: 1) to relate costs of production and use of isotope generators to their technical capacity to perform a given job, 2) to compare costs of competing power sources on a consistent basis, and 3) to see the contribution to costs made by each major stage in production and use so as to identify areas where improvements might be made. These objectives can be accomplished by:

1) developing estimates of capital and operating costs of various types and sizes of units to allow computation of a total annual cost per installed unit;

2) classifying known costs into major contributing cost categories on total and unit bases in order to develop capital and operating cost estimates; 
3) identifying changes in technical, economic, and socio-political factors which might have a significant impact on major cost categories to include specifically the learning curve effect on production costs of production line quantities of generator units.

Subsequent studies can further improve this cost analysis by adding greater detailed examination of contributing factors affecting each of the major cost categories identified.

\section{Annual Costs of Using Isotope Generators}

The information used in deriving annual costs estimated for using isotope generators has been 1 imited to data and charts made available from ERDA, reports by industrial firms to ERDA agencies, reports by private industrial firms, and cost data and information acquired from individuals interviewed or contacted during the course of the field survey made in the first part of the program. In order to reconcile the disparate nature of the information, a factored cost estimating technique has been used to estimate capital, operating, and equivalent total annual costs of using radioisotope generators (see Tables E-1 through E-4). This technique is widely used in engineering cost studies for industrial plant and equipment. Fundamentals of this approach to cost estimation are given in Peters and Timmerhaus. (2)

The total equivalent annual cost method has been selected as a consistent means for comparing alternative power systems. This approach accounts for capital costs, operating costs, and return on investment considerations. Subsequently, sensitivity of total annual costs of use to variations in equipment costs, fuel costs, licensing costs, etc., can be defined. The total equivalent annual cost method is well developed in Grant and Ireson, (3) while sensitivity analysis, in terms of annual costs at the firm and industry level, is discussed in Baumol, Chapter 19. (4) The engineering-economic systems approach taken here welds these related techniques into a useful tool for economic problem definition from the user or customer point of view. 
TABLE E-1. Estimated Capital costs for RTG User, $\$ 1,000$ s

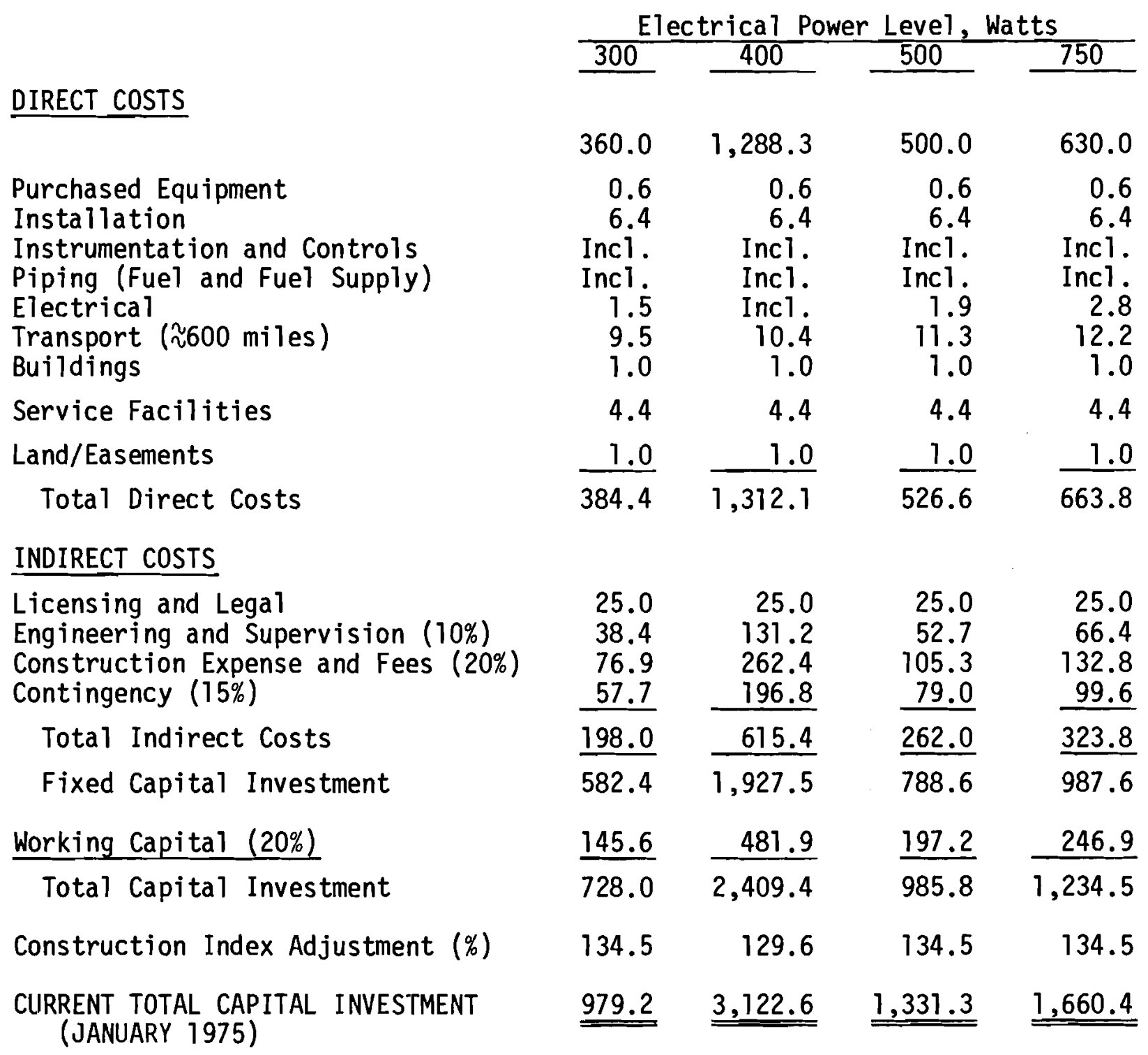


IABLE E-2. Estimated Operating Costs for RTG User, $\$ 1,000$ s

Electrical Power Leve1, Watts

\begin{tabular}{|c|c|c|c|}
\hline 300 & 400 & 500 & 750 \\
\hline - & - & - & - \\
\hline $0 . \overline{3}$ & $0 . \overline{3}$ & $0 . \overline{3}$ & 0.3 \\
\hline $\begin{array}{l}4.0 \\
\text { Inc1. } \\
\text { Inc1 } \\
\text { Inc1 } \\
\text { Incl. }\end{array}$ & $\begin{array}{l}4.0 \\
\text { Incl. } \\
\text { Incl. } \\
\text { Incl. } \\
\text { Incl. }\end{array}$ & $\begin{array}{l}4.0 \\
\text { Incl. } \\
\text { Incl. } \\
\text { Incl. } \\
\text { Incl. }\end{array}$ & $\begin{array}{l}4.0 \\
\text { Incl. } \\
\text { Incl. } \\
\text { Incl. } \\
\text { Incl. }\end{array}$ \\
\hline $\begin{array}{r}5.8 \\
5.8 \\
\end{array}$ & $\begin{array}{l}19.3 \\
19.3 \\
\end{array}$ & $\begin{array}{l}7.9 \\
7.9 \\
\end{array}$ & $\begin{array}{r}9.9 \\
9.9 \\
\end{array}$ \\
\hline 15.9 & 42.9 & 20.1 & 24.1 \\
\hline
\end{tabular}

INDIRECT COSTS

Support Facility Overheads (50\%)

Interest Expense

$\begin{array}{llll}2.0 & 2.0 & 2.0 & 2.0\end{array}$

Administrative Expenses (15\%)

Total Operating Costs

$\begin{array}{llll}0 . \overline{6} & \overline{6} & \overline{6} & 0 . \overline{6}\end{array}$

$\begin{array}{llll}0.6 & 0.6 & 0.6 & 0.6\end{array}$

$\frac{2.6}{18.5} \quad \frac{2.6}{45.5} \quad \frac{2.6}{22.7} \quad \frac{2.6}{26.7}$

Cost Index Adjustment (\%)

$\underline{134.5} \quad \underline{129.6} \quad \underline{134.5} \quad \underline{134.5}$

CURRENT TOTAL OPERATING COSTS

(JANUARY 1975)

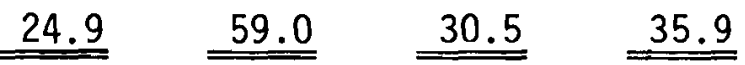


TABLE E-3. Estimated Capital Costs for User of Alternative Smal1 Power Sources, \$1,000s

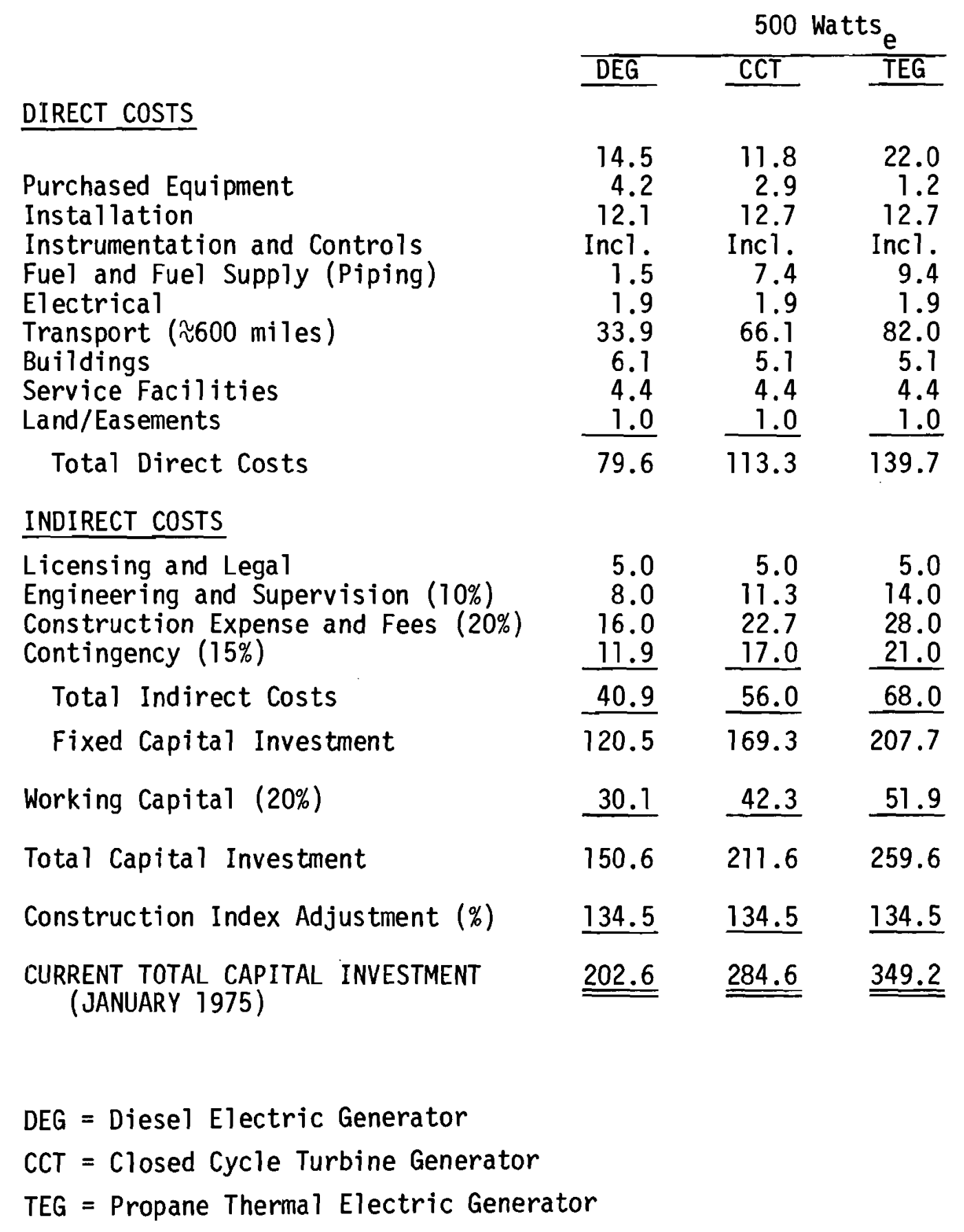


TABLE E-4. Estimated Operating Costs for User of Alternative Smal1 Power Sources, $\$ 1,000$ s

\begin{tabular}{|c|c|c|c|}
\hline \multirow{3}{*}{ DIRECT COSTS } & \multirow[b]{2}{*}{ DEG } & \multicolumn{2}{|c|}{500 watts $\mathrm{e}$} \\
\hline & & CCT & \multirow[t]{2}{*}{ TEG } \\
\hline & & & \\
\hline $\begin{array}{l}\text { Fuel } \\
\text { Fuel Resupply } \\
\text { Spare Parts } \\
\text { Maintenance/Support and Transport } \\
\text { Refueling } \\
\text { Spares Replacement } \\
\text { Overhaul (5th year) } \\
\text { Emergency Services } \\
\text { Local Taxes }(1 \%) \\
\text { Insurance }(1 \%)\end{array}$ & $\begin{array}{r}\text { Incl. } \\
15.2 \\
1.6 \\
31.8 \\
0.6 \\
3.0 \\
\text { Inc } 1 . \\
\text { Incl. } \\
0.8 \\
0.8 \\
\end{array}$ & $\begin{array}{r}\text { Incl } \\
45.2 \\
0.6 \\
15.9 \\
2.4 \\
3.2 \\
2.1 \\
\text { Inci. } \\
1.1 \\
1.1 \\
\end{array}$ & $\begin{array}{r}\text { Incl } \\
56.8 \\
0.8 \\
11.9 \\
3.0 \\
3.2 \\
4.9 \\
\text { Inci. } \\
1.4 \\
1.4 \\
\end{array}$ \\
\hline Subtotal & 53.8 & 71.6 & 83.4 \\
\hline \multicolumn{4}{|l|}{ INDIRECT COSTS } \\
\hline $\begin{array}{l}\text { Support Facility Overheads }(50 \%) \\
\text { Interest Expense } \\
\text { Administrative Expenses (15\%) }\end{array}$ & $\begin{array}{r}15.9 \\
\text { Inci. } \\
\quad 4.8 \\
\end{array}$ & $\begin{array}{r}7.8 \\
\text { Inci. } \\
2.4 \\
\end{array}$ & $\begin{array}{r}6.0 \\
\text { Inc } 1 . \\
1.8 \\
\end{array}$ \\
\hline Subtotal & 20.7 & 10.2 & 7.8 \\
\hline Total Operating Costs & 74.5 & 81.8 & 91.2 \\
\hline Cost Index Adjustment (\%) & 134.5 & 134.5 & 134.5 \\
\hline $\begin{array}{l}\text { CURRENT TOTAL OPERATING COSTS } \\
\text { (JANUARY 1975) }\end{array}$ & 100.2 & $\underline{110.0}$ & 122.7 \\
\hline
\end{tabular}




\section{Relative Costs of Using RTGs}

Total annual costs of using Radioisotope Thermoelectric Generators (RTGs) have been estimated for a typical remote cold region application. Four sizes of units at power ratings of $300,400,500$ and 750 watts $\left(W_{e}\right)$ have been used as examples. In addition, three competing technology power units are used for comparison. These units are specified at the 500-W power level and consist of a diesel-electric generator (DEG), a propane closed-cycle turbine generator (CCT), and a propane-fueled thermoelectric generator (TEG). All four types of generator units are assumed to be comparably equipped for temporary power storage, component heating, and redundancy, representing the best existing level of engineering technology and functionally, the same power unit capability.

Total equivalent annual costs for the four sizes of RTGs are given in Table E-5. In addition to the absolute dollar amounts, unit costs per

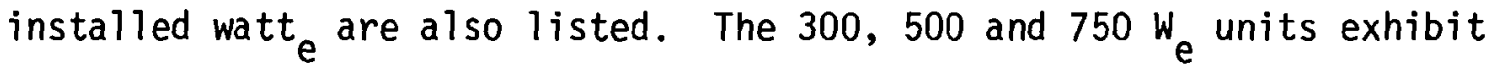
linear relationship such that higher power levels are inversely proportional to total annual equivalent costs both in absolute costs and unit costs. The rate of decrease is on the order of $\$ 73 / 100 \mathrm{~W}_{e}$ increase in power. This linear relationship is a direct result of the linear capital or equipment cost estimate for the power unit alone. This cost estimate was based on the results interpreted from a private industrial study of Cold Regions RTGs. (1) Since the basic design of the power unit does not change over this range, the rate of decrease does not seem out-of-keeping with scale assumptions. That is, the fabrication labor for a $300 \mathrm{w}_{\mathrm{e}}$ unit should be about the same for a $750 \mathrm{~W}_{\mathrm{e}}$ unit with material costs increasing, but at a decreasing rate, thus giving rise to production economies of size.

The anomaly occurs for the $400 \mathrm{w}_{e}$ unit. Our estimate resulted in a unit cost of $\$ 2.33$ thousand/ $w_{e}$ of power which is solely a reflection of the extraordinary capital cost of equipment based on a space systems application. The capital costs are derived from Reference 5. Specifically, total annual costs of using a space systems design RTG in a Cold Regions terrestrial application could cost $2-1 / 3$ times as much as an RTG unit assumed to 
TABLE E-5. Estimated Total Equiyajent Annual Costs

for RTG User, $\$ 1,000(a)$

Capital Costs, Total

Annualized Capital Costs (b)

(10 yr, 25\%, $0.28007 \mathrm{crf}$ )

Tota1 Operating Costs

Total Equivalent

Annual Costs

Tota1 Equivalent Annual Cost/We

Equivalent Cost/kW $\mathrm{e}^{-h r}$

$\frac{\text { Electrical Power Level, } W}{\frac{300}{979.2}} \frac{400}{3,122.6} \frac{\frac{500}{1,331.3}}{\frac{750}{1,66}}$

$\begin{array}{llll}274.2 & 874.6 & 372.9 & 465.0\end{array}$

\begin{tabular}{l}
$24.9 \quad 59.0 \quad 30.5 \quad 35.9$ \\
\hline
\end{tabular}

299.1

933.6

403.4

500.9

1.00

2.33

0.81

0.67

0.114

0.266

0.076

(a) Converted to current (January 1975) dollars.

(b) Capital recovery over 10 years at $25 \%$ internal rate of return to account for interest costs on invested capital $(\approx 10 \%)$ and net profits $(\approx 15 \%)$ before income taxes.

be designed for the specific location/application. ${ }^{(c)}$ This assumption is not evident from previous estimates with in the ERDA contractors where cost comparison charts essentially equilibrate space and Cold Regions applications under categories such as "with significant environmental restraints". The comparison of cost estimates for space and Cold Regions application as shown in Table E-1 should indicate that these two applications cannot necessarily be assumed to impose equivalent design constraints and hence cost constraints. Weights of power units due to such design constraints may be the principal factor in these disparate estimates.

(c) The SNS study contained a very detailed development of capital costs of RTGs in quantities of 10 and 20 production lots. The private industrial study contained no such detailed engineering-cost analysis. Hence, greater credence can be attached to the space application estimate and much less can be attached to the industry cold regions equipment cost estimate. However, a separate verbal estimate for a cold regions RTG was received from industry at about the $\$ 500,000$ level so that some corroboration of the Cold Regions RTG estimate has been acquired. 
Total annual costs have been estimated for competing technology power units using the same method as that for RTGs; these costs (both absolute and unit costs) are given in Table E-6. Assuming that the costs for Cold Region RTGs are relatively accurate in comparison with alternate power units, it is evident that costs of using RTGs must be reduced by a factor of over 2 to bring RTGs to a competitive cost position with respect to existing power unit technology. That is, at the $500 \mathrm{~W}_{e}$ power level, total annual costs to the user of an RTG is estimated to be $\$ 0.81$ thousand/ $W_{e}-y r$, while the CCT power unit is estimated to cost the user only $\$ 0.38$ thousand $/ W_{e}-y r$.

\section{TABLE E-6. Estimated Total Equivalent Annual Costs} for Alternative Sma11 Power Sources, $500 \mathrm{~W}_{\mathrm{e}}$

\begin{tabular}{|c|c|c|c|c|}
\hline & $D E G$ & CCT & TEG & RTG \\
\hline Capital Costs, Total & 202.6 & 284.6 & 349.2 & $1,331.3$ \\
\hline $\begin{array}{l}\text { Annualized Capital Costs(b) } \\
(10 \mathrm{yr}, 25 \%, 0.28007 \mathrm{crf})\end{array}$ & 56.7 & 79.7 & 97.8 & 372.9 \\
\hline Total Operating Costs & 100.2 & 110.0 & 122.7 & 30.5 \\
\hline $\begin{array}{l}\text { Total Equivalent } \\
\text { Annual Costs }\end{array}$ & 156.9 & 189.7 & 220.5 & 403.4 \\
\hline $\begin{array}{l}\text { Total Equivalent Annual } \\
\text { Cost/We }\end{array}$ & 0.31 & 0.38 & 0.44 & 0.81 \\
\hline Equivalent $\operatorname{Cos} t / k W_{e}-h r$ & 0.035 & 0.043 & 0.050 & 0.092 \\
\hline
\end{tabular}

(a) Converted to current (January 1975) dollars.

(b) Capital recovery over 10 years at $25 \%$ internal rate of return to account for interest costs on invested capital $(10 \%)$ and net profits before income taxes $(15 \%)$.

It is appropriate at this point to ask: "Which factors will contribute to a lowering of the costs of using an RTG?" 


\section{REVERSE SENSITIVITY ANALYSIS}

Determination of the impact on design objectives of an incremental change in an input to a process, design, or model is termed sensitivity analysis. To answer the rhetorical question posed above, the reverse procedure needs to be used, i.e., in order to reach our competitive cost objective, what incremental changes in RTG costs are required?

There are four elements in our cost estimates which, given significant departures from their current estimated values, may greatly alter the gap between RTG costs and competing power unit costs:

- The potential impact of engineering design and manufacturing technology on lowering the costs of RTG generator equipment,

- The potential impact of significant advances in fuel costs for diesel and propane power units in the face of only moderate increases in costs of isotope fuels. Such action may significantly narrow the annual cost gap between isotope and alternative generator systems,

- The potential impact of a reduction in regulatory-licensing costs of using isotope generators to the same level of costs of environmental impact review necessary for using existing technology power units (DEGs, CCTS, TEGs),

- The potential impact of extraordinary equipment failures by isotope generators with normal failures assumed for diesel and propane fueled power units.

The first three cases above involve changes which would favor narrowing of the cost gap between RTGs and alternative power units; the fourth case could have a detrimental effect. The impact of each of these potential incremental changes will be discussed in the next subsection. In addition, the net effect of concurrent combinations of these changes will be identified in order to establish likely boundary conditions or reasonable upper and lower limits to results of these changes. The discussion in all cases will be based on the $500 \mathrm{~W}_{\mathrm{e}}$ power unit. 


\section{Lower RTG Equipment Costs}

In order to lower annual unit costs from $\$ 0.81$ thousand/ $W_{e}$-year to $\$ 0.38$ thousand/ $W_{e}$-year, base year purchase costs of RTGs must decrease from $\$ 5 C 0,000 / R T G$ to $\$ 351,000 / R T G$. This implies a required cost reduction of about $30.8 \%$ (see Table E-7 for derivation of costs sensitive analys is formulae and results). It is feasible to assume that this can occur by the following conditions.

Industry has found that for complex equipment systems such as airplanes, large machine tools, etc., which have a high value per equipment unit, a learning curve effect takes place when these units are placed under a production line regimen. (a) The result of the learning curve effect is that for a doubling of the number of equipment units produced, unit costs of production are expected to be reduced by a certain percentage (30\%). Given this result, one would say that the production system is on a $70 \%$ learning curve. It is also well known that the rate of decrease in production costs decreases as the number of units produced increase. A limit is reached beyond which unit costs do not decline. However, in cases where the item being manufactured is based on new technology and single or small quantity fabrication, learning curve effects typically play a significant part. This is not to say that there may not also be manufacturing cost savings by production line methods applied to radioisotope equipment.

Assuming that a learning curve effect is attainable for RTG production, then what are the alternatives for attaining 30\% lower costs in production? Additionally, what would be an expected average sales price to the user of an RTG system?

\section{Average RTG Sales Price}

Let us assume that the producer of RTGs wishes to provide an average sales price to potential users for at least a given production run. This price is to include all production and overhead costs and expected profits.

(a) This is related to another way of interpreting the diminishing marginal product principle of microeconomic theory. See Reference 6. 
TABLE E-7. Derivation of Formulae for Cost Sensitivity Analysis

Nomenclature:

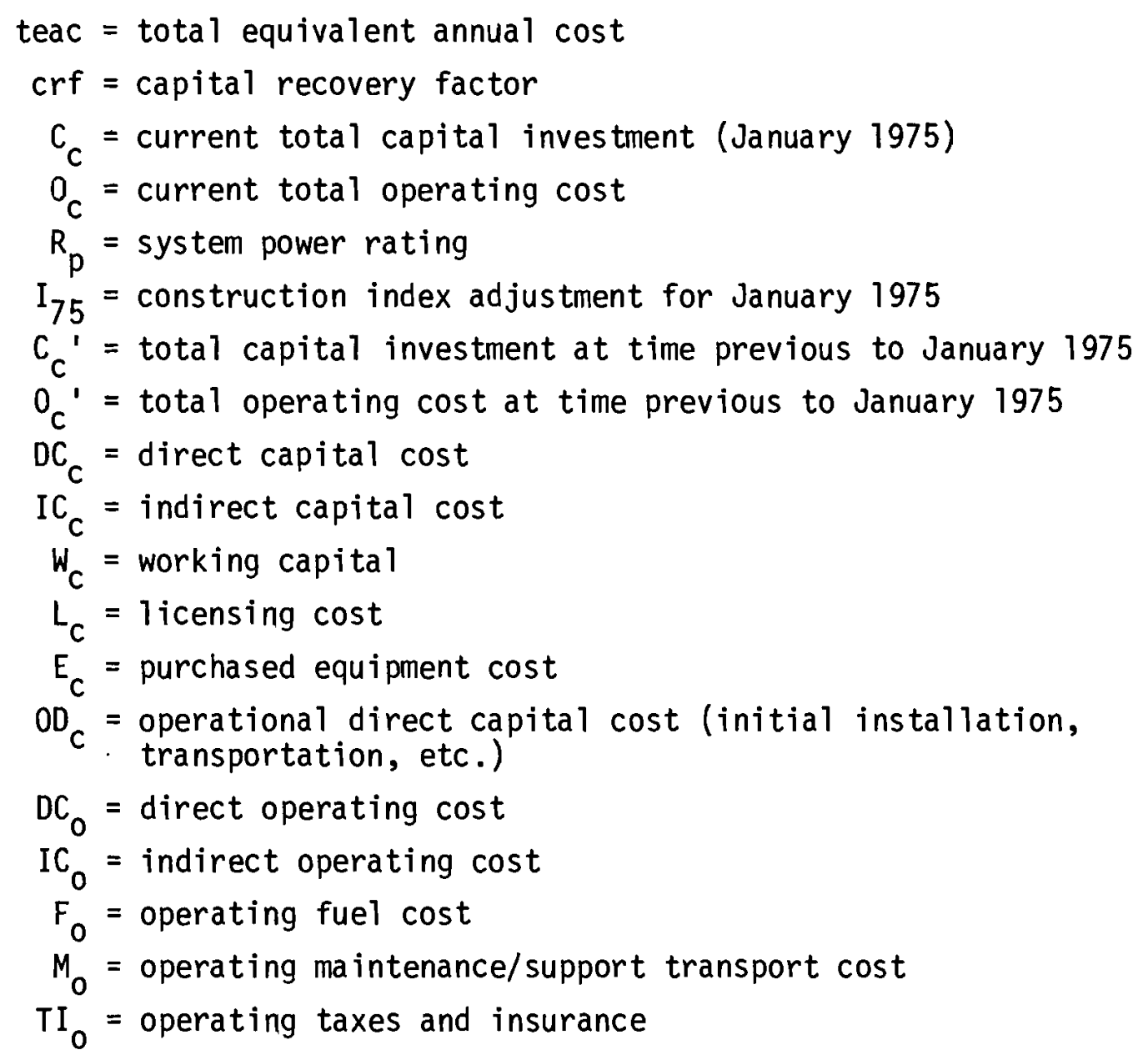

Note: "c" subscript refers to "capital" item.

"o" subscript refers to "operating item.

\section{Equipment Cost in Terms of Total Equivalent Annual Cost}

Per Unit of Power

(The relationships between various terms can be found in Tables E-1 through E-4.)

$$
\text { teac }=\left[\operatorname{crf} c_{c}+0_{c}\right] / R_{p}
$$


TABLE E-7. (contd)

$$
\begin{aligned}
& =\left[\operatorname{crf} C_{c}{ }^{\prime}+0_{c}{ }^{\prime}\right]\left(I_{75}\right) / R_{p} \\
& =\frac{I_{75}}{R_{p}} \operatorname{crf} C_{c}{ }^{\prime}+\frac{I_{75}}{R_{p}} 0_{c}{ }^{\prime} \\
& =k\left[\operatorname{crf} C_{c}{ }^{\prime}+0_{c}{ }^{\prime}\right], \text { where } k=\frac{I_{75}}{R_{p}}
\end{aligned}
$$

Development of each term in the brackets separately,

$$
\begin{aligned}
& k \operatorname{crf} C_{c}{ }^{\prime} \equiv k_{1} C_{c}{ }^{\prime} \text {, where } k_{1}=k(c r f) \\
& \equiv k_{1}\left[D C_{C}+I C_{C}+W_{C}\right] \\
& =k_{1}\left[D C_{C}+I C_{C}+\left(\frac{D C_{C}+I C_{C}}{.8}\right)\right] \\
& =\frac{k_{1}}{.8}\left[1.8\left(D C_{C}+I C_{C}\right)\right] \\
& =2.25 k_{1}\left(D C_{C}+I C_{C}\right) \\
& =k_{1}{ }^{\prime}\left(D C_{C}+0.65 D C_{C}+L_{c}\right) \text {, where } k_{1}{ }^{\prime}=2.25 \\
& =k_{1}{ }^{\prime}\left(1.65 D C_{C}+L_{C}\right) \\
& =k_{1}^{\prime}\left[1.65\left(E_{C}+O D C_{C}\right)+L_{c}\right]
\end{aligned}
$$

Thus,

$k \operatorname{crf} C_{C}{ }^{\prime}=2.25 \mathrm{crft} k\left(1.65 E_{C}+1.650 D C_{C}+L_{c}\right)$

For the second term in (2),

$$
\begin{aligned}
k 0_{C}^{\prime} & \equiv k\left(D C_{0}+I C_{0}\right) \\
& =k\left[\left(F_{0}+M_{0}+T I_{0}\right)+\left(0.65 M_{0}\right)\right] \\
& =k\left[F_{0}+1.65 M_{0}+0.02\left(D C_{C}+I C_{C}\right)\right] \\
& =k\left[F_{0}+1.65 M_{0}+0.02\left[1.65\left(E_{C}+0 D C_{C}\right)+L_{C}\right]\right] \\
& =k\left[F_{0}+1.65 M_{0}+0.03 E_{C}+0.030 D C_{C}+0.02 L_{C}\right]
\end{aligned}
$$




\section{TABLE E-7. (contd)}

Thus,

$$
k 0_{c}^{\prime}=k\left[0.03 E_{c}+0.030 D C_{C}+0.02 L_{c}+1.65 M_{0}+F_{0}\right] .
$$

And substituting (5) and (7) in (2):

$$
\begin{aligned}
& \text { teac }=2.25 \mathrm{crf} k\left(1.65 \mathrm{E}_{\mathrm{c}}+1.650 \mathrm{ODC} \mathrm{C}_{\mathrm{c}}+\mathrm{L}_{\mathrm{c}}\right) \\
& +k\left(0.03 E_{c}+0.030 D C_{c}+0.02 L_{c}+1.65 M_{0}+F_{0}\right) \\
& =k\left[(2.25)(\mathrm{crf})(1.65) \mathrm{E}_{c}+(2.25)(\mathrm{crf})(1.65) 0 D C_{c}+(2.25)(\mathrm{crf}) \mathrm{L}_{c}\right. \\
& \left.+0.03 E_{C}+0.0300 C_{C}+0.02 L_{C}+1.65 M_{0}+F_{0}\right] \\
& =k\left[(3.71 \mathrm{crf}+0.03) \mathrm{E}_{\mathrm{c}}+(3.71 \mathrm{crf}+0.03) 00 \mathrm{C}_{\mathrm{c}}+(2.25 \mathrm{crf}\right. \\
& \left.L_{c}+1.65 M_{0}+F_{0}\right]
\end{aligned}
$$

Solving for $E_{C}$,

$$
\begin{aligned}
= & \left\{\frac{\text { teac }}{k}-\left[(3.75 \mathrm{crf}+0.03) 0 D C_{c}+2.25(\mathrm{crf}+0.02) L_{c}\right.\right. \\
& \left.\left.+1.65 M_{0}+F_{0}\right]\right\}(3.71 \mathrm{crf}+0.03)
\end{aligned}
$$

For incremental changes,

$$
\begin{aligned}
& \Delta \mathrm{E}_{\mathrm{C}}=\Delta\left[\begin{array}{lll}
(\quad\} /() & \}
\end{array}\right. \\
& =\alpha \Delta\{\quad\} \text {, where } \alpha=\frac{1}{(3.71 \mathrm{crf}+0.03)} \\
& =\alpha\left\{\left(\frac{\Delta \text { teac }}{k}\right)-[\text { constrant }]\right\}
\end{aligned}
$$

Thus, if $\Delta$ teac $=0.81-0.38=0.43$,

Then, $\Delta E_{c}=\alpha\left\{\frac{0.43}{k}\right\}=0.935\left\{\frac{0.43}{k}\right\}=\frac{0.935(0.43)}{(0.0027)}=149$.

Thus to lower total equivalent unit cost from $0.81 \mathrm{~W} / \mathrm{yr}$ to $0.38 / \mathrm{W} / \mathrm{yr}$, RTG generation cost must decrease by $\$ 149,000$ or $30.8 \%$. 


\section{Legal-Regulatory Costs:}

From Equation (8):

$$
\begin{aligned}
\text { teac }= & k\left[(3.71 \mathrm{crf}+0.03) \mathrm{E}_{\mathrm{c}}+(3.71 \mathrm{crf}+0.03) 0 \mathrm{ODC}{ }_{\mathrm{C}}\right. \\
& \left.+(2.25 \mathrm{crf}+0.02) \mathrm{L}_{\mathrm{c}}+1.65 \mathrm{Mo}+\mathrm{Fo}\right]
\end{aligned}
$$

Solving for $L_{C}=f($ teac, $R)$,

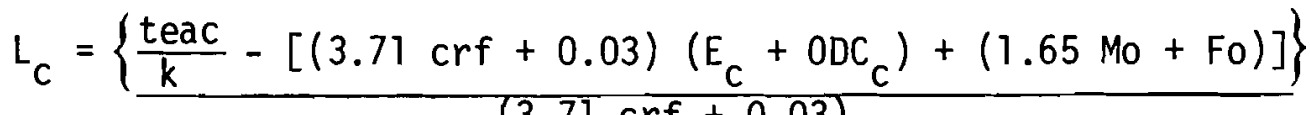

$$
\begin{aligned}
& (3.71 \mathrm{crf}+0.03)
\end{aligned}
$$

$\Delta$

$$
\begin{aligned}
\Delta \mathrm{L}_{\mathrm{C}} & =\alpha\left\{\frac{\Delta \text { teac }}{\mathrm{k}}-\Delta\left[(3.71 \mathrm{crf}+0.03) \not \mathcal{C}_{\mathrm{c}}+(1.65 \mathrm{Mo}+\mathrm{Fo})\right]\right\} \\
& =\frac{\alpha \Delta \text { teac }}{\mathrm{k}}=\frac{0.935(-0.37)}{0.0027} \\
\Delta \mathrm{L}_{\mathrm{C}} & =-131.6 \approx-132
\end{aligned}
$$

Thus, legal-regulatory costs would need to decrease by $-\$ 128,000$ to lower RTG costs from $\$ 0.81$ to $\$ 0.44$ since legal regulatory costs are estimated to be only $\$ 25,000$ (see Table E-1). Thus, a legal-regulatory subsidy of at least $\$ 103,000$ would be necessary as part of capital costs of inducing users to implement RTG power units. 
Thus, a unit price would occur at some point between the cost of the first unit and the cost of the last unit in a given run. In our example thus far, the RTG must be priced at about $\$ 350,000$ to bring user costs in line with existing alternative remote power units. If we pick this value as our objective sales price and $\$ 500,000 / R T G$ as the cost of the first unit produced in a given run, then what learning curve rates and first production run quantities are necessary to achieve this sales price objective? Typical learning curve rates in normal industry range from 80 to $90 \%$.

Required Learning Curve Rates

Learning curve rates of 80 to $90 \%$ have projected first production run quantities of about 60 and 120 RTGs, respectively, based on the pricing criteria developed above; this range of values is shown in Figure E-2. Production lots within a run are based on $10 \mathrm{RTGS} / 10 \mathrm{t}$. We assume that the $\$ 500,000$ unit price for the first group or lot of units is based on a fabrication lot of 10 RTGs. (a)

Lower pricing in subsequent production runs would be constrained by a decreasing learning curve effect (i.e., the next run may range between 87 and $97 \%$, rather than 80 and $90 \%$ ). This is a matter for detailed analysis at later stages of RTG development.

In perspective, the production quantity and pricing objectives at normal levels of industrial learning curve effects are seemingly comfortable. Thus one could conjecture that it may very well be feasible to lower unit costs of RTGs by $30 \%$ to bring user costs into line with competing power sources. (b)

(a) The $\$ 1.3$ million unit price of the $400 \mathrm{~W}_{\mathrm{e}}$ unit was computed on the basis on a production lot of 10 units. (1)

(b) Diesel-electric, CCT and TEG power units are relatively low cost units and are currently produced under a manufacturing rather than a fabrication regimen. Consequently, the author assumes that these power units are rapidly approaching or are very near the lowest relative unit cost which can be realistically achieved in their manufacture. 


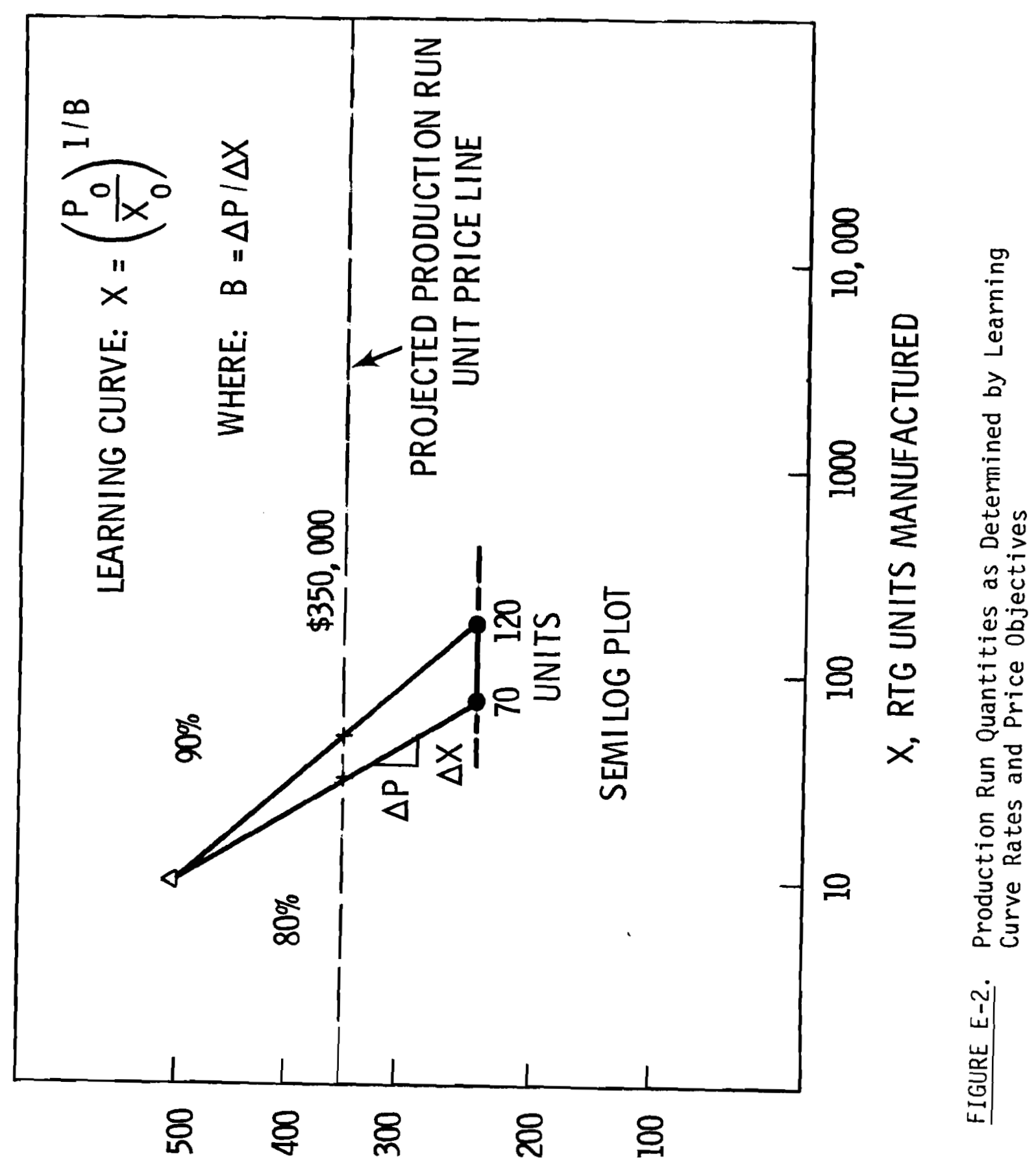

SAGTTOO JO SANGSחOHI '(9LY/LSOJ) d 
What will be the effect of a significant increase in the cost of diesel and propane fuels? This is a likely occurrence. Restated, the question becomes: By how much will fuel costs need to be increased to move diesel-electric power units to a total annual cost level equivalent to RTG costs?

Higher Diesel Fuel Costs

If the total equivalent annual cost/ $W_{e}$-year of $D E G s$ is to increase from $\$ 0.31$ thousand to $\$ 0.81$ thousand, aggregate costs of diesel fuel and fuel transport (aircraft fuel, etc.) must increase from $\$ 15,200$ to $\$ 276,000$. (a) This approximation is an 18-fold increase in the price of fuel which seems unrealistic even in today's era of petro-politics. Consequently, one would have to conclude that fuel costs will probably not contribute significantly toward narrowing the gap of using RTGs in place of DEGs. This will be true providing the relative costs of DEGs and RTGs remain as they are shown in Table E-6.

What are the effects of a decrease in 1 icensing/regulatory costs for RTGs?

Marginal Licensing/Regulatory Costs

In the absence of a more precise estimate, a one-time licensing/ regulatory cost of $\$ 25,000$ has been assumed for each RTG installation. This includes costs of environmental impact statements, nuclear regulatory costs, etc. (see Table E-1). It is not known what actual costs of such activities have been or will be for a single RTG installation.

This cost element would have to decrease to a negative or subsidy value of $\$-103,000$ in order for RTG annual costs to decline to a level comparable to the TEG (see Table E-7). The TEG is the highest cost alternative power unit based on the data used for this analysis as indicated in Table E-6.

(a) Derived from changes in fuel costs required to bring DEG costs to the same level as RTG costs based on the $500 \mathrm{~W}_{\mathrm{e}}$ unit. 
Two conclusions come from this brief look at regulatory/licensing costs. The first is that, given present costs, regulatory/licensing costs do not significantly alter the cost to the user of implementing RTG applications provided these legal costs are not essentially different from the $\$ 25,000$ / unit-installation used here. Second, if licensing/regulatory costs are completely absorbed by the government and, in addition, if a capital cost subsidy on the order of $\$ 100,000$ is made for each RTG installation, present costs of use might very well be comparable to costs of alternative technology power units.

The potential problem of RTG equipment failures is the fourth major concern in determining the economic feasibility of RTG use.

Cost of RTG Replacement

The cost estimates developed earlier in this appendix include operating cost items identified as emergency services as part of Maintenance and Support Transport costs. For RTGs, Reference 1 assumed that unscheduled maintenance visits would require 0.5 visits/year whereas DEGs might require 4.0 visits/year. For $500 \mathrm{~W}_{\mathrm{e}}$ units the relative costs are negligible for RTGs but become significant for DEGs ( $\$ 4 \mathrm{~K}$ versus $\$ 30 \mathrm{~K}$, annually). These estimates did not include RTG replacement within the 10-year life cycle but did include a fifth year overhaul for DEGs. What would be the effect on the relative costs of RTGs and alternatives if an RTG had to be replaced?

Assuming that RTG replacement occurs at the fifth year, with a 11 that implies for cost amortization, the net effect of RTG replacement at a unit cost of $\$ 500,000$ would be to move the total equivalent annual cost of RTGs from $\$ 0.81$ thousand $/ W_{e}$-year to $\$ 1.20$ thousand $/ W_{e}-y e a r$. This assumes that: 1) the replaced RTG has no salvage value, 2) it incurs a removal cost equivalent to the original cost of installation, but 3) it incurs no "disposal" cost by being returned to the manufacturer as scrap-in-trade for no-cost disposal and/or refabrication. However, if the replaced RTG has a significant salvage value then an entirely different situation might result.

Consider the extreme case where the salvage value of the RTG is equivalent to the current book value or undepreciated value of the unit at 
the time of replacement. If costs of removal and installation are disregarded then annual rates of capital recovery continue as before with no change in annual costs of the installed unit. The only change has been an extension of the lifetime of the RTG installation for a 10-year period from the replacement date.

A realistic assessment of the financial effects of a complete unit replacement will probably fall within these two extremes. Consequently, if net capital replacement costs were to occur at $30 \%$ of the new value of the $R T G$, then total equivalent annual costs of the RTG installation would be $\$ 0.89$ thousand/ $W_{2}-y r$.

What if replacement occurs in conjunction with a sequence of the other three events discussed above? To answer this question, the net impact on the economics of selected sequences of these four events or cases will now be explored.

Combinations of Cost Events

Two combinations of events have been constructed which demonstrate a set of "best" conditions and a set of "worst" conditions for RTG economic acceptance. The set of all possible combinations of events and the two selected limiting combinations are depicted in Figure E-3. The "best" combination of events favorable to RTGs consists of: a) lower RTG capital costs, b) lower regulatory costs, c) increased diesel/propane fuel costs, and d) no change in RTG replacement rate. In comparison the "worst" combination of events would consist of: a) no change in RTG capital costs, b) increased licensing/regulatory costs, c) no change in diesel/propane fuel costs, and d) one total replacement of an RTG at year 5 in a 10-year installation.

The cumulative effects of these two sequences of events has been mapped in Figure E-4. Corresponding values for these incremental changes are given in Table E-8. It is evident that RTG capital costs control the ability of RTGs to become competitive (at the same level) with competing power units. 


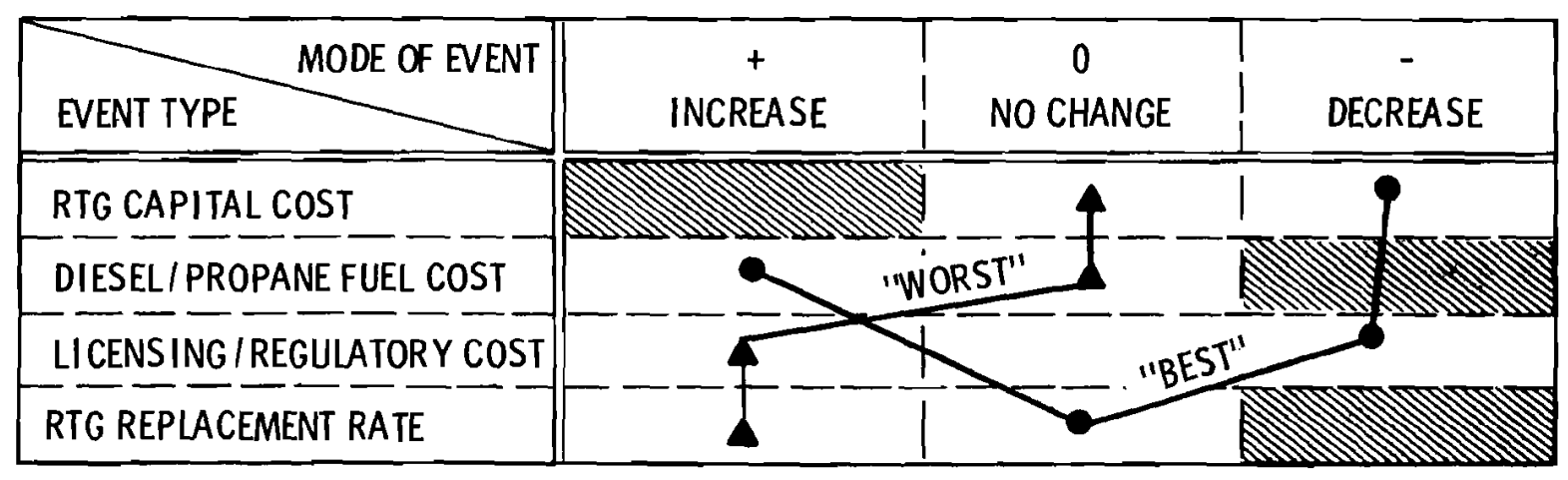

- "BEST" CASE EVENT

$\triangle$ 'WORST' CASE EVENT

EVENT NOT-ALLOWED IN THE ANALYSIS

FIGURE E-3. Combinations of Events Which Might Increase or Decrease Economic Feasibility of RTG's

TABLE E-8. Percentage Change in Factors Relative to Base Case Conditions, \%

\begin{tabular}{|c|c|c|c|}
\hline \multirow[b]{2}{*}{ Event Type } & \multicolumn{3}{|c|}{ Mode of Event } \\
\hline & $\begin{array}{c}+ \\
\text { Increase } \\
\end{array}$ & $\begin{array}{c}0 \\
\text { No Change } \\
\end{array}$ & Decrease \\
\hline RTG Capital Cost & & $0 \%$ & $30 \%$ \\
\hline $\begin{array}{l}\text { Diesel/ } \\
\text { Propane Fuel Cost }\end{array}$ & $100 \%$ & $0 \%$ & \\
\hline $\begin{array}{l}\text { Licensing/ } \\
\text { Regulatory cost }\end{array}$ & $100 \%$ & & $100 \%$ \\
\hline RTG Failure Rate & $10 \%$ & $0 \%$ & \\
\hline
\end{tabular}



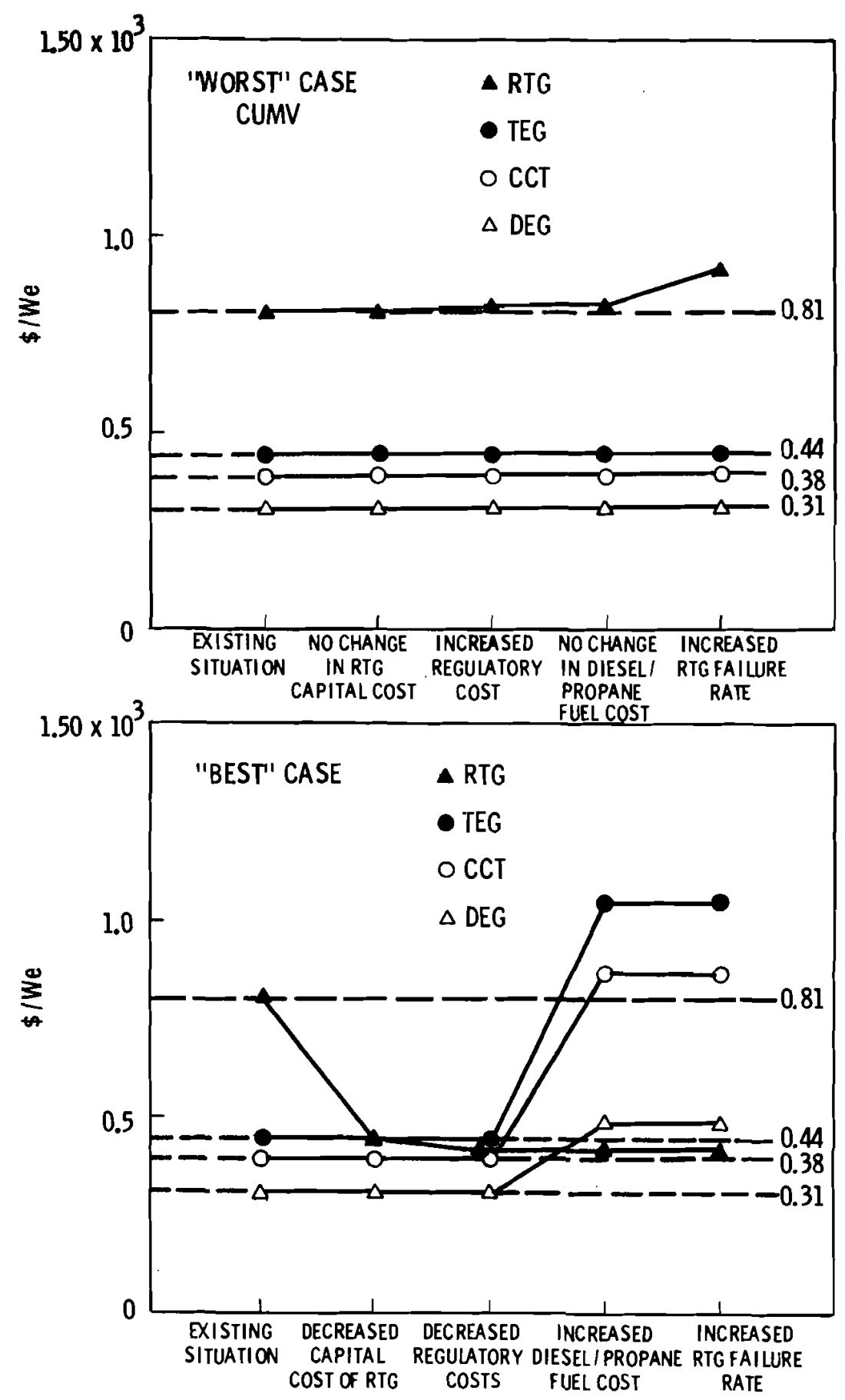

EVENTS

FIGURE E-4. Cumulative Effects of Best and Worst Conditions for RTG Economic Acceptance, Total Equivalent

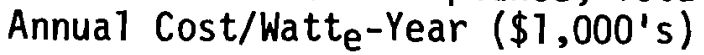


Similarly, a fivefold increase in diesel and propane fuel costs control the ability of competing systems to become uneconomic with respect to RTGs (except for diesel systems).

CONCLUSIONS AND IMPLICATIONS

The questions posed at the beginning of this preliminary economic analys is related to the technical, economic, and socio-political factors of the economic costs of using RTGs. Partial answers have been developed for each of these factors by testing the total equivalent annual cost of using RTGs and competing power units. These tests have been in the form of a sensitivity analysis of total annual cost to, respectively: 1) user purchase price of RTG equipment, 2) diesel and propane fuel costs for competing power units, and 3) licensing-regulatory costs of RTG power units.

One of the major results included a recognition that a $30 \%$ decrease in average manufacture costs of RTGs might be feasible based on 80 to $90 \%$ improvement or learning curve effects. This presumes that the base price of the RTG was not previously based on a learning curve effect but represented only a limited ( 5 to 10 ) number of units manufactured. This technical factor or capital cost reduction is believed to be the single most important criteria for bringing RTG systems to a competitive level with conventional power units at the ratings considered herein.

The most important factor which might cause competing diesel, propane cycle, or propane thermoelectric power units to become uneconomic with respect to RTGs was a significant (18-fold) increase in fuel and fuel delivery costs for remote units ( $\approx 600$ miles distant). The effect of one complete RTG replacement, requiring unit replacement, midpoint in a 10-year installation would be expected to cause less cost impact than the $30 \%$ capital cost reduction or pricing. This presumes a significant salvage value, however, for the unit that is removed.

The cost of socio-political or regulatory operations, even when doubled to $\$ 50,000 /$ RTG installation, would have only minor effects on the 
competitiveness of RTGs with respect to competing units. However, it is not known whether this level of regulatory costs is realistic in a commercial environment.

There are several implications of these analytical results for ERDA policy considerations as well as additional research and development effort associated with RTGs. First, one must recognize that a potential user (even of only one RTG) must see a clear economic advantage before adopting the RTG for a remote power source. Second, government agencies in control of the technology can both push and pull economics of RTG use into a competitive position. However, some policies might be more cost-effective than others. For instance, direct subsidies to manufacturers of RTGs could lower the sales price to the end user (but not the total economic cost). On the other hand, if a manufacturer's market research indicates that sufficient demand exists for several hundred units and if it can be shown that manufacturing economics (learning curve effects, etc.) do occur, then natural economic drives to lower costs of production in a competitive environment might possibly act to reduce costs of RTGs appropriately. Similarly, direct subsidies for replacement unit RTGs could stimulate demand by lessening risk. However, the same effect could be achieved through industrial insurance underwriting without necessarily involving the government agencies. Minimum insurance requirements would then become the policy implications. Another implication involves disposal/reuse of retired RTGs. These costs have not been addressed in this analysis but become important if the number of RTGs increase. This is an area where a government agencyoperated secondary or "used car and scrap" market would serve to stimulate use of RTGs by lessening future risks and costs associated with RTG disposal. The effect would be one of pulling RTGs through the manufacture-use-disposal cycle.

In summary, one should take the foregoing analysis with caution, recognizing that it has been entirely preliminary. A detailed manufacturing cost for RTGs designed for terrestrial, remote application needs to be prepared as part of further development and design efforts. Solar energy 
converters likewise need to be injected into the competing technology analysis because it too is a "new" technology and might undergo similarly decreasing costs over time--the decreasing industry cost curve of economic theory. Notably, the relationships established in this analysis are much more important than the absolute value of the numbers.

\section{REFERENCES}

1. R. T. McCoy, "An Economic Comparison of Mid-Range Power Sources," B1uebird Associated, Timonium, Maryland, March 31, 1972.

2. M. E. Peters and K. D. Timmerhaus, Plant Design and Economics for Chemical Engineers, Second Edition, McGraw-Hi11 Book Co., N.Y., 1968.

3. E. L. Grant and W. G. Ireson, Principles of Engineering Economy, Fourth Edition, The Ronald Dress Co., N.Y., 1964.

4. W. J. Baumol, Economic Theory and Operations Analysis, Second Edition, Prentice-Ha11, Inc., Englewood Cliffs, N.J., 1965.

5. Space Nuclear Systems Division, USAEC, "Economic Radioisotope Thermoelectric Generator Study Program, Cost Effectiveness Study," November 1973, prepared by Teledyne Isotopes under AEC Contract SNSO-3.

6. Richard J. Alden, "Learning Curves: An Example," Industrial Engineering, pp. 34-37, December 1974.

\section{BIBLIOGRAPHY}

Saul H. Hyman, Probability Theory with Applications to Econometrics and Decision Making, Prentice-Ha11, Inc., Englewood Cliffs, N.J., 1967.

Sang M. Lee, Goal Programming for Decision Analysis, Averbach Publishers, Inc., Philadelphia, PA, 1972.

J. Johnston, Statistical Cost Analysis, McGraw-Hill Book Co., Inc., N.Y., 1960.

Robert M. Rodden, "Radioisotope Energy Sources for Smal1 Manned Antarctic Stations," Nuclear Applications, vol. 3, pp. 226-232, April 1967.

USAEC, Selected Charts and Graphs Excerpted from Working Documents and Reports, and made available to the author. 
DISTRIBUTION

NO. OF

COPIES

\section{OFFSITE}

1

11

27

1

1

1

3
ERDA Chicago Patent Attorney

9800 S. Cass Avenue

Argonne, IL 60439

A. A. Churm

ERDA Nuclear Research and Applications Division Washington, D.C. 20545

R. T. Carpenter

G. P. Dix

T. J. Dobry, Jr.

N. Goldenberg

A. P. Litman (3)

J. J. Lombardo

W. C. Remini

B. J. Rock

E. J. Wahlquist

ERDA Technical Information Center

Alyeska Pipeline Service Company

1835 South Brogan Street

P. 0. Box 4-Z

Anchorage, AK 99503

W. L. N. Fisken

Alaska Region Office

Federal Aviation Administration

632 Sixth Avenue

Anchorage, AK 99501

G. W. Boedecker

Alaskan Resource Sciences Corporation

2550 Spenard Road

Anchorage, AK 99503

Dr. J. F. Schindler

Arctic Environmental Research Laboratory

Environmental Protection Agency

College, AK 99504

R. C. Gordon

R. W. Latimer

B. H. Reid 
B. Ogle, Consultant 3801 West 44 th

Anchorage, AK 99507

Community Planning Division

Department of Community and Regional Affairs

State of Alaska

Juneau, AK 99801

K. Waring

Cold Regions Research and Engineering Laboratory

U.S. Army Corps of Engineers

Hanover, NH 03755

H. W. C. Aamot

Control and Treatment Integration Branch

Municipal Pollution Control Division

Environmental Protection Agency

Waterside Ma11, Washington, DC 20545

D. Wright

Department of the Army

Headquarters, U.S. Army

Facilities Engineering Support Agency

Fort Belvoir, VA 22060

H. Musselman, Technical Director

2

Department of Environmental Conservation 419 Sixth Street

State of Alaska

Juneau, AK

J. Reinwand, Deputy Commissioner

J. Sargent

Department of Highways

State of ATaska

Juneau, AK 99801

W. B. Parker

$1 \quad$ Department of the Navy

Nuclear Power Division

Naval Facilities Engineering Command

200 Stoval1 Street

Alexandria, VA 22332

M. D. Starr 
NO. OF

COPIES

1

Division of Planning and Research

Office of the Governor

State of Alaska

Juneau, AK 99801

Ms. K. L. Allred

Electronics and Applied Physics Division

Building 347.3, AERE Harwe11

Oxfordshire 0X11 ORA

Great Britain

E. H. Cooke-Yarborough

ERDA Division of Biomedical and Environmental Research Washington, DC 20545

J. N. Maddox

2

ERDA Division of Production and Materials Management Washington, DC 20545

F. P. Baranowski

R. W. Ramsey, Jr.

ERDA Oak Ridge Operations Office

P. 0. Box E

Oak Ridge, TN 37830

D. C. Davis, Jr.

3

ERDA Savannah River Operations Office

P. 0. Box A

Aiken, SC 29801

R. H. Bass

T. B. Hindman

R. K. Huntoon

1

FESA

R \& D Division

U.S. Army Corps of Engineers

Fort Belvoir, VA

$1 \quad$ General Atomic Company

P. 0. Box 81601

San Diego, CA 92138

H. C. Carney 
NO. OF

COPIES

1

1

3

1

Industrial Products Group

Atomic Energy of Canada, Ltd.

Ottawa, Canada

J. W. Anstee

1

Institute of Marine Science University of Alaska

College, AK 99504

D. W. Hood

1

1

Health Research Division

University of California

Los Alamos Scientific Laboratory

Los Alamos, NM

w. Hanson

Monsanto Research Corporation

Mound Laboratory (ERDA)

Nuclear Operations

P. 0 . Box 32

Miamisburg, $\mathrm{OH} 45342$

W. T. Cave

Naval Arctic Research Laboratory Barrow, AK 99723

W. W. Denner

L. Underwood 
Naval Nuclear Power Unit

P. 0. Box 96

Fort Belvoir, VA 22060

F. E. Rosell

Naval Facilities Engineering Command

Nuclear Power Division (FACO4N)

200 Stoval1 Street

Alexandria, VA 22332

G. E. Krauter

Navy Office of the Chief of Naval Operations Washington, DC 20390

Head, Reactor Branch

1

Northern Engineering Services Company, Ltd.

615 6th Avenue S.W.

Calgary, Alberta

Canada

R. W. Peddie

4

Oak Ridge National Laboratory

0ak Ridge, TN 37830

R. S. Crouse

J. R. DiStefano

E. Lamb

A. C. Schaffhauser

3

Office of Environmental Health

U.S. Public Health Service

Anchorage, Alaska

F. Reiff

W. L. Ryan

L. P. Wallace

1

Sandia Laboratories

Albuquerque, NM 87115

H. D. Sivinski

3

Teledyne Energy Systems

110 W. Timonium Road

Timonium, MD 21093

P. Dick

R. Hannah

P. Vogelberger 
NO. OF

COPIES

3

Teledyne Isotopes

110 West Timonium Road

Timonium, MD 21093

J. H. Morrison

G. F. Linkous

W. A. McDonald

1

Senator Ted Stevens' Office

01d Senate Office Building

Washington, DC 20545

G. Nethercutt

1

Westinghouse Astronuclear Laboratory

P. 0. Box 10864

Pittsburgh, PA 15236

C. C. Silverstein

ONSITE

2

ERDA Richland Operations

W. C. Johnson

B. J. Melton

Atlantic Richfield Hanford Company

L. I. Brecke

R. E. Isaacson

L. M. Knights

C. W. Malody

J. D. Moore

G. C. Oberg

H. P. Shaw

Battelle-Northwest

J. W. Bartlett

T. D. Chikalla

M. 0 . Cloninger

R. L. Dillon

H. T. Fullam

K. M. Harmon

A. J. Haverfield

J. H. Jarrett

R. S. Kemper

R. P. Marsha 11

R. W. McKee
J. M. Nielsen

R. E. Nightingale

D. E. Olesen

L. D. Perrigo (10)

A. M. Platt

W. E. Sande

J. L. Simmons

H. H. Van Tuy 1

R. E. Westerman

Technical Information Files

Technical Publications 